\title{
Bisphenols as Environmental Triggers of Thyroid Dysfunction: Clues and Evidence
}

\author{
Francesca Gorini ${ }^{*}+\oplus$, Elisa Bustaffa ${ }^{\dagger}$, Alessio Coi $\odot$, Giorgio Iervasi and Fabrizio Bianchi $(\mathbb{D}$ \\ Institute of Clinical Physiology, National Research Council, 56124 Pisa, Italy; elisa.bustaffa@ifc.cnr.it (E.B.); \\ alessio.coi@ifc.cnr.it (A.C.); iervasi@ifc.cnr.it (G.I.); fabrizio.bianchi@ifc.cnr.it (F.B.) \\ * Correspondence: fgorini@ifc.cnr.it; Tel.: +39-050-315-3250 \\ + These authors equally contributed to the manuscript.
}

Received: 23 March 2020; Accepted: 10 April 2020; Published: 13 April 2020

\begin{abstract}
Bisphenols (BPs), and especially bisphenol A (BPA), are known endocrine disruptors (EDCs), capable of interfering with estrogen and androgen activities, as well as being suspected of other health outcomes. Given the crucial role of thyroid hormones and the increasing incidence of thyroid carcinoma in the last few decades, this review analyzes the effects of BPS on the thyroid, considering original research in vitro, in vivo, and in humans published from January 2000 to October 2019. Both in vitro and in vivo studies reported the ability of BPs to disrupt thyroid function through multiple mechanisms. The antagonism with thyroid receptors (TRs), which affects TR-mediated transcriptional activity, the direct action of BPs on gene expression at the thyroid and the pituitary level, the competitive binding with thyroid transport proteins, and the induction of toxicity in several cell lines are likely the main mechanisms leading to thyroid dysfunction. In humans, results are more contradictory, though some evidence suggests the potential of BPs in increasing the risk of thyroid nodules. A standardized methodology in toxicological studies and prospective epidemiological studies with individual exposure assessments are warranted to evaluate the pathophysiology resulting in the damage and to establish the temporal relationship between markers of exposure and long-term effects.
\end{abstract}

Keywords: Bisphenol A; bisphenols; endocrine disruptors; thyroid hormones; thyroid cancer

\section{Introduction}

Thyroid hormones (THs) play a critical role in the regulation of physical development, somatic growth, metabolism, and energy provision and are essential for normal brain development in humans [1]. Thus, any interference with THs status and signaling during development may have an impact on physical health, and can be associated with neurological deficits and even irreversible mental retardation in the case of severe maternal TH deficiency [2]. Meanwhile, thyroid cancer (TC) incidence rates have been rising in many western countries, including the United States where the incidence increased 3.6\% per year during 1974 to 2013 [3]. TC is the most common endocrine malignancy, and by 2030, it is estimated to become the fourth leading cancer diagnosis in the United States [4]. Papillary thyroid cancer (PTC), in particular, is the most frequent histotype with a typically excellent prognosis, accounting for $70 \%$ to $90 \%$ of well-differentiated thyroid malignancies, and though over diagnosis of small tumors is thought to contribute significantly to the increase in incidence, PTC incidence has significantly increased for every stage and tumor size category [3]. The etiology of TC is multifactorial and the proposed risk factors in the literature include sex, family history of TC, radiation exposure, excess weight, iodine intake, and dietary habits [5]. Although the thyroid is characterized by a low proliferation index, it is particularly susceptible to environmental chemicals that may contribute to the increasing incidence of TC [6]. 
According to a recent statement by the Endocrine Society, endocrine disrupting chemicals (EDCs) are defined as single exogenous agents or mixture of compounds capable of interfering with any aspect of hormone action, from the synthesis to the transport, catabolism, and elimination of the hormones produced [1,7]. One of the characteristics of many EDCs is a nonmonotonic dose response that replicates hormone characteristics; thus, a proportionally greater effect is observed at low doses than at high doses because of hormone receptor saturation and overstimulation that decrease the response [7,8]. Increasing evidence has shown the ability of several EDCs (e.g., polybrominated diphenyl ethers, polychlorinated biphenyls, pesticides, and phthalates) to exhibit thyroid disrupting activities in animals and, with some inconsistencies, in humans [1,9]. Interference of environmental chemicals with thyroid function can occur at multiple levels including, among others, toxicity at the thyroid gland, disturbance of THs synthesis, secretion and metabolism, competitive binding with the TH binding proteins, and interaction with thyroid hormone receptors (TRs) $[1,10]$.

Bisphenol A (BPA; 2,2-bis(4-hydroxyphenyl)propane) is described as an EDC able to interact with human estrogen receptors (ERs) [11]. In rodent models, a variety of effects was observed in estrogen-target organs (e.g., brain, mammary gland, ovary, and uterus) following exposure to BPA at or below the lowest observed adverse effect level (LOAEL) during prenatal and neonatal periods [12]. Changes in one of the target organs can lead to secondary alterations in bone, adipose tissue, cardiovascular tissue, and the immune system [13]. In humans, increased levels of BPA were associated with adverse health outcomes including cancer [14,15], reproductive disorders [16], altered neurobehavior [17], cardiovascular disease [18], type 2 diabetes [19], and obesity [20]. In addition, BPA acts as an antiandrogen, affecting steps of the activation and function of the androgen receptor [21] and spermatogenesis in both animals [22] and humans [23].

Though not systematic, the present effort is a thorough review (173 references included in the full text), comprising in vitro, in vivo, and epidemiological studies that have assessed the effects of bisphenols (BPs), namely bisphenol A (BPA), its analogues, and its halogenated derivatives on the thyroid, considering their actions at different levels in cells or organs, in different animal models and in humans and their potential to exert a risk in causing a direct impact on the gland. Original studies published in English in peer-reviewed journals from 1 January 2000 to 31 October 2019 were searched in Pubmed through the search strategy: ((bisphenol* OR BPA OR tetrabromobisphenol* OR TBBP* OR tetrachlorobisphenol OR TCBPA) [ALL FIELDS]) AND (thyroid OR thyroid disorders OR thyroid function OR thyroid cancer OR thyroid nodule [ALL FIELDS]). From the initial search of 303 records, a total of 82 studies were selected by two authors on the basis of adherence to the purposes mentioned above.

\section{Bisphenols in the Environment and Humans}

BPA is a monomer in the manufacture of polycarbonate plastics and epoxy resins widely used in diverse consumer products such as food and liquid containers, protective coatings inside metallic food and beverage cans and medical devices, as well as in flame retardants and thermal papers [24]. It is one of the 2000 endocrine disruptors known as "highest volume" chemicals, with an annual production of at least 8 million tons throughout the world [25].

BPA can be released from both effluent discharge of manufacturing plants and from transport, processing, and disposal of waste of BPA-containing products in landfills and incinerators [26]. Less than $1 \%$ of environmental BPA has been estimated to occur in the atmosphere, where it undergoes photo-oxidation and breakdown [27]. Nonetheless, the presence of BPA in the environment, though at low levels and despite the short half-life, is ubiquitous [28].

Due to its lipophilicity, detectable levels of the unconjugated form of BPA were measured in adipose tissue, brain, liver, and breast milk in humans (Table 1a). Moreover, BPA can pass through the placenta and amniotic fluid thereby exposing the fetus, as well as the developing infant, to exposure and accumulation [29] (Table 1a). 
The first safety standard for humans set by the US-Environmental Protection Agency in 1988, adopted by the Food and Drug Administration as the reference dose and based on the LOAEL for BPA, was 50 micrograms per kilogram of body weight per day [30]. In 2013, the re-evaluation of BPA exposure and toxicity led the European Food Safety Authority to considerably reduce the safe level of BPA from 50 to $4 \mu \mathrm{g} / \mathrm{kg} /$ day (31). Human exposure to BPA is continuous and widespread, and diet is likely the major source of exposure in all population groups because of the ability of BPA to migrate from polycarbonate containers and metallic cans to food and beverages [31]. In 2011, the European Union banned the manufacture of baby bottles containing BPA [32], followed in 2012 by the Food and Drug Administration [33]. Infants and toddlers exhibit the highest estimated external average exposure because of their elevated consumption of food and beverages per $\mathrm{kg}$ of body weight [31] (Table 1a). Other routes of exposure are represented by inhalation of outdoor and indoor air, ingestion of domestic dust, dermal contact with thermal paper and cosmetics, and, for children, mouthing of toys [31]. The estimates for exposure to dietary and non-dietary sources are at least one order lower than the tolerable daily intake set by the European Food Safety Authority, except daily intake of infants fed with canned liquid formula in polycarbonate bottles (Table 1a).

BPA has a half-life in humans of about $6 \mathrm{~h}$ [34]. Following the oral exposure, in humans BPA is absorbed from the gastrointestinal tract and then metabolized in the liver, where is primarily conjugated with glucuronic acid to the non-active BPA-glucuronide, which is the main metabolite in urine and blood [34]. Urinary total BPA (conjugated + free), considered the most appropriate biomarker to assess human exposure [35], was detected among the different age classes in $88 \%$ to $98 \%$ of volunteers who participated in the National Health and Nutrition Examination Survey [35]. Significantly higher concentrations have been detected in children than in adolescents and adults whereas BPA levels measured in the blood of adults are approximately one order of magnitude lower than those found in the corresponding urine [36] (Table 1a).

Several structural analogues were introduced in the market to replace BPA [37]. Bisphenol F (BPF; 4,4'-dihydroxydiphenylmethane), bisphenol S (BPS; 4,4'-sulfonyldiphenol), and bisphenol Z (BPZ; 1,1-bis(4-hydroxyphenyl)-cyclohexane) are used in epoxy resin products [38], in cleaning products and thermal paper [39], and in highly heat resistant plastic materials and electrical insulation [40], respectively. BPAF (1,1,1,3,3,3-hexafluoro-2,2-bis(4-hydroxyphenyl)propane) is a fluorinated derivative widely used in the manufacturing of polycarbonate copolymers with 10,000 to 500,000 pounds annually produced in the United States [41]. BPA substitutes have been detected in various environmental matrices, and, with a few exceptions, their concentration values in urine are lower than those of BPA [42] (Table 1b).

Tetrabromobisphenol A (TBBPA), a persistent compound synthesized by bromination of BPA initially replaced polybrominated diphenylthers, at present is the most widely employed brominated flame retardant, with a reported 2011 volume of 120 million pounds in the United States [43]. In the last years, tetrabromobisphenol S (TBBPS) and tetrachlorobisphenol A (TCBPA) have been extensively used as alternatives to TBBPA [44]. TBBPA is measured in the environment and in human body [45], and TBBPA exposure represents a significant health risk especially for children residing in an e-waste processing region [46] (Table 1c). 
Table 1. Concentration of bisphenols in the environment and human body, and estimated exposure by age groups to bisphenol A (a), principal bisphenol A substitutes (b), and halogenated derivatives of bisphenol A (c).

\begin{tabular}{|c|c|c|}
\hline \multicolumn{3}{|l|}{ (a) Bisphenol A } \\
\hline Environmental Matrix & Concentration & Reference \\
\hline Surface water & nd-1.95 $\mu \mathrm{g} / \mathrm{L}$ & [47] \\
\hline Sediments (industrialized areas) & nd-13,370 $\mu \mathrm{g} / \mathrm{kg}$ dry weight & [41] \\
\hline Soil & $<0.01-1000 \mu \mathrm{g} / \mathrm{kg}$ & [29] \\
\hline Indoor dust & nd-39.1 $\mu \mathrm{g} / \mathrm{g}$ & [48] \\
\hline Atmosphere & $10^{-3}-1.74 \mathrm{ng} / \mathrm{m}^{3}$ & [49] \\
\hline Landfill leachate (hazardous waste site) & Up to $17,200 \mu \mathrm{g} / \mathrm{L}$ & [50] \\
\hline Human Body & Concentration & Reference \\
\hline Brain & Mean: $0.91 \mathrm{ng} / \mathrm{g}$ & [51] \\
\hline Liver & Mean: $1.30 \mathrm{ng} / \mathrm{g}$ & [5] \\
\hline Adipose tissue & Mean: $3.78 \mathrm{ng} / \mathrm{g}$ & [51] \\
\hline Breast milk & Mean: $0.61 \mu \mathrm{g} / \mathrm{L}$ & [52] \\
\hline Blood (adults) & Mean: $0.20 \mu \mathrm{g} / \mathrm{L}$ & [36] \\
\hline Cord blood & Mean: $0.13 \mu \mathrm{g} / \mathrm{L}$ & [36] \\
\hline Urine (European adult population) & Geometric mean: $2.5-3.6 \mu \mathrm{g} / \mathrm{L}$ & [31] \\
\hline Urine (North America children) & Geometric mean: $1.3-3.7 \mu \mathrm{g} / \mathrm{L}$ & [31] \\
\hline Urine (North America adults) & Geometric mean: $1.0-2.6 \mu \mathrm{g} / \mathrm{L}$ & [31] \\
\hline Age Group/Source of Exposure & Average External Exposure & Reference \\
\hline Infants (0-3 month)/Formula fed from polycarbonate bottles & $2.4 \mu \mathrm{g} / \mathrm{kg} / \mathrm{day}$ & [53] \\
\hline Infants (0-6 month)/Formula fed from non- polycarbonate bottles & $0.03 \mu \mathrm{g} / \mathrm{kg} / \mathrm{day}$ & [31] \\
\hline Infants (6-12 month) and toddlers (12-36 month)/Diet & $0.375 \mu \mathrm{g} / \mathrm{kg} /$ day & [31] \\
\hline Infants (6-12 month) and toddlers (12-36 month)/Oral dust and toys & $0.007-0.009 \mu \mathrm{g} / \mathrm{kg} / \mathrm{day}$ & [31] \\
\hline Infants (0-12 month) and toddlers (12-36 month)/Inhalation & $0.7 \mu \mathrm{g} / \mathrm{kg} /$ day & [31] \\
\hline General population ( $>3$ years)/Diet & $0.116-0.290 \mu \mathrm{g} / \mathrm{kg} / \mathrm{day}$ & [31] \\
\hline General population ( $>3$ years)/Thermal paper & $0.059-0.094 \mu \mathrm{g} / \mathrm{kg} / \mathrm{day}$ & [31] \\
\hline General population ( $>3$ years)/Cosmetics & $0.002 \mu \mathrm{g} / \mathrm{kg} /$ day & [31] \\
\hline General population ( $>3$ years)/Inhalation & $0.2-0.4 \mu \mathrm{g} / \mathrm{kg} / \mathrm{day}$ & [31] \\
\hline \multicolumn{3}{|c|}{ (b) Principal Bisphenol A Substitutes } \\
\hline Environmental Matrix & Concentration & Reference \\
\hline Surface water (BPF) & nd-2.850 $\mu \mathrm{g} / \mathrm{L}$ & [47] \\
\hline Sediments in industrialized areas (BPF) & nd-9650 $\mu \mathrm{g} / \mathrm{kg}$ dry weight & [41] \\
\hline Indoor dust (sum of several bisphenols including BPF, BPS, BPZ) & $0.00083-26.6 \mu \mathrm{g} / \mathrm{g}$ & [49] \\
\hline Human Body & Concentration & Reference \\
\hline Urine (BPS: general population—USA/Asian countries) & Geometric mean: $0.030-1.18 \mu \mathrm{g} / \mathrm{L}$ & [54] \\
\hline Age Group & Estimated Exposure & Reference \\
\hline Children and adolescents (<20 years) —USA/Asian countries (BPS) & Median: $0.009 \mu \mathrm{g} / \mathrm{kg} /$ day & [54] \\
\hline Adults ( $\geq 20$ years) - USA/Asian countries (BPS) & Median: $0.004 \mu \mathrm{g} / \mathrm{kg} /$ day & [54] \\
\hline \multicolumn{3}{|c|}{ (c) Tetrabromobisphenol A } \\
\hline Environmental Matrix & Concentration & Reference \\
\hline Atmosphere (e-waste dismantling site) & $66.01-95.04 \mathrm{ng} / \mathrm{m}^{3}$ & [55] \\
\hline Indoor dust & $42.21-46,191 \mathrm{ng} / \mathrm{g}$ dry weight & [46] \\
\hline Sediments & Up to $518 \mathrm{ng} / \mathrm{g}$ & [56] \\
\hline
\end{tabular}


Table 1. Cont.

\begin{tabular}{|c|c|c|}
\hline Soil (industrialized areas) & $1.64-7758 \mathrm{ng} / \mathrm{g}$ dry weight & [57] \\
\hline Surface water & $0.85-4.87 \mu \mathrm{g} / \mathrm{L}$ & [56] \\
\hline Human Body & Concentration & Reference \\
\hline Breast milk & $4.110 \mathrm{ng} / \mathrm{g}$ lipid weight & [58] \\
\hline Cord serum & Mean: $0.199 \mathrm{ng} / \mathrm{g}$ fresh weight & [58] \\
\hline Age group/Source of Exposure & Average External Exposure & Reference \\
\hline Infants/Breast-feeding & $<0.00018-0.171 \mu \mathrm{g} / \mathrm{kg} /$ day & [59] \\
\hline Infants/Dust ingestion (e-waste recycling site) & $0.00031-0.054 \mu \mathrm{g} / \mathrm{kg} / \mathrm{day}$ & [46] \\
\hline Adults/Dust ingestion (e-waste recycling site) & $0.00004-0.0075 \mu \mathrm{g} / \mathrm{kg} /$ day & [46] \\
\hline Adults/High fish consumers & $0.00026 \mu \mathrm{g} / \mathrm{kg} / \mathrm{day}$ & [59] \\
\hline
\end{tabular}

\section{Thyroid Disrupting Properties of BPs: in Vitro Studies}

Biological function of thyroid hormone triiodothyronine (T3) is generally mediated by the nuclear receptors TR $\alpha 1$, TR $\beta 1$, and TR $\beta 2$ that are conserved in all vertebrates. T3 binds to the TRs with similar affinities mediating TH-regulated transcription with different levels in different tissues [60]. TR $\alpha 1$ is the predominant subtype in cardiac muscle and bone, TR $\beta 1$ is the predominant subtype in kidney and liver, while TR $\beta 2$ is more abundantly expressed in the hypothalamus and in the pituitary gland, and has a critical role in the regulation of the hypothalamic-pituitary-thyroid (HPT) axis [61]. TRs bind at DNA as homodimers or forms heterodimers with the retinoid $\mathrm{X}$ receptor to $\mathrm{T} 3$ response elements and they can regulate transcription both in the absence and in the presence of ligands [62]. On positively regulated genes, the unliganded TRs bind to corepressor proteins such as the silencing mediator of retinoid and thyroid hormone receptor (SMRT) or the nuclear receptor corepressor ( $\mathrm{N}-\mathrm{CoR}$ ), resulting in the suppression of transcription [63]. The binding of T3 to TRs leads to a dissociation of the corepressors, and the subsequent recruitment of coactivator proteins, such as those of the p160/SRC (steroid receptor coactivator) family, including SRC1, SRC2, and SRC3, thus promoting activation of transcription [63].

In vitro models have tested and verified the ability of BPs to disturb thyroid function through multiple mechanisms that may produce different consequences depending on the heterogeneity of experimental conditions among studies such as the chemical tested, the concentrations used, and the presence/absence of T3 or T3 antagonists. BPs were reported to exert numerous effects on the thyroid, and each affected pathway may lead to perturbations of thyroid hormone levels, leading to a dysregulation of thyroid function. The pathways are not necessarily inter-connected, but there is some evidence that BPs may lead to an impact on the gland and its function at multiple levels, as reported in the following paragraphs.

\subsection{Interference with $T 3$ Transcriptional Activity}

Numerous studies have evaluated the ability of BPs to suppress hormonal transcriptional activities mediated by TR $\alpha 1$ and TR $\beta 1$ in competitive binding and transient expression assays (Table 2).

BPs mainly acts as TR antagonists, inhibiting crucial processes related to development [64-67]. The TH signaling interference can occur by a direct binding of BPs to the receptor due to the high degree of structural similarity with THs (Figure 1) and preventing the binding of T3 [10,68-71]. Inhibitory effects of BPs on T3 hormonal activity were reported in different cell lines at doses of $10^{6}-10^{-4}$ M [2,10,64,65,69,72-74], with brominated bisphenols showing a much stronger anti-TH activity than BPA and BPS [68].

Whereas BPA alone did not induce visible effects on T3-induced transcription $[2,73,75,76]$, in the presence of physiological concentrations of T3, low-dose BPA enhanced the interaction of TR with N-CoR by directly binding to TR [2]. 


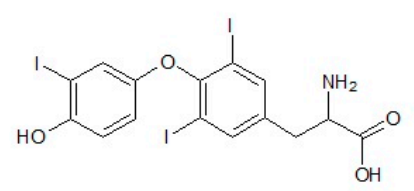

L-3,5,3'-triiodothyronine (T3)

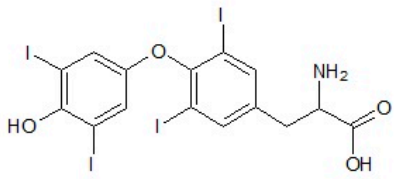

L-3,5,3',5'-tetraiodothyronine (T4)

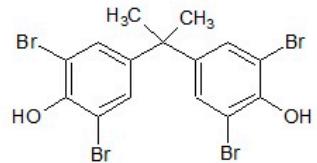

Tetrabromobisphenol A (TBBPA)

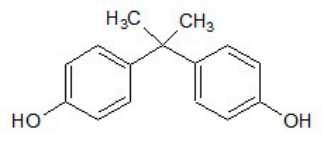

Bisphenol A (BPA)

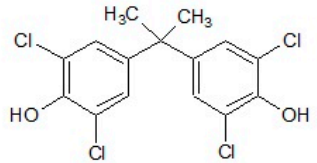

Tetrachlorobisphenol A (TCBPA)

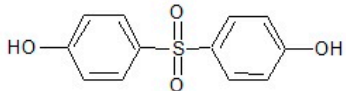

Bisphenol S (BPS)

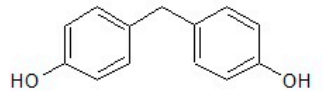

Bisphenol F (BPF)

Figure 1. Bisphenol A, its analogues bisphenol $\mathrm{F}$ and bisphenol $\mathrm{S}$, and the halogenated derivatives tetrabromobisphenol A and tetrachlorobisphenol A show a high degree of similarity with the thyroid hormones in regards the chemical structure.

BPA may exert disrupting effects on TH-mediated transcription interfering with a different non-genomic mechanism mediated by integrin $\alpha v \beta 3$, a heterodimeric transmembrane glycoprotein [77]. In normal conditions, $\mathrm{T} 3$ and thyroxine (T4) induce serine phosphorylation of TR- $\beta 1$ by binding to $\alpha v \beta 3$ and activating mitogen-activated protein kinases (MAPK) and/or c-Src/PI3K pathways [78], which determines the dissociation of $\mathrm{N}-\mathrm{CoR}$ or SMRT from TR- $\beta 1$ and consequent activation of transcription. The competitive binding of BPA to $\alpha \mathrm{v} \beta 3$ antagonizes the serine phosphorylation of TR- $\beta 1$ leading to the recruitment of N-CoR/SMRT to TR- $\beta 1$ and suppression of transcription [79].

A few studies observed that, in the absence of T3, BPs behave as TR agonists $[65,69,70,72,80]$ and this thyromimetic effect can occur at very low concentrations $\left(10^{-8}-10^{-7} \mathrm{M}\right)[69,70]$ and disappear at high doses $\left(10^{-4} \mathrm{M}\right)[65,69]$, showing a biphasic concentration-response relationship.

\subsection{Cell Proliferation}

The rat tumor pituitary cell line GH3 has been frequently employed as a standard pituitary cell model for assessing TH effects [81]. Indeed, cell proliferation and growth hormone (GH) secretion primarily depend on THs [81] and involve TR-mediated mechanisms, specifically the induction of gene expression [82].

A series of investigations assessed the agonistic and antagonistic properties of BPs in GH3 cell growth both in absence and in presence of T3 (Table 2). BPA, and in particular BPA derivatives, generally promoted $\mathrm{GH} 3$ cell proliferation and $\mathrm{GH}$ release in the concentration range of $10^{-6}-10^{-4}$ $\mathrm{M}[70,81,83]$. In some studies, the agonistic activity was detected exclusively in the presence of T3 [82,84], whereas in others BPA and its substitutes inhibited cell growth with T3, and TH-antagonistic effects appeared to depend on the tested dose and the time of exposure [80,85].

Effects of BPs on cell growth were antagonized by amiodarone, a known TR antagonist [80]. Nonetheless, amiodarone was also reported to act as a slight agonist at low concentrations and antagonist at increasing doses, and BPA and its halogenated derivatives exhibited comparable dose-response curves [76]. In PTC cells, BPA had similar proliferative effects as $E_{2}$ [86], and consistent with this finding, co-exposure to $\mathrm{E}_{2}$ potentiated the increased GH3 cell proliferation (from $190 \%$ to $252 \%$ after $96 \mathrm{~h}$ ) by BPA and BPAF [85]. In contrast, TBBPA could not counteract the inhibitory effect of fulvestrant, a strong antiestrogen, on cell growth [81]. 
Cell growth was further antagonized by U0126, an inhibitor of MEK, the kinase responsible for the activation of ERK in the Raf-MEK-ERK pathway in mammalian cells [87]. Similarly, TBBPA at concentrations in the lower micromolar range caused arrest of cells growth in the G1 or G2 phase, depending on the duration and intensity of the treatment and on cell specific and dose dependent modulations of the Raf-MEK-ERK pathway [87].

\subsection{Cytotoxicity}

MAPKs have an important role in cellular signaling pathways, and the kinases JNKs/SAPKs and p38 MAPKs are often activated by cellular stresses and thus primarily linked to cytokine biosynthesis and induction of apoptosis [88]. Thus, any interference of exogenous chemicals with kinases and phosphatases involved in cellular signaling processes can result in possible cytotoxic effects, including cell death [87].

Similar to cell proliferation, cell viability has been evaluated in cell lines exposed to BPs (Table 2).

Cytotoxicity was observed after exposure to BPA and its halogenated derivatives at a concentration range of $10^{-5}-10^{-4} \mathrm{M}$; alone and/or with $\mathrm{T} 3[10,73,76,82,87]$. TBBPA was found to produce cytotoxicity 100 times higher than BPA [75] although in other cell models comparable doses of BPA, TBBPA, and TCBPA did not cause changes in cell viability $[65,70,89]$.

\subsection{Competitive Binding with Thyroid Hormone Binding Proteins}

One of the possible mechanisms of BPs for disrupting TH homeostasis is the competitive binding with serum transport proteins due to the structural similarity to T4 and T3. THs mainly bind to three transport proteins in human serum, namely thyroxine-binding globulin (TBG), which is responsible for $75 \%$ of the specific T4 binding activity, transthyretin (TTR), and human serum albumin [90]. A few studies tested the capability of these chemicals to compete with THs for binding to TTR, which in non-mammalian vertebrates exhibit a higher affinity for T3 than T4, whereas in human plasma is responsible for only $10 \%$ to $15 \%$ of the TH transport [91] (Table 2).

Meertz et al. [92] found no TTR binding for 17 polybrominated diphenyl ethers at maximum concentrations confirming that hydroxylation at the para position with at least one adjacent halogen substituent could represent a prerequisite for TTR binding. Indeed, TBBPA was the most potent competitor among the phenolic compounds tested, binding to TTR in a range from 1.6 [84] to 10.6-fold [92] stronger than the natural ligand T4. Moreover, the affinity of TBBPA for TTR was three times greater than that of BPA [70], and this is in line with the higher binding affinity of halogenated derivatives for TRs compared with BPA [10,71]. Actually, the hydroxylated derivatives of BPA also exhibited a strong affinity for TBG, as elucidated in a transport protein-based biosensor assay [93]. Using a fluorescent probe, Cao et al. observed that BPA affinity for TTR and TBG was weaker than T4 by 300 to 2666 fold; hence the current levels of BPA in humans are unable to interfere with T4 serum transport [90].

\subsection{Perturbation of Thyroid Hormone Uptake}

Thyroid hormone uptake into target cells is controlled by membrane bound transporters, such as monocarboxylate transporter (MCT) 8, MCT10, and multiple members of the Na-independent organic anion transport protein (OATP) family [94]. OATP1C1, in particular, shows a high degree of tissue selectivity, being expressed predominantly in brain and testis, and high preference for T4 and reverse T3 as the ligand [95], and it facilitates the transport of T4 across the blood-brain barrier [96]. In different species, MCT expression has been detected in numerous tissues including the brain wherein MCT8 is responsible for the neuronal uptake of T3 [95]. Mutations in the MCT8 gene cause a severe X-linked psychomotor retardation associated with highly elevated serum T3 levels and decreased T4 concentrations whereas the thyroid-stimulating hormone (TSH) values remain in the normal or slightly elevated range levels [97]. 
Table 2. Summary of in vitro studies analyzing effects of bisphenols on thyroid hormoneresponsive cell lines.

\begin{tabular}{|c|c|c|c|c|c|c|}
\hline Species & Model & Method & Exposure Time & Doses Tested & Principal Results & Reference \\
\hline \multicolumn{7}{|c|}{ Interference with T3 transcriptional Activity } \\
\hline $\begin{array}{l}\text { Yeast (Saccharomyces } \\
\text { cerevisiae Y190) }\end{array}$ & Yeast cells & $\begin{array}{l}\text { Recombinant } \\
\text { two-hybrid yeast } \\
\text { assay }\end{array}$ & $2.5 \mathrm{~h}$ & $\begin{array}{l}0.005 \mathrm{nM}-50 \mu \mathrm{M} \\
\mathrm{BPA} / \mathrm{BPS} / \mathrm{TBBPA} / \mathrm{TBBPS} \pm 10^{-4} \\
\mathrm{M} \text { T3 }\end{array}$ & $\begin{array}{l}\text { Antagonistic activity of BPs toward TR } \beta \\
\text { in a dose-dependent manner, with } \\
\text { TBBPS showing the strongest } \\
\text { antagonistic activity. } \\
\mathrm{IC}_{10} \mathrm{BPA}=884 \pm 65.3 \mathrm{nM} \\
\mathrm{IC}_{10} \mathrm{BPS}=312 \pm 25.9 \mathrm{nM} \\
\mathrm{IC}_{10} \text { TBBPA }=21.1 \pm 9.6 \mathrm{nM} \\
\mathrm{IC}_{10} \text { TBBPS }=10.1 \pm 5.1 \mathrm{nM}\end{array}$ & [68] \\
\hline \multirow[t]{2}{*}{$\begin{array}{l}\text { Yeast (Saccharomyces } \\
\text { cerevisiae Y190) }\end{array}$} & \multirow[t]{2}{*}{ Yeast cells } & \multirow[t]{2}{*}{$\begin{array}{l}\text { Yeast two-hybrid } \\
\text { assay }\end{array}$} & \multirow[t]{2}{*}{$4 \mathrm{~h}$} & $\begin{array}{l}10^{-8}-10^{-4} \mathrm{M} \\
\text { BPA/TCBPA/TBBPA } \\
\pm \text { rat liver } \mathrm{S} 9 \text { preparation }\end{array}$ & $\begin{array}{l}\text { Agonistic activity of TBBPA toward TR } \alpha \\
\text { with a dose-dependent response curve. } \\
\text { After exposure to } S 9 \text { metabolic } \\
\text { activation, increase of agonistic activity } \\
\text { of TBBPA and TCBPA. No activity } \\
\text { of BPA. }\end{array}$ & \multirow[t]{2}{*}{ [69] } \\
\hline & & & & $\begin{array}{l}0 / 1.6^{*} 10^{-7} / 8^{*} 10^{-7} / 4^{*} 10^{-6} / 2^{*} 10^{-5} \\
\text { M BPA/TCBPA/TBBPA } \pm 100 \\
\text { nM T3 } \pm \text { rat liver S9 } \\
\text { preparation }\end{array}$ & $\begin{array}{l}\text { With T3, significant antagonistic activity } \\
\text { of TBBPA and TCBPA toward TR } \alpha \text {, } \\
\text { enhanced by exposure to } S 9 \text { metabolic } \\
\text { activation at the same concentration. }\end{array}$ & \\
\hline \multirow{2}{*}{$\begin{array}{l}\text { Zebrafish } \\
\text { (Danio rerio) }\end{array}$} & \multirow{2}{*}{$\begin{array}{l}\text { Hepatocyte } \\
\text { (ZFL cells) }\end{array}$} & \multirow{2}{*}{$\begin{array}{l}\text { Luciferase reporter } \\
\text { gene assay }\end{array}$} & \multirow{2}{*}{$24 \mathrm{~h}$} & $\begin{array}{l}\text { 5/10/25/37.5\% LC50 } \\
\text { BPA/TBBPA }\end{array}$ & $\begin{array}{l}\text { No induction of TR transcriptional } \\
\text { activity by BPA or TBBPA alone. }\end{array}$ & \multirow{2}{*}{ [75] } \\
\hline & & & & $\begin{array}{l}\text { 1/2.5/5/10/25\% LC50 } \\
\text { BPA/TBBPA +0.1 nM T3 }\end{array}$ & $\begin{array}{l}\text { With T3, decrease of transcriptional } \\
\text { activity by BPA. }\end{array}$ & \\
\hline \multirow[b]{2}{*}{$\begin{array}{c}\text { Amphibian (Xenopus } \\
\text { laevis) }\end{array}$} & \multirow[b]{2}{*}{ Tadpole tail culture } & \multirow[b]{2}{*}{$\begin{array}{l}\text { Semi-quantitative } \\
\text { RT-PCR }\end{array}$} & \multirow[b]{2}{*}{5 days } & $10^{-7}-10^{-5} \mathrm{M} \mathrm{BPA}$ & $\begin{array}{l}\text { Inhibition of } \operatorname{Tr} \alpha \text { and } \operatorname{Tr} \beta \text { mRNA } \\
\text { expression with a greater effect on the } \\
\text { expression of } \operatorname{Tr} \beta \text { than } \operatorname{Tr} \alpha \text {. Moderate } \\
\text { suppression of } R X R \gamma \text { mRNA expression. }\end{array}$ & \multirow[b]{2}{*}{ [66] } \\
\hline & & & & $\begin{array}{l}10^{-5} \mathrm{M} \pm 2.5^{*} 10^{-8} / 10^{-7} / 4^{*} 10^{-7} \\
\mathrm{~T} 3\end{array}$ & $\begin{array}{l}\text { T3 counteracts the inhibitory effects of } \\
\text { BPA on } \operatorname{Tr} \alpha \text { and } \operatorname{Tr} \beta \text { mRNA expression, } \\
\text { and, in the case of } \operatorname{Tr} \beta \text {, dose-dependently. } \\
\text { Dose-dependent suppressive effect of T3 } \\
\text { on } R X R \gamma \text { gene expression independently } \\
\text { of the presence of BPA. }\end{array}$ & \\
\hline $\begin{array}{c}\text { Amphibian (Xenopus } \\
\text { laevis) }\end{array}$ & $\begin{array}{l}\text { XL58-TRE-Luc } \\
\text { cells }\end{array}$ & $\begin{array}{l}\text { Luciferase reporter } \\
\text { gene assay }\end{array}$ & $24 \mathrm{~h}$ & $\begin{array}{l}10^{-8}-10^{-6} \mathrm{M} \text { BPA/TBBPA } \pm 2 \\
\mathrm{nM} \mathrm{T3}\end{array}$ & $\begin{array}{l}\text { With T3, inhibition of transcription in a } \\
\text { dose-dependent manner. In the absence } \\
\text { of T3, agonistic activity. }\end{array}$ & [70] \\
\hline
\end{tabular}


Table 2. Cont.

\begin{tabular}{|c|c|c|c|c|c|c|}
\hline Species & Model & Method & Exposure Time & Doses Tested & Principal Results & Reference \\
\hline $\begin{array}{l}\text { Amphibian } \\
\text { (Xenopus laevis) }\end{array}$ & $\begin{array}{l}\text { XL58-TRE-Luc } \\
\text { cells }\end{array}$ & $\begin{array}{l}\text { Luciferase reporter } \\
\text { gene assay }\end{array}$ & $24 \mathrm{~h}$ & $0 / 10^{-8}-10^{-6}$ TBBPA $\pm 2 \mathrm{nM}$ T3 & $\begin{array}{l}\text { With T3, inhibition of transcription in a } \\
\text { dose-dependent manner. }\end{array}$ & [74] \\
\hline \multirow{2}{*}{ Chinese hamster } & \multirow{2}{*}{$\begin{array}{l}\text { Ovary } \\
\text { (CHO-K1 cells) }\end{array}$} & \multirow{2}{*}{$\begin{array}{l}\text { Luciferase reporter } \\
\text { gene assay }\end{array}$} & \multirow{2}{*}{$24 \mathrm{~h}$} & $\begin{array}{l}10^{-10}-10^{-4} \mathrm{M} \\
\text { BPA/TBВPA/ТСВРА }\end{array}$ & $\begin{array}{l}\text { Suppression of transcription in cell } \\
\text { transfected with TR } \alpha 1 \text { or TR } \beta 1 \text { by both } \\
\text { TBBPA and TCBPA }\end{array}$ & \multirow{2}{*}{ [10] } \\
\hline & & & & $\begin{array}{l}\text { 0/3.1/6.3/13/25/50/100 } \mu \mathrm{M} \\
\text { TBBPA/TCBPA +10 nM T3 }\end{array}$ & $\begin{array}{l}\text { With T3, inhibition of transcriptional } \\
\text { activities by TBBPA and TCBPA/ }\end{array}$ & \\
\hline Mouse & $\begin{array}{l}\text { Cerebellum } \\
\text { (C17. } \alpha \text { cells) }\end{array}$ & $\begin{array}{l}\text { Luciferase reporter } \\
\text { gene assay }\end{array}$ & $24 \mathrm{~h}$ & $\begin{array}{l}\text { 0/10-9 }-10^{-5} \text { M TBBPA } \\
\pm 0.1 / 1 / 10 \\
\mathrm{nM} \mathrm{T3}\end{array}$ & $\begin{array}{l}\text { Antagonistic effect at least in part } \\
\text { independent from } \mathrm{T} 3 \text { concentration. }\end{array}$ & [64] \\
\hline Mouse & $\begin{array}{l}\text { Oligodendrocyte } \\
\text { precursors cells }\end{array}$ & Stimulation/inhibition & $48 \mathrm{~h}$ & $0 / 10^{-5} \mathrm{M}$ BPA $\pm 100 \mathrm{nM} \mathrm{T} 3$ & $\begin{array}{l}\text { No variation in TR } \alpha \text { levels; TR } \beta 1 \text { levels } \\
\text { significantly decreased compared to } \\
\text { controls. }\end{array}$ & [67] \\
\hline Rat & $\begin{array}{l}\text { Adrenal medulla } \\
\text { pheochromocytoma } \\
\text { (PC12 cells) }\end{array}$ & $\begin{array}{l}\text { Luciferase reporter } \\
\text { gene assay }\end{array}$ & $16 \mathrm{~h}$ & $\begin{array}{l}0 / 10 / 20 / 40 / 60 / 100 \mu \mathrm{M} \text { TBBPA } \\
\pm 1 / 100 \mathrm{nM} \text { T3 }\end{array}$ & $\begin{array}{l}\text { Agonistic activity in the absence of T3. } \\
\text { With } 1 \mathrm{nM} \text { T3, antagonistic activity } \\
\text { counteracted by large excess of T3. }\end{array}$ & [65] \\
\hline \multirow[t]{2}{*}{ Rat } & \multirow[t]{2}{*}{$\begin{array}{l}\text { Thyroid pituitary } \\
\text { tumor (GH3 cells) }\end{array}$} & \multirow[t]{2}{*}{$\begin{array}{l}\text { Luciferase reporter } \\
\text { gene assay }\end{array}$} & \multirow[t]{2}{*}{$24 \mathrm{~h}$} & $\begin{array}{l}0-500 \mu \mathrm{M} \text { BPA/0-100 } \mu \mathrm{M} \\
\text { TBBPA/TCBPA } \pm 0.25 \mathrm{nM} \text { T3 }\end{array}$ & $\begin{array}{l}\text { With T3, slight induction of luciferase } \\
\text { activity at doses up to } 1 \mu \mathrm{M} \text {. Without T3, } \\
\text { no effect from TBBPA and TCBPA. }\end{array}$ & \multirow[t]{2}{*}{ [76] } \\
\hline & & & & $\begin{array}{l}0.25 \mathrm{nM} \mathrm{T} 3 \pm 0 / 0.5 / 1 / 5 / 10 / 15 \mu \mathrm{M} \\
\text { AM }\end{array}$ & $\begin{array}{l}\text { AM induced T3-mediated response up } \\
\text { to } 1 \mu \mathrm{M} \text {. }\end{array}$ & \\
\hline Rat & $\begin{array}{l}\text { Thyroid pituitary } \\
\text { tumor (GH3 cells) }\end{array}$ & $\begin{array}{l}\text { Luciferase reporter } \\
\text { gene assay }\end{array}$ & $24 \mathrm{~h}$ & $\begin{array}{l}\text { 0/0.1/1/5/10/50 } \mu \mathrm{M} \\
\mathrm{BPA} / \mathrm{BPS} / \mathrm{BPF} \pm 1 \mathrm{nM} \mathrm{T} 3\end{array}$ & $\begin{array}{l}\text { Agonistic activity of all chemicals on } \mathrm{TH} \\
\text { signaling in the absence of } \mathrm{T} 3 \text { and of } \\
\mathrm{BPA} \text { and BPF in the presence of } \mathrm{T} 3 \text {. }\end{array}$ & [80] \\
\hline $\begin{array}{l}\text { African green monkey } \\
\text { (Cerchopitecus aethiops) }\end{array}$ & $\begin{array}{l}\text { Kidney } \\
\text { (CV-1 cells) }\end{array}$ & $\begin{array}{l}\text { Luciferase reporter } \\
\text { gene assay }\end{array}$ & $24 \mathrm{~h}$ & $\begin{array}{l}10^{-6}-10^{-4} \mathrm{M} \\
\text { TBBPA/TCBPA/BPA } \\
+10 \mathrm{nM} \mathrm{T3}\end{array}$ & $\begin{array}{l}\text { With T3, antagonistic activity in cells } \\
\text { transfected with TR } \beta 1 \text {. In the absence of } \\
\text { T3, no effects of the three chemicals. }\end{array}$ & [73] \\
\hline
\end{tabular}


Table 2. Cont

\begin{tabular}{|c|c|c|c|c|c|c|}
\hline Species & Model & Method & Exposure Time & Doses Tested & Principal Results & Reference \\
\hline \multirow{4}{*}{$\begin{array}{l}\text { African green monkey } \\
\text { (Cerchopitecus aethiops) }\end{array}$} & \multirow{4}{*}{$\begin{array}{l}\text { Kidney } \\
\text { (CV-1 cells) }\end{array}$} & $\begin{array}{l}\text { Luciferase reporter } \\
\text { gene assay }\end{array}$ & n.d. & $10^{-9}-10^{-7} \mathrm{M} \mathrm{BPA} \pm 0.1 \mathrm{nM} \mathrm{T} 3$ & $\begin{array}{l}\text { With T3, suppression of TR-mediated } \\
\text { transcription also in the presence of } \\
\text { SRC1. No effects of BPA on transcription } \\
\text { in the absence of T3. }\end{array}$ & \multirow{4}{*}{ [77] } \\
\hline & & \multirow{3}{*}{$\begin{array}{l}\text { Mammalian } \\
\text { two-hybrid assay }\end{array}$} & \multirow{3}{*}{ n.d. } & $10^{-8} \mathrm{M} \mathrm{BPA} \pm 0.1 \mathrm{nM}$ T3 & $\begin{array}{l}\text { No effects of BPA on T3-mediated } \\
\text { binding of SRC1 to TR } \beta 1 .\end{array}$ & \\
\hline & & & & $\begin{array}{l}10^{-9}-10^{-7} \text { M BPA } \pm 0.1 \mathrm{nM} \\
\mathrm{T} 3 / \pm 10 \mathrm{nM} 44\end{array}$ & $\begin{array}{l}\text { Transcription activated by increasing } \\
\text { concentrations of BPA in the presence of } \\
\text { both T3/T4 and NCor/SMRT1. }\end{array}$ & \\
\hline & & & & $\begin{array}{l}10^{-8} \mathrm{M} \text { BPA } \pm 0.1 \mathrm{nM} \mathrm{T} 3 / \pm 10 \\
\mathrm{nM} \mathrm{T} 4\end{array}$ & $\begin{array}{l}\text { Overexpression of either } \beta \text {-integrin or } \\
\text { c-Src reduced recruitment of N-CoR or } \\
\text { SMRT to TR- } \beta 1 \text { stimulated by BPA in } \\
\text { the presence of T3/T4. }\end{array}$ & \\
\hline \multirow[t]{2}{*}{ Human } & \multirow[t]{2}{*}{$\begin{array}{l}\text { Hepatoblastoma } \\
\text { (HpeG2 cells) }\end{array}$} & \multirow{2}{*}{$\begin{array}{l}\text { Luciferase reporter } \\
\text { gene assay } \\
\text { Mammalian } \\
\text { two-hybrid } \\
\text { assay }\end{array}$} & $24 \mathrm{~h}$ & $\begin{array}{l}10^{-9} / 10^{-7} / 10^{-5} \mathrm{M} \mathrm{BPA}+10 \mathrm{nM} \\
\mathrm{T} 3\end{array}$ & $\begin{array}{l}\text { With T3, dose-dependent inhibition of } \\
\text { transcription mediated by native TR } \alpha 1 \\
\text { and TR } \beta 1 .\end{array}$ & \multirow[t]{2}{*}{ [2] } \\
\hline & & & n.d. & $\begin{array}{l}10^{-9} / 10^{-7} / 10^{-5} \mathrm{M} \mathrm{BPA} \pm 1 / 3 / 6 \\
\mathrm{nM} \mathrm{T3}\end{array}$ & $\begin{array}{l}\text { Enhancement of interaction of TRs with } \\
\mathrm{N}-\mathrm{CoR} \text { in a dose-dependent manner. }\end{array}$ & \\
\hline \multirow[t]{2}{*}{ Human } & \multirow[t]{2}{*}{$\begin{array}{l}\text { Hepatocarcinoma } \\
\text { (HepG2 cells) }\end{array}$} & $\begin{array}{l}\text { Luciferase reporter } \\
\text { gene assay }\end{array}$ & $24 \mathrm{~h}$ & $10^{-11}-10^{-5} \mathrm{M}$ TBBPA $\pm 1 \mathrm{nM} \mathrm{T} 3$ & $\begin{array}{l}\text { Activation of expression in the absence } \\
\text { of T3 and antagonistic effect with T3 at } \\
\text { the same dose }\left(10^{-4} \mathrm{M}\right) \text {. }\end{array}$ & \multirow[t]{2}{*}{ [72] } \\
\hline & & qRT-PCR & $24 \mathrm{~h}$ & $10^{-5} \mathrm{M}$ ТВВРА $\pm 1 \mathrm{nM}$ T3 & $\begin{array}{l}\text { Antagonistic effect on T3-induced DIO1 } \\
\text { expression. }\end{array}$ & \\
\hline Human & $\begin{array}{l}\text { Embryonic kidney } \\
\text { (HEK293 cells) }\end{array}$ & $\begin{array}{l}\text { Luciferase reporter } \\
\text { gene assay }\end{array}$ & $24 \mathrm{~h}$ & $\begin{array}{l}0,10^{-9}-10^{-5} \mathrm{M} \text { TBBPA } \\
\pm 0.1 / 1 / 10 \\
\mathrm{nM} \mathrm{T3}\end{array}$ & $\begin{array}{l}\text { Antagonistic effect stronger at lower } \mathrm{T} 3 \\
\text { concentration. }\end{array}$ & [64] \\
\hline
\end{tabular}


Table 2. Cont.

\begin{tabular}{|c|c|c|c|c|c|c|}
\hline Species & Model & Method & Exposure Time & Doses Tested & Principal Results & Reference \\
\hline \multicolumn{7}{|c|}{ Cell Proliferation } \\
\hline \multirow{2}{*}{ Rat } & \multirow{2}{*}{$\begin{array}{l}\text { Thyroid pituitary } \\
\text { tumor (GH3 cells) }\end{array}$} & \multirow{2}{*}{$\begin{array}{l}\text { WST-1 cell } \\
\text { proliferation assay }\end{array}$} & \multirow{2}{*}{$48 / 96 \mathrm{~h}$} & $\begin{array}{l}10^{-9}-10^{-6} \mathrm{M} \\
\mathrm{BPA} / \mathrm{BPAF} / \mathrm{BPAP} / \mathrm{BPB} \\
/ \mathrm{BPC} / \mathrm{BPF} / \mathrm{BPM} / \mathrm{BPP} / \mathrm{BPS} / \mathrm{BPZ} \\
\pm 6.4^{*} 10^{-10} \mathrm{M} 3-\mathrm{EC}_{50}\end{array}$ & $\begin{array}{l}\text { All BPA analogues alone stimulated cell } \\
\text { proliferation at the highest concentration. } \\
\text { BPAF had the strongest effect. With T3, } \\
\text { inhibition of cell proliferation at } 48 \mathrm{~h} \text {; } \\
\text { agonistic effects at } 96 \text { h by high doses of } \\
\text { BPA, BPAF, BPF, BPS, BPZ. }\end{array}$ & \multirow{2}{*}{ [85] } \\
\hline & & & & $\begin{array}{l}10^{-9}-10^{-6} \mathrm{M} \mathrm{BPA} / \mathrm{BPAF} \\
\pm 10^{-12} \mathrm{M} \mathrm{E}_{2} / \pm 6.4^{*} 10^{-10} \mathrm{M} \\
\mathrm{T}^{-}-\mathrm{EC}_{50}\end{array}$ & $\begin{array}{l}\text { Additive like-effects of co-treatment } \\
\text { with BPA analogues and } E_{2} \text {. With T3, } \\
\text { inhibition of analogues alone and } \\
\text { enhancement of cell proliferation by } \\
\text { co-treatment with } E_{2} \text {. }\end{array}$ & \\
\hline \multirow[t]{2}{*}{ Rat } & \multirow[t]{2}{*}{$\begin{array}{l}\text { Thyroid pituitary } \\
\text { tumor (GH3 cells) }\end{array}$} & $\begin{array}{l}\text { WST-1 cell } \\
\text { proliferation assay }\end{array}$ & 7 days & $\begin{array}{l}10^{-8}-10^{-4} \mathrm{M} \text { ТТВРА/ТСВРА } \\
\pm 0.1 / 1 \mathrm{nM} \mathrm{T3}\end{array}$ & $\begin{array}{l}\text { Stimulation of cell growth and, with T3, } \\
\text { no inhibition of induction of GH3 cell } \\
\text { growth. }\end{array}$ & \multirow[t]{2}{*}{ [71] } \\
\hline & & GH-production assay & $48 \mathrm{~h}$ & $10^{-8}-10^{-4} \mathrm{M}$ ТTВPA/ТCВРА & Stimulation of GH release from cells. & \\
\hline Rat & $\begin{array}{l}\text { Thyroid pituitary } \\
\text { tumor (GH3 cells) }\end{array}$ & GH production assay & $48 \mathrm{~h}$ & $\begin{array}{l}10^{-8}-10^{-5} \mathrm{M} \\
\text { BPA/TTBPA/TCBPA }\end{array}$ & $\begin{array}{l}\text { Stimulation of GH release from cells by } \\
\text { only TTBPA and TCBPA. With T3, no } \\
\text { inhibition of cell growth. }\end{array}$ & [83] \\
\hline Rat & $\begin{array}{l}\text { Thyroid pituitary } \\
\text { tumor (GH3 cells) }\end{array}$ & T-screen assay & n.d. & $\begin{array}{l}\text { 0/0.1/1/5/10/50 } \mu \mathrm{M} \\
\mathrm{BPA} / \mathrm{BPS} / \mathrm{BPF} \pm 1 \mathrm{nM} \mathrm{T} 3 \pm 2 \mu \mathrm{M} \\
\mathrm{AM}\end{array}$ & $\begin{array}{l}\text { For all chemicals, induction of cell } \\
\text { proliferation only with T3, } \\
\text { and inhibition of growth in the absence } \\
\text { of T3. Agonistic actions of BPs were } \\
\text { antagonized by AM. }\end{array}$ & {$[80]$} \\
\hline \multirow[b]{2}{*}{ Rat } & \multirow[b]{2}{*}{$\begin{array}{l}\text { Thyroid pituitary } \\
\text { tumor (GH3 cells) }\end{array}$} & \multirow[b]{2}{*}{ T-screen assay } & \multirow[b]{2}{*}{6 days } & $\begin{array}{l}10^{-8}-10^{-5} \mathrm{M} \\
\mathrm{BPA} / \mathrm{BPA}-\mathrm{DM} / \mathrm{TBBPA} \\
\pm 0.5 \mathrm{nM} \mathrm{T} 3\end{array}$ & $\begin{array}{l}\text { Stimulation of growth by all tested } \\
\text { chemicals. In presence of T3, } \\
\text { potentiating effect on } \\
\text { T3-induced growth. }\end{array}$ & \multirow[b]{2}{*}{ [81] } \\
\hline & & & & $\begin{array}{l}0.5 / 1 \mathrm{nM} \mathrm{T3} ; 5^{*} 10^{-7}-5^{*} 10^{-6} \\
\text { BPA/BPA-DM; } \\
1^{*} 10^{-5} / 2.5^{*} 10^{-5} \mathrm{M} \text { TBBPA } \pm 1 \\
\text { nM ICI }\end{array}$ & $\begin{array}{l}\text { Suppression of induced cell proliferation } \\
\text { by the antiestrogen ICI. None of the } \\
\text { compounds able to counteract the } \\
\text { inhibitory effects of ICI. }\end{array}$ & \\
\hline
\end{tabular}


Table 2. Cont

\begin{tabular}{|c|c|c|c|c|c|c|}
\hline Species & Model & Method & Exposure Time & Doses Tested & Principal Results & Reference \\
\hline Rat & $\begin{array}{l}\text { Thyroid pituitary } \\
\text { tumor (GH3 cells) }\end{array}$ & T-screen assay & $96 \mathrm{~h}$ & $\begin{array}{l}10^{-7}-10^{-5} \mathrm{M} \\
\mathrm{BPA} / \mathrm{TBBPA} / \mathrm{TCBPA} \\
\pm 0.25 \mathrm{nM} \mathrm{T} 3\end{array}$ & $\begin{array}{l}\text { No effects on growth for all compounds } \\
\text { in the absence of T3. With T3, BPA } \\
\text { stimulated growth with maximum } \\
\text { potentiation at } 10^{-6} \mathrm{M} \text {, then cytotoxicity. }\end{array}$ & [82] \\
\hline Rat & $\begin{array}{l}\text { Thyroid pituitary } \\
\text { tumor (GH3 cells) }\end{array}$ & T-screen assay & $96 \mathrm{~h}$ & $\begin{array}{l}10^{-12}-10^{-6} \mathrm{M} \text { TBBPA } \pm 0.25 \mathrm{nM} \\
\mathrm{T} 3\end{array}$ & $\begin{array}{l}\text { With T3, potentiation of T3-mediated } \\
\text { cell growth. In the absence of T3, no } \\
\text { effects on cell proliferation. }\end{array}$ & [84] \\
\hline Human & $\begin{array}{l}\text { PTC } \\
\text { (BHP10-3 cells) }\end{array}$ & Cell Counting Kit- 8 & $24 / 48 / 72 \mathrm{~h}$ & $\begin{array}{l}10^{-8}-10^{-3} \mathrm{M} \mathrm{BPA} \\
10^{-9}-10^{-4} \mathrm{M} \mathrm{E}_{2}\end{array}$ & $\begin{array}{l}\text { Similar proliferative effects of BPA and } \\
\mathrm{E}_{2} \text { with non monotonic dose-response } \\
\text { curve and progressive effects over time. }\end{array}$ & [86] \\
\hline \multicolumn{7}{|c|}{ Cytotoxicity } \\
\hline \multirow{2}{*}{$\begin{array}{l}\text { Zebrafish } \\
\text { (Danio rerio) }\end{array}$} & \multirow{2}{*}{$\begin{array}{l}\text { Hepatocyte } \\
\text { (ZFL cells) }\end{array}$} & \multirow{2}{*}{$\begin{array}{l}\text { Fluorescence } \\
\text { (AlamarBlue }^{\mathrm{TM}} \\
\text { assay) }\end{array}$} & \multirow[t]{2}{*}{$24 / 96 \mathrm{~h}$} & 0/10-1000 $\mu \mathrm{M}$ BPA & $\begin{array}{l}24 \text { h LC50 of BPA: } 367.1 \mu \mathrm{M} \\
96 \text { h LC50 of BPA: } 357.6 \mu \mathrm{M}\end{array}$ & \multirow[t]{2}{*}{ [75] } \\
\hline & & & & 0/3.16/10 $\mu \mathrm{M}$ ТВВРА & $\begin{array}{l}24 \mathrm{~h} \text { LC50 of TBBPA: } 4 \mu \mathrm{M} \\
96 \mathrm{~h} \text { LC50 of TBBPA: } 4.2 \mu \mathrm{M}\end{array}$ & \\
\hline $\begin{array}{l}\text { Amphibian (Xenopus } \\
\text { laevis) }\end{array}$ & $\begin{array}{l}\text { XL58-TRE-Luc } \\
\text { cells }\end{array}$ & $\begin{array}{l}\text { Cell Count Reagent } \\
\text { SF kit }\end{array}$ & $48 \mathrm{~h}$ & 0/0.5/1/2/4/8/16 $\mu \mathrm{M} \mathrm{BРА/ТВВРА}$ & $\begin{array}{l}\text { Cell viability not compromised up to } 4 \\
\mu \mathrm{M} \text { for both chemicals. }\end{array}$ & {$[70]$} \\
\hline Chinese hamster & $\begin{array}{l}\text { Ovary } \\
\text { (CHO-K1 cells) }\end{array}$ & EGFP fluorescence & $24 \mathrm{~h}$ & $\begin{array}{l}\text { 0/3.1/6.3/13/25/50/100 } \mu \mathrm{M} \\
\text { TBBPA/TCBPA +10 nM T3 }\end{array}$ & $\begin{array}{l}\text { Cytotoxicity at the highest } \\
\text { concentrations tested for all chemicals. }\end{array}$ & [10] \\
\hline $\begin{array}{l}\text { African green monkey } \\
\text { (Cerchopitecus aethiops }\end{array}$ & $\begin{array}{l}\text { Kidney } \\
\text { (CV-1 cells) }\end{array}$ & MTT assay & $24 \mathrm{~h}$ & $\begin{array}{l}1 / 10 / 20 / 50 / 100 \mu \mathrm{M} \\
\text { TBBPA/TCBPA/BPA } \\
\pm 10 \mathrm{nM} \text { T3 }\end{array}$ & $\begin{array}{l}\text { Cytotoxicity of all chemicals at the } \\
\text { highest concentration tested in the } \\
\text { absence and in the presence of } \mathrm{T} 3 \text {. }\end{array}$ & [73] \\
\hline Rat & $\begin{array}{l}\text { Adrenal medulla } \\
\text { pheochromocytoma } \\
\text { (PC12 cells) }\end{array}$ & MTT assay & $16 \mathrm{~h}$ & $100 \mu \mathrm{M}$ ТВВРА/ТCВРА & No significant effects on cell viability. & [65] \\
\hline Rat & $\begin{array}{l}\text { Thyroid pituitary } \\
\text { tumor (GH3 cells) }\end{array}$ & $\begin{array}{l}\text { Fluorescence } \\
(\text { AlamarBlue } \\
\text { assay }\end{array}$ & $4 \mathrm{~h}$ & $\begin{array}{l}0-500 \mu \mathrm{M} \text { BPA/0-100 } \mu \mathrm{M} \\
\text { TBBPA/TCBPA } \pm 0.25 \mathrm{nM} \text { T3 }\end{array}$ & $\begin{array}{l}\text { At doses }>10 \mu \mathrm{M} \text { TBBPA and TCBPA or } \\
100 \mu \mathrm{M} \text { BPA visible cytotoxicity. }\end{array}$ & [76] \\
\hline Rat & $\begin{array}{l}\text { Immortalized } \\
\text { thyroid } \\
\text { follicular cells } \\
\text { (FRTL-5 cells) }\end{array}$ & MTT-assay & $24 / 72 \mathrm{~h}$ & $10^{-9}-10^{-4} \mathrm{M} \mathrm{BPA}$ & $\begin{array}{l}\text { No effects on cell survival at any dose at } \\
\text { either } 1 \text { day or } 3 \text { days of treatment. }\end{array}$ & [79] \\
\hline
\end{tabular}


Table 2. Cont

\begin{tabular}{|c|c|c|c|c|c|c|}
\hline Species & Model & Method & Exposure Time & Doses Tested & Principal Results & Reference \\
\hline Human & $\begin{array}{l}\text { Thyroid anaplastic } \\
\text { carcinoma } \\
\text { (Cal-62 cells) }\end{array}$ & \multirow{2}{*}{$\begin{array}{l}\text { MTT assay } \\
\text { (on each cell type) }\end{array}$} & \multirow{2}{*}{$24 \mathrm{~h}$} & \multirow{2}{*}{$\begin{array}{l}\text { 0/25/50/75/100/150/200 } \mu \mathrm{M} \\
\text { BPA/TBBPA }\end{array}$} & \multirow{2}{*}{$\begin{array}{l}\text { TBBPA EC }_{50} \\
\text { Cal } 62 \text { cells: } 200 \mu \mathrm{M} \\
\text { A549 cells: } 168 \mu \mathrm{M} \\
\text { NRK cells: } 52 \mu \mathrm{M} \\
\text { No toxic effects of BPA in the tested } \\
\text { concentration range. }\end{array}$} & \multirow{3}{*}{ [87] } \\
\hline Rat & $\begin{array}{l}\text { Kidney epithelial } \\
\text { (NRK cells) }\end{array}$ & & & & & \\
\hline Human & $\begin{array}{l}\text { Epithelial alveolar } \\
\text { type II-like lung } \\
\text { (A549 cells) }\end{array}$ & $\begin{array}{l}\text { DNA synthesis by } \\
\text { BrdU-assay } \\
\text { (on each cell type) }\end{array}$ & $\begin{array}{l}24 / 48 / 72 / \\
96 / 120 \mathrm{~h}\end{array}$ & $\begin{array}{l}0 / 25 / 50 / 75 / 100 / 150 / 200 \mu \mathrm{M} \\
\text { TBBPA } \\
\pm 10 \mu \mathrm{M} \text { U0126 }\end{array}$ & $\begin{array}{l}\text { NRK cells the most sensitive to TBBPA } \\
\text { (decreased growth at }>10 \mu \mathrm{M}) \text {. In Cal- } 62 \\
\text { cells, significant inhibition of growth } \\
\text { after } 24 \text { exposure to TBBPA }>100 \mu \mathrm{M} \text { or } \\
10 \mu \mathrm{M} \text { U0126. }\end{array}$ & \\
\hline \multicolumn{7}{|c|}{ Competitive Binding With Thyroid Hormone Binding Proteins } \\
\hline $\begin{array}{c}\text { Amphibian (Xenopus } \\
\text { laevis) }\end{array}$ & $\begin{array}{l}\text { XL58-TRE-Luc } \\
\text { cells }\end{array}$ & $\begin{array}{l}\text { TTR and TR } \\
\text { competitive binding } \\
\text { assay }\end{array}$ & $1-1.5 \mathrm{~h}$ & $\begin{array}{l}10^{-10}-10^{-5} \text { M BРА/ТВBPA + } 0.1 \\
\mathrm{nM}^{125} \mathrm{I}-\mathrm{T} 3\end{array}$ & $\begin{array}{l}\text { Inhibition of T3 binding to TTR }(\mathrm{TBBPA} \\
\mathrm{IC}_{50}=3.7+0.29 \mathrm{nM} ; \mathrm{BPA} \mathrm{IC}_{50}=1670+30 \\
\mathrm{nM}) \text { and, with weaker affinity, to TR. }\end{array}$ & [70] \\
\hline Chinese hamster & $\begin{array}{l}\text { Ovary } \\
\text { (CHO-K1 cells) }\end{array}$ & $\begin{array}{l}\text { Competitive binding } \\
\text { assay }\end{array}$ & $40 \mathrm{~min}$. & $\begin{array}{l}10^{-7}-10^{-4} \mathrm{M} \\
\text { BPA/TTBPA/TCBPA } \\
+0.1 \mathrm{nM}^{125} \mathrm{I}-\mathrm{T} 3\end{array}$ & $\begin{array}{l}\text { Inhibition of binding to TR }\left(\mathrm{IC}_{50} \mathrm{TBBPA}\right. \\
\left.=3.5 \mu \mathrm{M} ; \mathrm{IC}_{50} \mathrm{TCBPA}=9.5 \mu \mathrm{M}\right)\end{array}$ & [10] \\
\hline Rat & $\begin{array}{l}\text { Thyroid pituitary } \\
\text { (MtT/E-2 cells) }\end{array}$ & $\begin{array}{l}\text { Competitive binding } \\
\text { assay }\end{array}$ & $40 \mathrm{~min}$. & $\begin{array}{l}10^{-7}-10^{-4} \mathrm{M} \text { TTBPA/TCBPA; } \\
10^{-5}-10^{-4} \mathrm{M} \text { BPA }+0.1 \mathrm{nM} \\
125 \mathrm{I}-\mathrm{T} 3\end{array}$ & $\begin{array}{l}\text { Inhibition of T3 binding to TR by TBBPA } \\
\text { and TCBPA. Little effect by BPA. }\end{array}$ & [71] \\
\hline Rat & $\begin{array}{l}\text { Thyroid pituitary } \\
\text { tumor (GH3 cells) }\end{array}$ & $\begin{array}{l}\text { T4-TTR competition } \\
\text { binding assay }\end{array}$ & Overnight & $\begin{array}{l}1 \mathrm{nM}-1 \mu \mathrm{M} \text { TBBPA } \\
+55 \mathrm{nM}\left({ }^{125} \mathrm{I}-\mathrm{T} 4+\mathrm{T} 4\right)\end{array}$ & $\begin{array}{l}\text { Potent antagonism with T4 in TTR } \\
\text { binding. } \mathrm{IC}_{50}=0.031 \mu \mathrm{M} .\end{array}$ & [85] \\
\hline Rat & Liver microsomes & $\begin{array}{l}\text { T4-TTR competition } \\
\text { binding assay }\end{array}$ & Overnight & $\begin{array}{l}\text { 1.95-500 nM TBBPA/TCBPA } \\
+55 \mathrm{nM}\left({ }^{125} \mathrm{I}-\mathrm{T} 4+\mathrm{T} 4\right)\end{array}$ & $\begin{array}{l}\text { For TBBPA, maximum displacement } \\
(96.5 \%) \text { of T4 from TTR at } 500 \mathrm{nM} . \mathrm{IC}_{50} \\
=7.7 \pm 0.9 \mathrm{nM}\end{array}$ & [92] \\
\hline \multicolumn{7}{|c|}{ Perturbation of Thyroid Hormone Uptake } \\
\hline Dog & $\begin{array}{l}\text { Kidney tubule } \\
\text { (MDCK cells) }\end{array}$ & MCT8HTS assay & $10 \mathrm{~min}$. & $\begin{array}{l}2 / 4 / 8 / 18 / 32 / 62 / 125 / 250 \mu \mathrm{M} \mathrm{BPA} \\
+3.3 \mu \mathrm{M} \mathrm{T} 3\end{array}$ & $\begin{array}{l}\text { Inhibition of T3 uptake mediated by } \\
\text { MCT8. }\end{array}$ & [94] \\
\hline Mouse & Primary astrocytes & $\begin{array}{l}\text { Nonradioactive } \\
\text { uptake assay }\end{array}$ & $15 \mathrm{~min}$. & $10 \mu \mathrm{M}$ BPA $+10 \mu \mathrm{M}$ T3 & Decrease in MCT8-mediated T3 uptake. & [98] \\
\hline
\end{tabular}


Table 2. Cont.

\begin{tabular}{|c|c|c|c|c|c|c|}
\hline Species & Model & Method & Exposure Time & Doses Tested & Principal Results & Reference \\
\hline \multicolumn{7}{|c|}{ Dysregulation of Gene Expression } \\
\hline $\begin{array}{l}\text { Zebrafish } \\
\text { (Danio rerio) }\end{array}$ & $\begin{array}{l}\text { Hepatocyte } \\
\text { (ZFL cells) }\end{array}$ & qRT-PCR & $24 \mathrm{~h}$ & 10/25/50\% LC50 BPA/TBBPA & $\begin{array}{l}\text { Inhibition of expression of Dio1, Dio3, } \\
\text { Trb, Sult1-st1, -st2, -st3, -st-5 and Ugt2a1, } \\
\text { and induction of } U g t 1 a b \text { genes by BPA. } \\
\text { Inhibition of expression of Dio3, and } \\
\text { up-regulation of Ttr, Sult1-st2, sult1-st5, } \\
\text { and Ugt2a1 by TBBPA. }\end{array}$ & [75] \\
\hline $\begin{array}{c}\text { Amphibian (Xenopus } \\
\text { laevis) }\end{array}$ & Tadpole tail culture & $\begin{array}{l}\text { Semi-quantitative } \\
\text { RT-PCR }\end{array}$ & 5 days & $\begin{array}{l}10^{-7}-10^{-5} \mathrm{M} \mathrm{BPA} \\
\pm 2.5^{*} 10^{-8} / 10^{-7} / 4^{*} 10^{-7} \mathrm{~T} 3\end{array}$ & $\begin{array}{l}\text { Inhibition of } \operatorname{Tr} \alpha \text { and } \operatorname{Tr} \beta \text { mRNA } \\
\text { expression. T3 counteracts the inhibitory } \\
\text { effects of BPA on } \operatorname{Tr} \alpha \text { and } \operatorname{Tr} \beta \text { mRNA } \\
\text { expression dose-dependently. }\end{array}$ & [66] \\
\hline \multirow{2}{*}{ Rat } & \multirow{2}{*}{$\begin{array}{l}\text { Liver and brown } \\
\text { adipose tissue }\end{array}$} & Deiodinase 1 assay & $1 \mathrm{~h}$ & \multirow{2}{*}{ 0/0.005/0.05/0.5/5 mmol/L BPA } & \multirow{2}{*}{$\begin{array}{l}\text { Inhibition of both hepatic DIO1 and } \\
\text { brown adipose tissue DIO2 activities, } \\
\text { with a greater effect on DIO1. } \\
\mathrm{IC}_{50}(\mathrm{D} 1 \text { activity) }=0.183 \mathrm{mmol} / \mathrm{L} \\
\mathrm{IC}_{50}(\mathrm{D} 2 \text { activity) }=1.11 \mathrm{mmol}\end{array}$} & \multirow{2}{*}{ [102] } \\
\hline & & Deiodinase 2 assay & $3 \mathrm{~h}$ & & & \\
\hline Rat & $\begin{array}{l}\text { Thyroid pituitary } \\
\text { tumor (GH3 cells) }\end{array}$ & qRT-PCR & $48 \mathrm{~h}$ & $\begin{array}{l}10^{-9}-10^{-6} \mathrm{M} \mathrm{BPA} / \mathrm{BPAF} \pm 10^{-12} \\
\mathrm{M} \mathrm{E}_{2}\end{array}$ & $\begin{array}{l}\text { Inhibition of transcription of } \operatorname{Tsh} \beta, \operatorname{Tr} \alpha, \\
\text { and } \operatorname{Tr} \beta, D i o 1 \text { and } \operatorname{Dio} 2 . \text { With } \mathrm{E}_{2}, \text { a more } \\
\text { pronounced decrease of } \operatorname{Tr} \alpha, \operatorname{Tr} \beta \text { and } \\
\text { Dio2, and increase of } \operatorname{Tsh} \beta \text { transcription }\end{array}$ & [85] \\
\hline \multirow{2}{*}{ Rat } & $\begin{array}{l}\text { Immortalized } \\
\text { thyroid follicular } \\
\text { cells } \\
\text { (FRTL-5 cells) }\end{array}$ & \multirow{2}{*}{ qRT-PCR } & $24 \mathrm{~h}$ & $\begin{array}{l}\text { 0/1/10/100 } \\
\mathrm{mg} / \mathrm{LBPA} / \mathrm{BPB} / \mathrm{BPF} / \mathrm{BPS} \\
0 / 0.1 / 1 / 10 \mathrm{mg} / \mathrm{L} \\
\mathrm{BPAF} / \mathrm{BPAP} / \mathrm{BPC} / \mathrm{BPM} / \mathrm{BPP} / \mathrm{BPZ}\end{array}$ & $\begin{array}{l}\text { Stimulation of transcription of Tsh-r, } \\
\text { Pax8, Nkx2-1, S lc5a5, Tg, Tpo by BPA, } \\
\text { BPAF, BPAP, BPM, BPS. }\end{array}$ & \multirow{2}{*}{ [99] } \\
\hline & $\begin{array}{l}\text { Thyroid pituitary } \\
\text { Tumor } \\
\text { (GH3 cells) }\end{array}$ & & $48 \mathrm{~h}$ & $\begin{array}{l}\text { 0/0.01/0.1/1/10 mg/L } \\
\mathrm{BPA} / \mathrm{BPAF} / \mathrm{BPAP} / \mathrm{BPB} / \mathrm{BPC} / \\
\mathrm{BPF} / \mathrm{BPM} / \mathrm{BPP} / \mathrm{BPS} / \mathrm{BPZ}\end{array}$ & $\begin{array}{l}\text { Inhibition of transcription of } \operatorname{Tsh} \beta, \operatorname{Tr} \alpha, \\
\text { and } \operatorname{Tr} \beta \text {, and Dio2 by BPA, BPF, BPM, } \\
\text { and BPZ. Some analogues but not BPA } \\
\text { down-regulated Dio1. }\end{array}$ & \\
\hline
\end{tabular}


Table 2. Cont.

\begin{tabular}{|c|c|c|c|c|c|c|}
\hline Species & Model & Method & Exposure Time & Doses Tested & Principal Results & Reference \\
\hline \multirow{3}{*}{ Rat } & \multirow{3}{*}{$\begin{array}{l}\text { Immortalized } \\
\text { thyroid follicular } \\
\text { cells } \\
\text { (FRTL-5 cells) }\end{array}$} & qRT-PCR & $6 / 24 / 48 \mathrm{~h}$ & 0/10/30/100 $\mu \mathrm{M} \mathrm{BPA}$ & $\begin{array}{l}\text { Up-regulation of } T g, P a x-8, \text { Foxe- } 1 \text { and } \\
\text { down-regulation of Slc5a5, Tpo, and } \\
\text { Nkx2-1 transcripts at the highest dose. }\end{array}$ & \multirow{3}{*}{ [100] } \\
\hline & & \multirow[b]{2}{*}{ Iodine uptake assay } & $1 \mathrm{~h}$ & $10^{-7}-10^{-4} \mathrm{M} \mathrm{BPA}+10 \mu \mathrm{M} \mathrm{NaI}$ & $\begin{array}{l}\text { Concentration-dependent decrease of } \\
\text { iodine uptake. }\end{array}$ & \\
\hline & & & $24 / 48 \mathrm{~h}$ & 0/10/30/100 $\mu \mathrm{M} \mathrm{BPA}$ & $\begin{array}{l}\text { Significant decrease in iodine uptake at } \\
\text { non-cytotoxic doses of BPA in the } \\
\text { absence of NaI }\end{array}$ & \\
\hline \multirow[t]{2}{*}{ Rat } & \multirow{2}{*}{$\begin{array}{l}\text { Immortalized } \\
\text { thyroid follicular } \\
\text { cells } \\
\text { (FRTL-5 cells) }\end{array}$} & $\begin{array}{l}\text { Microarray analysis/ } \\
\text { qRT-PCR }\end{array}$ & $1 / 3 / 7$ days & $10^{-9} \mathrm{M} \mathrm{BPA}$ & $\begin{array}{l}\text { Deregulation of } 372 \text { and } 1041 \text { genes after } \\
3 \text { and } 7 \text { days, respectively. Most genes } \\
\text { had a fold change }>2 \text { at both time points. } \\
\text { Following exposure longer than } 7 \text { days, } \\
\text { inhibition of genes involved in the DNA } \\
\text { replication and repair network. }\end{array}$ & \multirow[t]{2}{*}{ [101] } \\
\hline & & $\begin{array}{l}\text { Alkaline comet assay/ } \\
\text { TUNEL assay }\end{array}$ & 28 days +5 days UV & $10^{-9} \mathrm{M} \mathrm{BPA}$ & $\begin{array}{l}\text { After irradiation at } 48 \text { and } 96 \mathrm{~h} \text {, higher } \\
\text { content of DNA damage in the } \\
\text { BPA-treated cells. Until } 120 \mathrm{~h} \text { post } \\
\text { irradiation, higher apoptotic levels in the } \\
\text { BPA-treated cells. }\end{array}$ & \\
\hline \multirow[t]{2}{*}{ Rat } & \multirow{2}{*}{$\begin{array}{l}\text { Immortalized } \\
\text { thyroid } \\
\text { follicular cells } \\
\text { (FRTL-5 cells) }\end{array}$} & \multirow{2}{*}{$\begin{array}{l}\text { Luciferase reporter } \\
\text { gene assay }\end{array}$} & \multirow[t]{2}{*}{$24 \mathrm{~h}$} & $\begin{array}{l}10^{-15}-10^{-4} \mu \mathrm{MBPA} \\
\pm 1.78 / 3.44 / 6.87 / 13.7 / 27.5 \mathrm{ng} / \mu \mathrm{l} \\
\text { TSH }\end{array}$ & $\begin{array}{l}\text { Enhancement of } T g \text {-promoter activity } \\
\text { also in the presence of the highest dose } \\
\text { of TSH. }\end{array}$ & \multirow{3}{*}{ [89] } \\
\hline & & & & $10^{-9} \mathrm{M} \mathrm{BPA} \pm 1 \mu \mathrm{M}$ ICI/TAM & $\begin{array}{l}\text { No effect of the two antiestrogen on the } \\
\text { activity of } T g \text {-promoter induced by BPA. }\end{array}$ & \\
\hline Human & $\begin{array}{l}\text { Ovary cells } \\
\text { (SVKO3 cells) }\end{array}$ & qRT-PCR & $24 \mathrm{~h} / 72 \mathrm{~h}$ & $10^{-9}-10^{-4} \mathrm{M} \mathrm{BPA}$ & $\begin{array}{l}\text { Increase of transcription levels of } S l c 5 a 5, \\
T p o, T s h-r, T g, \text { Pax } 8, \text { Nkx2-1, Foxe } 1 . \\
\text { Increase of transcription of PAX8 also in } \\
\text { SVKO3 cells. }\end{array}$ & \\
\hline
\end{tabular}


In a recent study performed in cells overexpressing the human MCT8 gene, among the several common environmental contaminants classified as flame retardants, pesticides, plasticizers, and others that are suspected to disrupt TH signaling, only BPA was observed to reduce T3 uptakes to around $60 \%$ and $40 \%$ of the control at concentrations $(125 \mu \mathrm{M})$ below those that reduced cell viability $<80 \%$ [94]. This finding is consistent with an earlier study that detected a slight inhibition of T3 transport capabilities of MCT8 by BPA, though at concentrations likely higher than those occurring in vivo [98].

\subsection{Dysregulation of Gene Expression}

In addition to the ability to interfere with TR signaling throughout a direct binding to the receptor, a number of studies observed that BPs may directly affect thyroid gene expression (Table 2).

At doses as low as $10^{-6} \mathrm{M}, \mathrm{BPA}$ and its analogues induced expression of transcripts of genes implicated in thyroid cell activity and proliferation (e.g., the Thyroid stimulating hormone-receptor (Tsh-r)), TH biosynthesis (e.g., Tg, Sodium iodide symporter (Slc5a5 encoding NIS), Thyroid-peroxidase (Tpo) and their transcription regulators (e.g., Paired box 8 (Pax8), NK2 homeobox 1 (Nkx2-1), and Forkhead box E1 (Foxe1)) by over 1.5 fold $[89,99,100]$. Conversely, BPA did not markedly affect transcriptional expression of Slc5a5, Nkx2-1, and Tpo but inhibited NIS-mediated iodide uptake [100]. BPA increased the expression of $\mathrm{Tg}$ gene in the presence of increasing TSH amounts, suggesting a potency similar to that of TSH in enhancing $T g$-promoter activity [94]. The authors also reported that two anti-estrogens, which alone induced the activity of the $T g$ promoter, were not able to enhance BPA activity on the $T g$ promoter, indicating that the effects triggered by BPA do not necessarily involve ER signaling [89]. BPA at the nanomolar range significantly impaired the transcriptome of thyroid cells in a time dependent manner [101]. In fact, whereas short-term exposure to BPA did not cause any relevant transcriptomic changes, long-term exposure, though unable to exert visible damage on cells, determined a slight deregulation of many genes involved in cell proliferation/death, cancer, and DNA repair [101].

BPA and its analogues BPZ, BPF, and bisphenol M (BPM; 4,4'-(1,3-phenylenediisopropylidene) bisphenol) suppressed the transcription of several genes involved in the regulation of the HPT axis (e.g., TSH-specific $\beta$ subunit (Tsh $\beta$ ), Thyroid hormone receptors ( $\operatorname{Tr} \alpha$ and $\operatorname{Tr} \beta$ ), and Deiodinases (Dio1 and Dio2)) in a concentration range of $10^{-7}-10^{-6} \mathrm{M}$, with BPA substitutes being able to disrupt thyroid regulation at lower doses than BPA $[75,85,99]$. Furthermore, co-exposure with $\mathrm{E}_{2}$ potentiated decreased expression of $\operatorname{Tr} \alpha, \operatorname{Tr} \beta$ and Dio2 [85].

BPA inhibited the activities of DIO1 and DIO2 [102], and both BPA and TBBPA markedly dysregulated transcription of Dio3, which is responsible for protection of tissues from TH excess and is the predominant deiodinase expressed in human placenta [103], and hepatic phase II metabolizing genes (Sulfotransferases (Sult1) and UDP-glucuronosyltransferases (Ugt)) [75]. TBBPA, but not BPA, increased expression of the Ttr gene [75], an action at mRNA level that corroborates the competing binding capabilities of TBBPA with TTR [70,84].

\section{Thyroid Disrupting Properties of BPs: in Vivo Studies}

In vivo effects of BP exposure on thyroid function/action are contradictory and difficult to compare, as a consequence of the scarce number of studies performed especially in mammals, the different models, and diversity of the experimental conditions, i.e., the chemical used, the time and dose of treatments, the outcomes assessed. In regards the risk of thyroid cancer associated to BPs exposure, the subject remains almost entirely unexplored.

\subsection{Rodents}

In rodents, most of the studies have been performed in pregnant females, and have evaluated the variations of TH levels in mothers and pups following prenatal and/or lactational exposures (Table 3).

In accordance with numerous in vitro studies, BPA can act as a selective TH antagonist on TR $\beta$, inhibiting TH-negative feedback. Indeed, Zoeller et al. [104] and Zhang et al. [105] observed a significant increase of serum T4 levels in pups of both sexes and in female adults, respectively, without 
any apparent interference on TSH release. In male adult rats, treatment with BPA led to an increase of T4 levels and a reduction of the T3/T4 ratio, suggesting that in exposed animals BPA may impair the peripheral conversion of T4 to T3 [102].

In other experiments, BPA exposure did not produce significant variations in plasma T4 levels [106-109] or, alternatively, the effects may not endure after BPA removal and metabolism [110-112]. It is still unclear whether exposure to BPA and its derivatives can cause hypothyroidism due to limited evidence. A decrease in T4 levels was found in male and female adult rodents $[110,113,114]$ and in rat pups of both sexes [114] or with a sex-specific effect $[112,115]$. The competition of BPs with TTR, as observed in vitro [70,84,92], resulting in a portion of serum T4 displaced from TTR, could determine an increased rate of T4 metabolism and elimination and the consequent reduction of T4 circulating levels [110].

Perinatal or neonatal exposure to BPA was associated with a significant increase of TSH levels in juvenile males [116] and in females in estrus [117,118], accompanied by a significant increase of GH levels and an impaired sensitivity of the thyroid gland to TSH stimulation, respectively, both of which indicate an alteration of the HPT axis [117]. On the other hand, the reduction of serum T3 or T4 after TBBPA treatment induced feedback stimulation, as suggested by the increased pituitary weight [114], whereas in other studies this was insufficient to affect serum TSH or TH levels, thyroid histopathology, and thyroid weight $[107,110]$.

Adult males treated with BPA showed a decrease activity of hepatic DIO1, coherently with what has been reported in vitro [102]. Moreover, in female adult rats BPA lowered thyroid iodide uptake and thyroid peroxidase (TPO) activity, which are two essential steps in TH biosynthesis, probably due to an elevation of reactive oxygen species (ROS) production. Both NIS and TPO have been found to be sensitive to ROS $[119,120]$, and in particular the decrease in TPO activity could be attributable to the oxidation of this enzyme [106]. Increased expression of pituitary Tsh $\beta$ was reported in female rat neonates exposed to BPA [117], whereas Silva et al. did not find any significant reduction of Tsh $\beta$ mRNA levels in treated female rats [106].

To date, it remains unclear whether BPA plays a role in the pathogenesis of thyroid carcinoma. Zhang et al. recently demonstrated that BPA could enhance the susceptibility to TC [105]. Rats pre-treated with N-bis (2-hydroxypropyl) nitrosamine, a drug stimulating thyroid proliferation and promoting a cancerous phenotype [121] and then exposed to BPA and excess iodine for 64 weeks, exhibited a significant increase in incidence of TC and thyroid hyperplasia lesions as well as the up-regulation of ER $\alpha$ in the hyperplasia lesions. The authors speculated that BPA could increase ER $\alpha$ expression in the thyroid, which possibly participated in the proliferation process [105].

\subsection{Sheep}

Sheep are considered a more relevant model to humans than rodents to evaluate fetal exposure to thyroid disruptors and their effects on the mother/newborn thyroid functions because of a similarity in the timing of the ontogenesis of thyroid [122]. In both species thyroxine binding globulin is the main blood transport protein for THs [123], and thyroid system maturation is qualitatively similar in the sheep and human fetuses, although the total maturation time is different (165 days vs. 300 days) [122,124].

Two studies have investigated the relationship of BPA exposure with thyroid function (Table 3). Viguié et al. [122] reported that BPA exposure of pregnant ewes was associated with a transitory hypothyroxinemia of both mothers and their newborn lambs, with a significant reduction of both circulating total T4 (TT4) and free T4 (FT4), findings in agreement with rodent studies [111,112]. In a following study, the authors confirmed alterations of gestational thyroid function, observing a significant reduction of FT4 and total T3 (TT3), but not TT4, in pregnant ewes treated with environmentally-relevant BPA concentrations via subcutaneous and dietary routes of administration [123]. After subcutaneous administration, the maximum serum concentration of BPA obtained was significantly higher $(0.4 \mathrm{nmol} / \mathrm{mL}$ vs. $0.1 \mathrm{nmol} / \mathrm{mL})$ and more prolonged than after dietary administration [123]. 


\subsection{Zebrafish}

Numerous studies have been published on the use of zebrafish (Danio rerio) to explore the effects of EDCs on the thyroid, due to several advantages: a short life cycle, high rates of production, real-time observations during the entire embryonic development, and high conservation of the molecular mechanisms regulating thyroid development with those of mammals $[125,126]$. The early life of fish, in particular, is acknowledged as highly sensitive to the effects of EDCs [127].

Coherently with results observed in vitro and in rodents, BPs may disturb TH homeostasis and gene expression in zebrafish embryos/larvae (Table 3).

Positive $[37,38,128]$ and negative $[37,38,128-131]$ associations between exposure to BPs and T3 and/or T4 levels have been reported, depending on the chemical used, the dose tested, and the time of exposure. Reductions in T4 concentrations, when accompanied with higher TSH contents, may compensate hypothyroidism in zebrafish larvae and stimulate TH synthesis [38,129]. Some experiments observed an interaction between TH levels and sex [129,131]. Tang et al. showed a reduction in whole-body TT4 and TT3 levels but not a significant variation of ratio TT3/TT4, which indicates the relative normal TH homeostasis [130].

Similarly, BPs disrupting effects on thyroid gene expression vary according to the different experimental conditions, especially the duration of exposure [126]. Hence, transcription levels of genes implicated in thyroid cell function and proliferation (Tsh-r), TH activity $(\operatorname{Tr} \alpha, \operatorname{Tr} \beta)$, and transport (Ttr) can be up- $[37,68,126,130,132,133]$ or down-regulated $[38,68,126,128,130,133]$. The transcription of Hematopoietically expressed homeobox (Hhex) was up-regulated in larval fish following exposure to BPA or BPF, although it is important to note that the Hhex gene is expressed in early life, contributing to differentiation and development of the thyroid gland, as well as of other organs, such as the pancreas and liver [37].

Increased $[89,128,129]$ or decreased $[130,132,134,135]$ expression of Slc5a5, Tpo, Pax8, and Tg transcripts was dependent on the dose and window of exposure. Additionally, BPA and BPS appeared to interact with PAX8 and thyroid transcription factor 1 (TTF1) in silico [135]. Genes such as Tpo, Tg, and Slc5a5 have binding sites for PAX8 or TTF1 on their enhancer or promoting regions. Differences of interactions between BPs and the transcription factors could be attributable to stimulation or inhibition with varying BPs doses, and produced as final effect altered expression of the genes controlled by PAX and TTF1 [135].

BPs stimulated thyroid signaling increases expression of Corticotrophin-releasing hormone (Crh) mRNA in the hypothalamus [37,38,129] and of Tsh and $T s h \beta$ in the pituitary gland $[89,128,130,132-134]$, except for TBBPA, which down-regulated Tsh $\beta$ mRNA in embryos [133].

Exposure to BPA and BPA analogues further induced transcription of genes involved in TH metabolism, i.e., Dio1 and/or Dio2 [37,129,132,134], which are implicated in activation/inactivation of $\mathrm{T} 4$ and in conversion of T4 to T3 in peripheral tissues, respectively [136,137], and Ugt1ab [37,38,129].

Notably, co-treatment with T3 appeared to reverse or eliminate thyroid disrupting effects of TBBPA on THs levels and gene transcription in zebrafish larvae [128], whereas a combined exposure of BPAF and sulfamethoxazole, an antibiotic used especially in aquaculture, produced more pronounced changes in transcription levels [134]. 
Table 3. Summary of in vivo studies analyzing effects of exposure to bisphenols on thyroid function.

\begin{tabular}{|c|c|c|c|c|c|}
\hline Species & Method & Window of Exposure & Doses Tested & Principal Results & Reference \\
\hline \multicolumn{6}{|c|}{ Rodents } \\
\hline $\begin{array}{l}\text { Male and female CD-1 } \\
\text { mice }\end{array}$ & ELISA & PND28-PND56 & 0/10/100 mg/L BPA in water & $\begin{array}{l}\text { Significant reduction of FT4 but not FT3 levels at } \\
\text { both doses. No effects of sex on FT3 and } \\
\text { FT4 levels. }\end{array}$ & [113] \\
\hline \multirow{2}{*}{$\begin{array}{l}\text { Pregnant female rats (Crj: } \\
\text { CD (SD) IGS strain) }\end{array}$} & $\begin{array}{l}\text { Chemiluminescence } \\
\text { immunoassay }\end{array}$ & GD6-PND20 & $\begin{array}{l}0 / 4 / 40 \mathrm{mg} / \mathrm{kg} \text { BW BPA per day } \\
\text { by diet }\end{array}$ & $\begin{array}{l}\text { In male and female offspring no significant } \\
\text { variations in T4 levels at 1,3,9 weeks of age. }\end{array}$ & \multirow[b]{2}{*}{ [108] } \\
\hline & TSH stimulation assay & $\begin{array}{l}\text { Offspring at } 9 \text { weeks of } \\
\text { age; } 1 \text { day treatment }\end{array}$ & $\begin{array}{l}\text { TSH } 25 \mathrm{mIU} / 5 \mu \mathrm{L} / \mathrm{g} \text { BW BPA } \\
\text { intraperitoneally }+125 \mathrm{mIU} \\
5 \mu \mathrm{L} / \mathrm{g} \text { BW BPA intramuscularly }\end{array}$ & $\begin{array}{l}\text { In response to exogenous TSH, elevation of T4 } \\
\text { levels, but any significant difference between } \\
\text { control and BPA groups of both sexes. }\end{array}$ & \\
\hline $\begin{array}{l}\text { Pregnant female Sprague } \\
\text { Dawley rats }\end{array}$ & Radioimmunoassay & GD6-PND20 & $\begin{array}{l}\text { 0/1/10/50 mg/kg BW BPA per } \\
\text { day by diet }\end{array}$ & $\begin{array}{l}\text { Increase of TT4 levels in both male and female } \\
\text { pups only on PND15. No effects on serum TSH in } \\
\text { male pups on PND15 among the different } \\
\text { treated-groups. }\end{array}$ & [104] \\
\hline \multirow{3}{*}{$\begin{array}{l}\text { Pregnant female Sprague } \\
\text { Dawley rats }\end{array}$} & $\begin{array}{l}\text { Electrochemiluminescence } \\
\text { immunoassay }\end{array}$ & \multirow{3}{*}{ GD10-PND20 } & \multirow{3}{*}{$\begin{array}{l}\text { 0/100/1000/10,000 ppm TBBPA } \\
\text { by diet }\end{array}$} & $\begin{array}{l}\text { In male pups on PND20, dose-unrelated, but } \\
\text { statistically significant decrease of serum T3 levels } \\
\text { whereas no significant variations of T4 and TSH. } \\
\text { At PNW11, any changes of THs levels in any } \\
\text { groups. }\end{array}$ & \multirow{3}{*}{ [107] } \\
\hline & Necropsy & & & $\begin{array}{l}\text { No significant changes in thyroid weights of } \\
\text { treated dams and offspring compared with } \\
\text { controls but dose-unrelated increased thyroid } \\
\text { weight in all treated groups of dams. }\end{array}$ & \\
\hline & Histology & & & $\begin{array}{l}\text { No significant increased incidence of diffuse } \\
\text { thyroid follicular cell hypertrophy in dams at the } \\
\text { highest dose. }\end{array}$ & \\
\hline $\begin{array}{l}\text { Pregnant female Sprague } \\
\text { Dawley rats } \\
\text { (strain code 23) }\end{array}$ & Radioimmunoassay & GD6-PND15 & $\begin{array}{l}0 / 2.5 / 25 / 250 / 2500 / 25,000 \mu \mathrm{g} / \mathrm{kg} \\
\text { BW BPA per day by diet }\end{array}$ & $\begin{array}{l}\text { No effects on T4 and TRH levels in male and } \\
\text { females pups on PND15. }\end{array}$ & [109] \\
\hline $\begin{array}{l}\text { Pregnant female Sprague } \\
\text { Dawley rats }\end{array}$ & ELISA & GD11-PND21 & $\begin{array}{l}0 / 0.1 / 50 \mathrm{mg} / \mathrm{L} \text { BPA per day in } \\
\text { water }\end{array}$ & $\begin{array}{l}\text { In dams, at } 0.1 \mathrm{mg} / \mathrm{L} \text { reduction of FT4 levels at } \\
\text { delivery and on PND7. } \\
\text { In male pups on PND7, increased FT4 levels at } 0.1 \\
\mathrm{mg} / \mathrm{mL} \text { and decreased FT4 levels at } 50 \mathrm{mg} / \mathrm{L} \text {. } \\
\text { In females no effects at each dose at all days. }\end{array}$ & [112] \\
\hline
\end{tabular}


Table 3. Cont.

\begin{tabular}{|c|c|c|c|c|c|}
\hline Species & Method & Window of Exposure & Doses Tested & Principal Results & Reference \\
\hline Sprague Dawley rat dams & Radioimmunoassay & $\begin{array}{l}\text { GD6-PND15 } \\
\text { GD6-PND21 } \\
\text { GD6-PND90 }\end{array}$ & $\begin{array}{l}2.5-2700 / 100,000 / 300,000 \mu \mathrm{g} / \mathrm{kg} \\
\text { BW BPA per day by diet }\end{array}$ & $\begin{array}{l}\text { No effects on THs levels, thyroid weight, or } \\
\text { thyroid histology in the "low-dose" region. On } \\
\text { PND15, elevation of T3 at both high doses. On } \\
\text { PND90, increase of TSH in females at both high } \\
\text { doses and of T4 in males at the highest dose. }\end{array}$ & [118] \\
\hline $\begin{array}{l}\text { Female Sprague Dawley } \\
\text { rats }\end{array}$ & ELISA & GD11-PND21 & $0.1 \mathrm{mg} / \mathrm{L}$ BPA per day in water & $\begin{array}{l}\text { In dams, after } 10 \text { days from exposure, significant } \\
\text { decrease in TT4 and FT4 levels, but no variation of } \\
\text { TT3 and FT3 levels. } \\
\text { On PND21 but not on PND90, significant decrease } \\
\text { of TT4, TT3, FT4, and FT3 levels in male pups. }\end{array}$ & [111] \\
\hline $\begin{array}{l}\text { Female Sprague Dawley } \\
\text { rats }\end{array}$ & Radioimmunoassay/ELISA & PND1-PND10 & $\begin{array}{l}0,5 \mu \mathrm{g} / 50 \mu \mathrm{L} \text { BPA (B5), } 50 \mu \mathrm{g} / 50 \\
\mu \mathrm{L} \text { BPA (B50), } 500 \mu \mathrm{g} / 50 \mu \mathrm{L} \\
\text { BPA (B500) in castor oil }\end{array}$ & $\begin{array}{l}\text { On PND13, no differences in TSH levels. In estrus, } \\
\text { on PND90, increased TSH levels following } \\
\text { exposure to B50, but not B5 or B500. In adult } \\
\text { females, lower T4 levels at B5 and B500, but not } \\
\text { B50. No significant differences of T3 among } \\
\text { groups. }\end{array}$ & [117] \\
\hline $\begin{array}{l}\text { Neonatal males } R \text {. } \\
\text { norvegicus (Wistar strain) }\end{array}$ & ELISA & PND15-PND30 & $\begin{array}{l}0 / 20 / 40 \mathrm{mg} / \mathrm{kg} \text { BW/BPA per day } \\
\text { by diet }\end{array}$ & $\begin{array}{l}\text { On PND30, significant elevation of TSH levels, } \\
\text { accompanied by a notable reduction of T3, T4, } \\
\text { and GH levels in a dose-dependent manner. }\end{array}$ & [116] \\
\hline \multirow[t]{2}{*}{ Male and female $C D^{\circledR}$ rats } & $\begin{array}{l}\text { Electrochemical } \\
\text { luminescence } \\
\text { immunoassay }\end{array}$ & \multirow{2}{*}{$\begin{array}{l}13 \text { consecutive weeks. } \\
6 \text {-week recovery period of } \\
\text { animals for both control } \\
\text { and } 1000 \mathrm{mg} / \mathrm{kg} / \\
\text { day groups. }\end{array}$} & \multirow[t]{2}{*}{$\begin{array}{l}\text { 0/100/300/1000 mg/kg BW } \\
\text { TBBPA per day by diet }\end{array}$} & $\begin{array}{l}\text { No effects on TSH and T3 levels at any dose or } \\
\text { time in both sexes. Decrease of T4 levels at all } \\
\text { doses in both males and females. } \\
\text { Following recovery period, T4 levels in males but } \\
\text { not in females at } 1000 \mathrm{mg} / \mathrm{kg} \text { were comparable } \\
\text { to controls. }\end{array}$ & \multirow[t]{2}{*}{ [110] } \\
\hline & Necropsy/Histology & & & $\begin{array}{l}\text { No effects of treatment on thyroid weight and } \\
\text { histopathology }\end{array}$ & \\
\hline Wistar rats dams & Radioimmunoassay & GD1-PND21 & $\begin{array}{l}0 / 10(\text { BPA10) } / 50 \mu \mathrm{g} / \mathrm{kg} \text { BW per } \\
\text { day (BPA50) by diet }\end{array}$ & $\begin{array}{l}\text { On PND21, no change in THs levels in dams and } \\
\text { in female pups, whereas in the BPA10 group of } \\
\text { male pups lower T3 levels without any variation } \\
\text { in T4 levels. } \\
\text { On PND180, decrease of T3 levels in females and } \\
\text { T4 levels in males among the BPA10 group. }\end{array}$ & [115] \\
\hline
\end{tabular}


Table 3. Cont.

\begin{tabular}{|c|c|c|c|c|c|}
\hline Species & Method & Window of Exposure & Doses Tested & Principal Results & Reference \\
\hline \multirow{4}{*}{ Adult female Wistar rats } & Radioimmunoassay & \multirow{4}{*}{15 days } & \multirow{4}{*}{$\begin{array}{l}40 \mathrm{mg} / \mathrm{kg} \mathrm{BW} \text { per day BPA } \\
\text { by diet }\end{array}$} & $\begin{array}{l}\text { Higher T4 levels in BPA-exposed animals, } \\
\text { whereas no variations of T3 levels. }\end{array}$ & \multirow{4}{*}{ [106] } \\
\hline & $\begin{array}{l}\text { Thyroid iodine } \\
\text { uptake/TPO activity }\end{array}$ & & & Significant reduction of TPO and NIS activity. & \\
\hline & ROS generation & & & $\begin{array}{l}\text { In BPA-treated animals, significant generation of } \\
\mathrm{H}_{2} \mathrm{O}_{2} \text { generation in the thyroid. }\end{array}$ & \\
\hline & qRT-PCR & & & $\begin{array}{l}\text { Significant reduction of } T s h \beta \text { mRNA levels in the } \\
\text { pituitary of the treated rats. }\end{array}$ & \\
\hline Adult male Wistar rats & RIA & 15 days & $\begin{array}{l}\text { 0/40 mg/kg BW/BPA per day by } \\
\text { diet }\end{array}$ & $\begin{array}{l}\text { After } 15 \text { days of treatment, significant reduction of } \\
\text { liver DIO1 activity, whereas no effects on brown } \\
\text { adipose tissue DIO2 activity. Significant increase } \\
\text { of TT4 levels but no variations of TT3 levels. } \\
\text { Significant reduction of T3/T4 ratio. }\end{array}$ & [102] \\
\hline \multirow{3}{*}{$\begin{array}{l}\text { Wistar rats (HsdCpb:WU) } \\
\text { of both sexes }\end{array}$} & Radioimmunoassay & \multirow{3}{*}{$\begin{array}{l}70 \text { or } 14 \text { days before } \\
\text { mating - after mating } \\
\text { (males) or PND21 } \\
\text { (females) } \\
28 \text { days }\end{array}$} & \multirow{3}{*}{$\begin{array}{l}\text { 0/3/10/30/100/300/1000/3000 } \\
\mathrm{mg} / \mathrm{kg} \text { BW TBBPA per day by } \\
\text { diet (reproduction study) } \\
\text { 0/30/100/300 } \mathrm{mg} / \mathrm{kg} \text { BW TBBPA } \\
\text { per day by diet (subacute } \\
\text { toxicity study) }\end{array}$} & $\begin{array}{l}\text { In the reproduction study, decrease of T4 levels in } \\
\text { pups of both sexes, and increase of T3 levels only } \\
\text { in females. } \\
\text { In the subacute toxicity study, significant decrease } \\
\text { of T4 and increase of T3 levels in males, whereas } \\
\text { in females parallel though not significant trends. }\end{array}$ & \multirow{3}{*}{ [114] } \\
\hline & Necropsy & & & $\begin{array}{l}\text { Dose-dependently increase of pituitary weight in } \\
\text { male pups in the reproduction study. No effects in } \\
\text { the subacute toxicity study. }\end{array}$ & \\
\hline & Histology & & & $\begin{array}{l}\text { No changes observed in the histology of the } \\
\text { pituitary gland both in the reproduction and in the } \\
\text { subacute toxicity studies. }\end{array}$ & \\
\hline
\end{tabular}


Table 3. Cont.

\begin{tabular}{|c|c|c|c|c|c|}
\hline Species & Method & Window of Exposure & Doses Tested & Principal Results & Reference \\
\hline \multirow{4}{*}{ Female F344 rats } & Necropsy & \multirow{4}{*}{64 weeks } & \multirow{4}{*}{$\begin{array}{l}250 / 1000 \mu \mathrm{g} / \mathrm{kg} \text { BW per day BPA } \\
\text { by diet } \pm 2800 \mathrm{mg} / \mathrm{kg} \text { sc. DHPN } \\
\pm 1000 \mu \mathrm{g} / \mathrm{L} \mathrm{KI} \mathrm{in} \mathrm{water}\end{array}$} & $\begin{array}{l}\text { In the group exposed to DHPN, statistical } \\
\text { significances among all groups, and the KI group } \\
\text { had the heaviest thyroid weights. In the group not } \\
\text { exposed, no significant differences were found } \\
\text { among groups. }\end{array}$ & \multirow{4}{*}{ [105] } \\
\hline & Histology & & & $\begin{array}{l}\text { In the group exposed to DHPN + KI + 1000BPA, } \\
\text { all thyroids had a tumor or focal hyperplasia. } \\
\text { Significant difference in the total number of } \\
\text { hyperplasia lesions among all groups of animals } \\
\text { exposed to DPNA. }\end{array}$ & \\
\hline & $\begin{array}{l}\text { Chemiluminescence } \\
\text { immunoassay/ELISA }\end{array}$ & & & $\begin{array}{l}\text { In the groups exposed to DHPN, TSH was } \\
\text { significantly higher in the KI group than in the } \\
\text { controls and the highest FT4 concentration was in } \\
\text { the BPA1000 group. In the groups not exposed to } \\
\text { DHPN, the highest concentration of TSH was in } \\
\text { the controls whereas FT4 increased with } \\
\text { increasing doses of BPA. }\end{array}$ & \\
\hline & Western blotting detection & & & $\begin{array}{l}\text { In the groups exposed to DPNA, increased protein } \\
\text { levels of ER } \alpha \text { in the BPA250 and BPA1000 groups } \\
\text { compared to the control. }\end{array}$ & \\
\hline \multicolumn{6}{|c|}{ Sheep } \\
\hline Lacaune ewes & Radioimmunoassay & GD28-GD128 & $\begin{array}{l}0 / 0.5 / 50 / 5000 \mu \mathrm{g} / \mathrm{kg} \text { per day sc. } \\
\text { BPA }\end{array}$ & $\begin{array}{l}\text { In mothers, no effects on TT4 and TSH levels, but } \\
\text { significant decrease of FT4 (at the lowest dose) } \\
\text { and TT3 (at the lowest and middle doses) } \\
\text { throughout pregnancy. No changes in TT4 and } \\
\text { FT4 levels in fetal jugular blood on GD132-GD134. }\end{array}$ & [123] \\
\hline Lacaune ewes & Radioimmunoassay & GD28-GD145 & 0/5 mg/kg BW per day sc BPA & $\begin{array}{l}\text { In pregnant ewes, reduction with time of TT4 but } \\
\text { not of FT4. Decrease of jugular blood TT4 and FT4 } \\
\text { concentration within the } 1^{\text {st }} \text { hour of life and of TT4 } \\
\text { concentration in cord blood. Slight decrease of } \\
\text { TT3 in the } 1^{\text {st }} \text { hour of life. At } 2 \text { months of life no } \\
\text { changes in THs levels. }\end{array}$ & [122] \\
\hline
\end{tabular}


Table 3. Cont.

\begin{tabular}{|c|c|c|c|c|c|}
\hline Species & Method & Window of Exposure & Doses Tested & Principal Results & Reference \\
\hline \multicolumn{6}{|c|}{ Zebrafish } \\
\hline $\begin{array}{l}\text { GFP-positive transgenic } \\
\text { zebrafish embryos }\end{array}$ & Fluorescence & 24-48hpf/24-72 hpf & $\begin{array}{l}10^{-7} / 5 \times 10^{-7} / 10^{-6} / 5^{*} 10^{-6} / 10^{-5} \\
\mathrm{M} \mathrm{BPA} \pm 10^{-8} \mathrm{M} \text { T3 }\end{array}$ & $\begin{array}{l}\text { In the presence of T3, the two highest doses of BPA } \\
\text { inhibited T3-induced transcriptional activity } \\
\text { during } 48 \text { h exposure. No effects of BPA or T3 in } \\
\text { the presence of T3 during } 24 \mathrm{~h} \text { exposure. }\end{array}$ & [126] \\
\hline $\begin{array}{l}\text { Wild-type zebrafish } \\
\text { (Danio rerio) embryos }\end{array}$ & qRT-PCR & $72 \mathrm{~h}$ & $\begin{array}{l}0.01 / 0.1 / 1.0 \mu \mathrm{M} \\
\text { BPA/BPS/TBBPA/TBBPS }\end{array}$ & $\begin{array}{l}\text { At } 0.1 \mu \mathrm{M}, \text { BPA and TBBPS up-regulated Tr } \beta \\
\text { transcripts whereas BPS and TBBPS showed no } \\
\text { significant effect. At } 1.0 \mu \mathrm{M} \text { BPS and TBBPS } \\
\text { up-regulated Tr } \beta \text { mRNA levels, while BPA had a } \\
\text { down-regulating effect. }\end{array}$ & [68] \\
\hline $\begin{array}{l}\text { Wild-type zebrafish } \\
\text { (Danio rerio) embryos }\end{array}$ & qRT-PCR & $24-48 \mathrm{hpf}$ & $10^{-8}-10^{-6} \mathrm{M} \mathrm{BPA}$ & $\begin{array}{l}\text { Induction of } T g \text { expression at } 10^{-8} \text { and } 10^{-6} \mathrm{M} \text {. } \\
\text { Up-regulation of } \operatorname{Pax} 8 \text { transcripts at low and high } \\
\text { doses and of } \operatorname{Pax} 2 a \text { and Tsh transcripts only at high } \\
\text { dose. }\end{array}$ & [89] \\
\hline \multirow[b]{2}{*}{$\begin{array}{l}\text { Wild type zebrafish (Danio } \\
\text { rerio) embryos }\end{array}$} & \multirow[b]{2}{*}{$\begin{array}{l}\text { ELISA } \\
\text { qRT-PCR }\end{array}$} & \multirow[b]{2}{*}{ 2-168 hpf } & \multirow[b]{2}{*}{ 0/5/50/500 $\mu \mathrm{g} / \mathrm{L}$ BPAF } & $\begin{array}{l}\text { Significant decrease of TT3, FT4 and TT4 levels at } \\
50 \text { and } 500 \mu \mathrm{g} / \mathrm{L} \text {. Reduction of FT3 levels in all } \\
\text { treated groups. }\end{array}$ & \multirow[b]{2}{*}{ [13]) } \\
\hline & & & & $\begin{array}{l}\text { Up-regulation of } T s h \beta \text { at } 50 \mu \mathrm{g} / \mathrm{L} \text { and significant } \\
\text { decrease of transcription at the highest dose. } \\
\text { Up-regulation of } T g \text { and Dio } 2 \text { at } 50 \mu \mathrm{g} / \mathrm{L}, \text { Dio } 1 \text { at } 50 \\
\text { and } 500 \mu \mathrm{g} / \mathrm{L} \text {, and } T \operatorname{tr} \text { at all doses. } \\
\text { Down-regulation of transcription of } \operatorname{Tr} \beta \text { at } 50 \mu \mathrm{g} / \mathrm{L} \text {, } \\
\text { Slc } 5 a 5 \text { and } \operatorname{Tr} \alpha \text { at } 50 \text { and } 500 \mu \mathrm{g} / \mathrm{L} \text {. }\end{array}$ & \\
\hline $\begin{array}{l}\text { Wild type zebrafish (Danio } \\
\text { rerio) embryos }\end{array}$ & ELISA & $75 \mathrm{dpf}$ & 0/0.1/1/10 and $100 \mu \mathrm{g} / \mathrm{L}$ BPS & $\begin{array}{l}\text { Lower levels of T3 and T4 in males exposed to } 10 \\
\text { and } 100 \mu \mathrm{g} / \mathrm{L} \text {. Lower levels of T3 and T4 in } \\
\text { females exposed to } 100 \mu \mathrm{g} / \mathrm{L} \text {. }\end{array}$ & [131] \\
\hline \multirow{2}{*}{$\begin{array}{l}\text { Wild-type zebrafish (Danio } \\
\text { rerio) embryos-larvae }\end{array}$} & ELISA & \multirow[t]{2}{*}{$<4-120 \mathrm{hpf}$} & $\begin{array}{l}\text { 0.08/0.4/2 mg/L BPA/BPF; } \\
\text { 2/10/50 mg/L BPS; } \\
\text { 0.04/0.18/0.68 mg/L BPZ }\end{array}$ & $\begin{array}{l}\text { Significant increase of T3 levels at } 0.4 \mathrm{mg} / \mathrm{L} \mathrm{BPA} \\
\text { and at } 50 \mathrm{mg} / \mathrm{L} \text { BPS (with a dose-response trend) } \\
\text { and of T4 at } 2.0 \mathrm{mg} / \mathrm{L} \mathrm{BPF} \mathrm{(with} \mathrm{a} \mathrm{dose-response} \\
\text { trend). }\end{array}$ & \multirow[t]{2}{*}{ [37] } \\
\hline & qRT-PCR & & $\begin{array}{l}0.4<72 \mathrm{mg} / \mathrm{L} \text { BPA or BPF; } 10 / 50 \\
\mathrm{mg} / \mathrm{L} \mathrm{BPS} ; 0.08 / 0.4 \mathrm{mg} / \mathrm{L} \mathrm{BPZ}\end{array}$ & $\begin{array}{l}\text { Up-regulation of Hhex, Tg, Ttr, Dio1, Ugt1ab genes } \\
\text { by BPA. Up-regulation of Hhex, Ugt1ab genes by } \\
\text { BPF, of Crh, Tsh } \beta \text {, Tsh-r, Hhex, Tpo, Ttr, Ugt1ab by } \\
\text { BPS, and of Tsh } \beta \text { by BPZ. }\end{array}$ & \\
\hline
\end{tabular}


Table 3. Cont.

\begin{tabular}{|c|c|c|c|c|c|}
\hline Species & Method & Window of Exposure & Doses Tested & Principal Results & Reference \\
\hline \multirow[b]{2}{*}{$\begin{array}{l}\text { Wild-type zebrafish (Danio } \\
\text { rerio) embryos-larvae }\end{array}$} & ELISA & \multirow{2}{*}{ 2-144 hpf } & \multirow{2}{*}{$0.2 / 2 / 20 / 200 \mu \mathrm{g} / \mathrm{L}$ BPF } & $\begin{array}{l}\text { Dose-dependent decrease of TT4 levels in BPF } \\
\text { treated groups. Significant elevation of TT3 at } 200 \\
\mu \mathrm{g} / \mathrm{L} \text { and TSH at } 20 \text { and } 200 \mu \mathrm{g} / \mathrm{L} \text { BPF. }\end{array}$ & \multirow{2}{*}[38]{} \\
\hline & qRT-PCR & & & $\begin{array}{l}\text { Up-regulation of } C r h \text { and } T g \text { at 2,20, } 200 \mu \mathrm{g} / \mathrm{L} \text {. } \\
\text { Induction of transcription of Slc5a5, Dio2, Ugt1ab } \\
\text { at } 20 \text { and } 200 \mu \mathrm{g} / \mathrm{L} \text {. Down-regulation of Ttr at } 20 \\
\text { and } 200 \mu \mathrm{g} / \mathrm{L} \text {. }\end{array}$ & \\
\hline $\begin{array}{l}\text { Wild-type zebrafish } \\
\text { (Danio rerio) } \\
\text { embryos-larvae }\end{array}$ & qRT-PCR & $\begin{array}{l}0 / 1 / 5 \mathrm{dpf} \text {; exposure for } \\
24 / 48 \mathrm{~h}\end{array}$ & $10^{-5} \mathrm{M} \mathrm{BPA} \pm 10^{-8} \mathrm{M}$ T3 & $\begin{array}{l}\text { Weak effects of BPA alone on gene expression } \\
\text { compared with controls, except for the induction } \\
\text { of TSH expression in the group } 1 \text { day } / 48 \mathrm{~h} \text {. } \\
\text { With T3, reduction of } \operatorname{Tr} \alpha, \operatorname{Tr} \beta \text {, and Tsh expression } \\
\text { in 1-day-old embryos at both } 24 \text { and } 48 \mathrm{~h} \text {, but } \\
\text { up-regulation of } \operatorname{Tr} \alpha \text { and } \operatorname{Tr} \beta, \text { by } 24 \text {-h exposure in } \\
\text { 0-day-old embryos and of } \operatorname{Tsh} \text { by } 48 \text {-h exposure in } \\
\text { 5-day-old larvae. }\end{array}$ & [126] \\
\hline \multirow{4}{*}{$\begin{array}{l}\text { Wild-type zebrafish (Danio } \\
\text { rerio) embryos-larvae }\end{array}$} & & \multirow{4}{*}{$2-144 \mathrm{hpf}$} & 50/100/200/400 $\mu \mathrm{g} / \mathrm{L}$ TBBPA & $\begin{array}{l}\text { Dose-dependent increase of T4 levels and } \\
\text { dose-dependent decrease of T3 levels. }\end{array}$ & \multirow{4}{*}{ [128] } \\
\hline & ELISA & & $\begin{array}{l}200 \mu \mathrm{g} / \mathrm{L} \text { TBBPA/20 } \mu \mathrm{g} / \mathrm{L} \mathrm{T} 3 / 200 \\
\mu \mathrm{g} / \mathrm{L} \text { TBBPA+20 } \mu \mathrm{g} / \mathrm{L} \mathrm{T} 3\end{array}$ & $\begin{array}{l}\text { After exposure to T3, significant decrease of T4 } \\
\text { and significant increase of T3 contents. After } \\
\text { co-treatment TBBPA and T3, decrease of T4 and } \\
\text { increase of T3 contents, which were significantly } \\
\text { different from the control group (only for T3 } \\
\text { increase) and the TBBPA treated group. }\end{array}$ & \\
\hline & \multirow[t]{2}{*}{ qRT-PCR } & & 50/100/200/400 $\mu \mathrm{g} / \mathrm{L}$ TBBPA & $\begin{array}{l}\text { Up-regulation of } T s h \text { and } T g \text { and down-regulation } \\
\text { of } T \operatorname{tr} \text { and } \operatorname{Tr} \beta \text { transcript levels. }\end{array}$ & \\
\hline & & & $\begin{array}{l}200 \mu \mathrm{g} / \mathrm{L} \text { TBBPA } / 20 \mu \mathrm{g} / \mathrm{L} \mathrm{T} 3 / 200 \\
\mu \mathrm{g} / \mathrm{L} \text { TBBPA+20 } \mu \mathrm{g} / \mathrm{L} \mathrm{T3}\end{array}$ & $\begin{array}{l}\text { After exposure to } \mathrm{T} 3 \text { and TBBPA }+\mathrm{T} 3 \text { significant } \\
\text { up-regulation of } T s h \text { and } T g \text { whereas no changes in } \\
T t r \text { and } T r \beta \text { mRNA levels. }\end{array}$ & \\
\hline
\end{tabular}


Table 3. Cont.

\begin{tabular}{|c|c|c|c|c|c|}
\hline Species & Method & Window of Exposure & Doses Tested & Principal Results & Reference \\
\hline \multirow[b]{2}{*}{$\begin{array}{l}\text { Wild-type zebrafish (Danio } \\
\text { rerio) embryos-larvae }\end{array}$} & ELISA & \multirow[b]{2}{*}{$2-168 \mathrm{hpf}$} & \multirow[b]{2}{*}{$1 / 3 / 10 / 30 \mu \mathrm{g} / \mathrm{L} \mathrm{BPS}$} & $\begin{array}{l}\text { Significant decrease of TT4 levels at } 10 \text { and } 30 \mu \mathrm{g} / \mathrm{L} \\
\text { and TT3 levels at the highest dose. Significant } \\
\text { increase of TSH in the 10-, and } 30 \mu \mathrm{g} / \mathrm{L} \text { exposure } \\
\text { groups. }\end{array}$ & \multirow[b]{2}{*}{ [129] } \\
\hline & qRT-PCR & & & $\begin{array}{l}\text { Up-regulation of } C r h, T g, D i o 1 \text {, and Ugt1ab at } 10 \\
\text { and } 30 \mu \mathrm{g} / \mathrm{L} \text {. Induction of transcription of } \operatorname{Pax} 8, \\
\text { Slc5a5, Tg, and Dio } 2 \text { at } 30 \mu \mathrm{g} / \mathrm{L} \text {. Down-regulation } \\
\text { of } T \operatorname{tr} \text { mRNA at } 3,10, \text { and } 30 \mu \mathrm{g} / \mathrm{L} \text {. No effects on } \\
\text { transcription of } \operatorname{Tr} \alpha, \operatorname{Tr} \beta \text {, and Dio3. }\end{array}$ & \\
\hline $\begin{array}{l}\text { Wild-type zebrafish } \\
\text { (Danio rerio) } \\
\text { embryos-larvae }\end{array}$ & qRT-PCR & 96-192 hpf & $\begin{array}{l}0 \% / 10 \% / 50 \% / 75 \% \text { of the } 96 \mathrm{~h} \\
\text {-LC50 BPA/TBBPA }\end{array}$ & $\begin{array}{l}\text { Induction of } \operatorname{Tr} \alpha, T s h \beta \text {, and } T t r \text { in larvae and of } \operatorname{Tr} \alpha \\
\text { and } T t r \text { transcripts in embryos by TBBPA. } \\
\text { Down-regulation of } \operatorname{Tr} \beta \text { and } T s h \beta \text { mRNA in } \\
\text { embryos by TBBPA. Up-regulation of Tsh } \beta \text { mRNA } \\
\text { in larvae by BPA. No effects on Slc5a } 5 \text { and } T g \\
\text { expression in larvae neither on Tpo in embryos. }\end{array}$ & [133] \\
\hline $\begin{array}{l}\text { Wild type zebrafish (Danio } \\
\text { rerio) larvae }\end{array}$ & qRT-PCR & $2-120 \mathrm{hpf}$ & 0/100/200/300/400 $\mu \mathrm{g} / \mathrm{L}$ TBBPA & $\begin{array}{l}\text { Slight up-regulation of Dio1, } \operatorname{Tr} \beta \text {, and Tsh, and } \\
\text { significant up-regulation of } \operatorname{Tr} \alpha \text { at low doses. } \\
\text { Significant down-regulation of Tpo. No significant } \\
\text { effects on expression of Dio2 and Dio3 transcripts. }\end{array}$ & [132] \\
\hline $\begin{array}{l}\text { Wild-type adult zebrafish } \\
\text { (Danio rerio) }\end{array}$ & qRT-PCR & $72 \mathrm{~h}$ & $50 \mu \mathrm{g} / \mathrm{L} / 100 \mu \mathrm{g} / \mathrm{L}$ BPA or BPS & $\begin{array}{l}\text { After BPA exposure, increase of } S l c 5 a 5 \text { mRNA } \\
\text { levels at both doses and } T p o \text { transcript levels at the } \\
\text { lowest dose. No effects on } T g \text { expression. } \\
\text { After BPS exposure, increased expression of } S l c 5 a 5 \\
\text { and } T g \text { transcripts at the highest dose and } T p o \\
\text { transcripts at the lowest dose. }\end{array}$ & [135] \\
\hline \multirow[b]{2}{*}{$\begin{array}{l}\text { Adult male zebrafish } \\
\text { (Danio rerio) }\end{array}$} & ELISA & \multirow[b]{2}{*}{21 days } & \multirow[b]{2}{*}{$\begin{array}{l}\text { 0/24.7 } \mu \mathrm{g} / \mathrm{L} \text { BPAF/5.6 } \mu \mathrm{g} / \mathrm{L} \\
\mathrm{SMX} / 24.7 \mu \mathrm{g} / \mathrm{L} \text { BPAF }+5.6 \mu \mathrm{g} / \mathrm{L} \\
\text { SMX }\end{array}$} & $\begin{array}{l}\text { Slight decrease of T4 levels in fish exposed to } \\
\text { BPAF. Significant increase of T4 in fish exposed to } \\
\text { the mixture BPAF + SMX. }\end{array}$ & \multirow[b]{2}{*}{ [134] } \\
\hline & qRT-PCR & & & $\begin{array}{l}\text { Up-regulation of } \operatorname{Trh}, \operatorname{Tr} h r, \operatorname{Tsh} \beta, D i o 2 \text { and } \\
\text { down-regulation of } \operatorname{Tpo}, \operatorname{Slc5a5}, \operatorname{Tg} \mathrm{mRNA} \text { levels } \\
\text { in fish exposed to BPAF. } \\
\text { Up-regulation of } \operatorname{Tr} \alpha, \operatorname{Tr} \beta, D i o 1, D i o 2, T p o, T g \text {, } \\
\text { Slc5a5 and down-regulation of Trh, Trhr, Tsh } \beta \\
\text { transcript in fish exposure to mixture. }\end{array}$ & \\
\hline
\end{tabular}




\section{Thyroid Disrupting Properties of BPs: Human Studies}

Perturbations in THs parameters consequent to exposure to BPA have been documented in humans, i.e., the general population, pregnant women, or occupational settings, although the study design, predominantly cross-sectional, does not allow establishment of any causal relationship. Research has highlighted positive, negative, or null associations with $\mathrm{T} 4$ levels, whereas a few prospective birth cohort studies suggest that prenatal BPA exposure may modify THs normal serum concentration in a sex-specific manner. Several investigations have demonstrated BPA-induced disruption of thyroid function by altering serum TSH levels. This effect could occur from a direct action of BPA on the pituitary gland via the estrogen signaling pathway or, alternatively, from a transient increase of T3 or T4 production that could lead to a feedback mechanism and the subsequent release inhibition of TSH. Overall, discrepant results among studies may be attributable to BPA levels, time of exposure, iodine intake, differences in age, ethnicity, diet, socioeconomic status, and the determination methods of THs, while at present the potential role of BPs in thyroid carcinogenesis in humans remains to be deeply explored (Table 4). It is noteworthy that the absence of adjustment for other confounding factors such as co-exposure to other EDCs makes the overall evaluation of thyroid dysfunction related to BPs exposure complex. Furthermore, a comparison between effects observed in animal models with those reported in epidemiological studies is complex given different serum T4 half-lives (12-24 h in rats vs. 5-9 days in humans), metabolic pathways of BPs, and doses of exposure, which in humans is more likely to be chronic and low level [138].

\subsection{Effects on Serum TH Levels}

Studies carried out in the general population and in mother/child cohorts showed positive [139-141], negative [142-145], and no associations between BPA exposure and serum T4 levels [143,146-151], whereas the relationship with serum T3 levels was estimated in few studies, with different findings $[139,141,142,149,150]$.

In agreement with results from studies in animals [104,105,108], exposure to BPA led to TSH release/suppression independent of alterations in circulating THs levels $[143,145,147,148,150,152]$ or, less frequently, was associated with variations of serum T4 levels [139,149].

There was no association of BPA with hypothyroidism in Japanese women with a history of recurrent miscarriages [151], nor any significant relationship between serum TBBPA in Korean infants with congenital hypothyroidism and THs levels [140]. Conversely, middle-aged and elderly Chinese with overt or subclinical hyperthyroidism had higher urinary BPA than euthyroid subjects [151], and an increased content of urinary BPA was also observed in obese adults undergoing a diet program or bariatric surgery compared to lean controls, probably due to differences in food intake [152].

Sex-related differences in the relationship between BPA and THs were reported both in the general population [142] and in newborns [143,148], coherently with studies performed in rats [112,115], and possibly attributable to a less efficient ability to metabolize BPA, i.e., a reduced expression of uridinediphosphate-glucuronosyltransferase 2B1 in male compared to female livers [153], or to a different androgen-related metabolism of BPA [154].

The interactions between BPA and THs during pregnancy and fetal development have been recently studied. The association between BPA and TSH levels in newborns was stronger when the time elapsed between the two measurements was shorter [143,148], suggesting that specific windows of exposure may influence susceptibility to BPA or, alternatively, that a transient effect on the HPT axis may occur, as shown in rodents $[111,112]$. However, the inverse association of BPA-TSH in pregnant women detected through repeated measures as well as stratified analyses by visit could indicate the absence of a specific window of vulnerability [139]. 


\subsection{Association with Thyroid Diseases}

The influence of BPA on thyroid autoimmunity is controversial (Table 4). Whereas urinary BPA concentration was associated with variations of TH levels both in children and adults of both sexes, independent of serum thyroglobulin antibodies (TgAb) and thyroid peroxidase antibodies (TPOAb) $[149,155]$, another study found a positive relationship between serum BPA and TPOAb in men and women [156]. Moreover, a significant negative correlation of serum BPA with FT4 in male subjects was found only after exclusion of subjects with positive thyroid antibodies, suggesting that $\mathrm{TgAb}$ might be a mediator of the relationship between BPA and FT4 [144].

Kim and Oh reported a slight positive correlation between serum TBBPA and thyroid-stimulating hormone receptor antibodies, indicative of metabolic diseases, in mothers of infants with congenital hypothyroidism, suggesting that brominated derivatives of BPA might affect thyroid function status [140].

Recent investigations have explored the role of BPs as risk factors of occurrence of thyroid nodules (TNs), palpably and/or ultrasonographically discrete lesions, distinct from the surrounding parenchyma of the thyroid gland, which are either benign or malignant [157]. A study reported no association between BPs and higher risk of TNs in adult females [147], whereas Wang et al. observed an inverse correlation of urinary BPA and the risk of multiple TNs but not of solitary TNs in schoolchildren [158]. On the other hand, a significant near linear association between BPA and higher risk of TNs was observed exclusively among participants positive for $\mathrm{TgAb}$ and TPOAb [159]. Both urinary BPA and creatinine-adjusted BPA levels were higher in Chinese women with TNs than those without TNs [159], which is consistent with the increased urinary BPA contents in patients with nodular goiter and PTC (160), while median urinary BPA levels were lower in the cases compared to controls among women from Cyprus and Romania [147]. In the study by Zhou et al. [160], which was aimed to investigate the relationship between BPA and iodine exposure with nodular goiter and PTC, sex-specific associations were shown, with higher concentrations of BPA in women than in men affected by PTC and nodular goiter, and a lower urinary BPA content in the female PTC group than the female nodular goiter group, probably due to differences in BPA elimination rates. Marotta et al. recently found a significant dose-independent correlation between BPAF and the risk of differentiated TC in subjects with TNs. Of note, this association was not related to an increase of TSH levels, indicating a potential direct mutagenic action of BPAF on thyroid cells [161]. 
Table 4. Summary of human studies on the association between bisphenols exposure and thyroid parameters.

\begin{tabular}{|c|c|c|c|c|c|c|c|c|}
\hline Study Design & Country & Study Sample & $\begin{array}{l}\text { Sample Size } \\
\text { (N) }\end{array}$ & Age & Principal Results & BPA Concentration & Confounders & Reference \\
\hline Prospective & Japan & $\begin{array}{l}\text { Women with a history of } \\
\text { three or more ( } 3-11) \\
\text { first-trimester miscarriages. } \\
\text { Blood samples collected } \\
5-9 \text { days after ovulation in } \\
\text { at least two cycles. }\end{array}$ & 45 patients & $27-36$ & $\begin{array}{l}\text { No difference in serum BPA levels } \\
\text { between patients with and without } \\
\text { hypothyroidism. } \\
\text { Serum TSH levels not estimated. }\end{array}$ & $\begin{array}{l}\text { Patients with hypothyroidism: } \\
\text { Mean (SD): } 2.99 \pm 3.04 \mu \mathrm{g} / \mathrm{L} \\
\text { Patients without hypothyroidism: } \\
\text { Mean (SD): } 2.50 \pm 5.70 \mu \mathrm{g} / \mathrm{L}\end{array}$ & - & [151] \\
\hline Prospective & Belgium & $\begin{array}{l}\text { Overweight and obese } \\
\text { individuals. } \\
\text { Lean individuals. } \\
\text { For obese individuals, } \\
\text { urine samples collected at } \\
\text { baseline, before starting a } \\
\text { weight loss program }(\mathrm{N}= \\
\text { 151) and after } 3(\mathrm{~N}=95), 6 \\
(\mathrm{~N}=53), 12 \text { months }(\mathrm{N}= \\
\text { 39). }\end{array}$ & $\begin{array}{l}151 \text { obese } \\
\text { individuals } \\
43 \text { lean } \\
\text { individuals }\end{array}$ & $\geq 18$ & $\begin{array}{l}\text { The obese group had higher } \\
\text { urinary levels of BPA. Positive } \\
\text { relationship of urinary BPA with } \\
\text { serum TSH in lean subjects. }\end{array}$ & $\begin{array}{l}\text { Obese individuals } \\
0 \text { - median: } 1.7 \mu \mathrm{g} / \mathrm{L} \\
3 \text { months—-median: } 2.0 \mu \mathrm{g} / \mathrm{L} \\
6 \text { months-median: } 1.7 \mu \mathrm{g} / \mathrm{L} \\
12 \text { months-median: } 1.5 \mu \mathrm{g} / \mathrm{L} \\
\text { Lean individuals } \\
\text { Median: } 1.2 \mu \mathrm{g} / \mathrm{L}\end{array}$ & {$[1,7,34]$} & [152] \\
\hline $\begin{array}{l}\text { Prospective } \\
\text { birth cohort }\end{array}$ & USA & $\begin{array}{l}\text { Pregnant women from the } \\
\text { CHAMACOS study. Urine } \\
\text { samples collected at } 12 \text { and } \\
26 \text { weeks of gestation. }\end{array}$ & 476 & $\geq 18$ & $\begin{array}{l}\text { In mothers, no association of } \\
\text { urinary BPA (average) with FT4 } \\
\text { and TSH levels, and negative } \\
\text { association (BPA } 26 \text { week) with } \\
\text { serum TT4. Inverse association } \\
\text { between maternal BPA (average, } \\
26 \text { week) and TSH in male } \\
\text { newborns but not in females. }\end{array}$ & $\begin{array}{l}\text { LOD: } 0.4 \mu \mathrm{g} / \mathrm{L} \\
\text { Mothers: } \\
\text { GM: } 1.3 \mu \mathrm{g} / \mathrm{g} \mathrm{cr} \\
\text { Median: } 1.2 \mu \mathrm{g} / \mathrm{g} \mathrm{cr}\end{array}$ & {$[1,2,4,8,10,12-21]$} & [143] \\
\hline $\begin{array}{l}\text { Prospective } \\
\text { birth cohort }\end{array}$ & USA & $\begin{array}{l}\text { Pregnant women from the } \\
\text { HOME study. Urine } \\
\text { samples collected at both } \\
16 \text { and } 26 \text { weeks of } \\
\text { gestation }(\mathrm{N}=237) \text {. }\end{array}$ & 249 & $\geq 18$ & $\begin{array}{l}\text { Neither association of maternal } \\
\text { BPA (16 week) with maternal THs } \\
\text { or TSH levels nor of maternal BPA } \\
\text { (average, } 16 \text { week, or } 26 \text { week) } \\
\text { with THs or TSH levels in } \\
\text { newborns. Significant inverse } \\
\text { association of maternal BPA with } \\
\text { TSH levels (average and } 26 \text { week } \\
\text { BPA) and slight positive } \\
\text { association with TT3 levels ( } 26 \\
\text { week BPA) in females. Stronger } \\
\text { relationship of BPA-TSH among } \\
\text { girls born from iodine-deficient } \\
\text { mothers. }\end{array}$ & $\begin{array}{l}\text { LOD: } 0.4 \mu \mathrm{g} / \mathrm{L} \\
16 \text { weeks } \\
\text { GM: } 2.0(95 \% \mathrm{CI} 1.8-2.2) \mu \mathrm{g} / \mathrm{g} \mathrm{cr} \\
26 \text { weeks } \\
\text { GM: } 2.3(95 \% \mathrm{CI} 2.1-2.5) \mu \mathrm{g} / \mathrm{g} \mathrm{cr}\end{array}$ & {$[1,2,8-10,15-17,19,20,22-25]$} & [148] \\
\hline
\end{tabular}


Table 4. Cont.

\begin{tabular}{|c|c|c|c|c|c|c|c|c|}
\hline Study Design & Country & Study Sample & $\begin{array}{l}\text { Sample Size } \\
\text { (N) }\end{array}$ & Age & Principal Results & BPA Concentration & Confounders & Reference \\
\hline $\begin{array}{l}\text { Prospective } \\
\text { birth cohort }\end{array}$ & Japan & $\begin{array}{l}\text { Pregnant women at 23-35 } \\
\text { weeks of gestation } \\
\text { (singleton babies). Cord } \\
\text { blood obtained at delivery. }\end{array}$ & 283 & $\geq 18$ & $\begin{array}{l}\text { No association between BPA } \\
\text { concentration in cord blood and } \\
\text { TSH or FT4 levels in newborns of } \\
\text { both sexes. }\end{array}$ & $\begin{array}{l}\text { LOQ: } 0.04 \mu \mathrm{g} / \mathrm{L} \\
\text { GM: } 0.051 \mu \mathrm{g} / \mathrm{L} \\
\text { IQR: }<\mathrm{LOQ}-0.076 \mu \mathrm{g} / \mathrm{L}\end{array}$ & {$[19,38]$} & [146] \\
\hline $\begin{array}{c}\text { Nested } \\
\text { case-control }\end{array}$ & USA & $\begin{array}{l}\text { Women who delivered } \\
\text { preterm } \\
\text { (<37 weeks of gestation) } \\
\text { and controls of women } \\
\text { who delivered a singleton } \\
\text { infant after } 37 \text { weeks of } \\
\text { gestation. Urine samples } \\
\text { collected at up to } 4 \text { visits } \\
\text { (median for each visit: } 9.64 \text {, } \\
17.9,26.0 \text {, and } 35.1 \text { weeks of } \\
\text { gestation). }\end{array}$ & $\begin{array}{l}116 \text { cases } \\
323 \text { controls }\end{array}$ & $\geq 18$ & $\begin{array}{l}\text { IQR increase in BPA } \\
\text { concentrations across study visits } \\
\text { was significantly associated with } \\
\text { lower TSH and higher FT4 levels. } \\
\text { No effect on FT3, and inverse but } \\
\text { not significant association of BPA } \\
\text { with TT4 levels. No association of } \\
\text { BPA with serum FT4 at visit } 3 \text {. } \\
\text { Significant inverse association of } \\
\text { BPA with TSH levels at visits } 3 \text { and } \\
4 \text { and a slight increase of serum } \\
\text { TT3 at visit } 4 \text {. }\end{array}$ & $\begin{array}{l}\text { Total: } \mathrm{GM} \pm \text { SD: } 1.18 \pm 2.82 \mu \mathrm{g} / \mathrm{L} \\
1 \text { visit: } \mathrm{GM} \pm \text { SD: } 1.33 \pm 2.84 \mu \mathrm{g} / \mathrm{L} \\
2 \text { visit: } \mathrm{GM} \pm \text { SD: } 1.04 \pm 2.85 \mu \mathrm{g} / \mathrm{L} \\
3 \text { visit: } \mathrm{GM} \pm \text { SD: } 1.22 \pm 2.84 \mu \mathrm{L} / \mathrm{L} \\
4 \text { visit: } \mathrm{GM} \pm \text { SD: } 1.12 \pm 2.70 \mu \mathrm{g} / \mathrm{L}\end{array}$ & {$[2-4,8,17,19,25,35-37]$} & [139] \\
\hline Case-control & Korea & $\begin{array}{l}\text { Infants with congenital } \\
\text { hypothyroidism } \\
\text { and their mothers; healthy } \\
\text { infants with their mothers. } \\
\text { Blood samples collected. }\end{array}$ & $\begin{array}{l}26 \text { congenital } \\
\text { hypothyroidism } \\
\text { mother-infant } \\
\text { pairs } \\
12 \text { normal } \\
\text { mother-infant } \\
\text { pairs }\end{array}$ & $\begin{array}{c}<24 \\
\text { months }\end{array}$ & $\begin{array}{l}\text { TBBPA levels not significantly } \\
\text { different in the two infant groups. } \\
\text { No significant correlation between } \\
\text { TBBPA and any of the THs levels } \\
\text { in infants with congenital } \\
\text { hypothyroidism. In their mothers, } \\
\text { positive weak correlation of TBBPA } \\
\text { with serum FT4 and thyroid } \\
\text { stimulating immunoglobulin. }\end{array}$ & $\begin{array}{l}\text { Normal group and their mothers } \\
\text { TBBPA mothers: } 10.93 \mathrm{ng} / \mathrm{g} \text { lipid } \\
\text { TBBPA infants: } 77.65 \mathrm{ng} / \mathrm{g} \text { lipid } \\
\text { Congenital hypothyroidism group and } \\
\text { their mothers } \\
\text { TBBPA mothers: } 8.89 \mathrm{ng} / \mathrm{g} \text { lipid } \\
\text { TBBPA infants: } 83.4 \mathrm{ng} / \mathrm{g} \text { lipid }\end{array}$ & {$[1,47-49]$} & [140] \\
\hline Case-control & $\begin{array}{c}\text { Cyprus }(\mathrm{n}=122) \\
\text { Romania } \\
(\mathrm{n}=90)\end{array}$ & $\begin{array}{l}\text { Females with thyroid } \\
\text { nodules (diameter }>3 \mathrm{~mm} \text { ). } \\
\text { Females without nodules. } \\
\text { Two spot urine samples } \\
\text { collected in Cyprus ( } 7 \text { day } \\
\text { apart from each other). } \\
\text { In Romania one spot } \\
\text { sample collected. }\end{array}$ & $\begin{array}{l}212: \\
106 \text { cases } \\
106 \text { controls }\end{array}$ & $\geq 18$ & $\begin{array}{l}\text { In the whole study population, } \\
\text { median TSH and BPA levels were } \\
\text { significantly lower in the cases. } \\
\text { Significant positive association of } \\
\text { BPA with TSH levels and TNs. } \\
\text { Neither association of BPA, BPF, or } \\
\text { ClxBPA with FT4 levels nor of BPF } \\
\text { and ClxBPA with serum TSH. No } \\
\text { association of BPF and ClxBPA } \\
\text { with TNs. }\end{array}$ & $\begin{array}{l}\text { LOD (BPA): } 10 \mu \mathrm{g} / \mathrm{L} \\
\text { LOD (BPF): } 13 \mu \mathrm{g} / \mathrm{L} \\
\text { LOD (ClxBPA): } 10-17 \mu \mathrm{g} / \mathrm{L} \\
\text { Median: } \\
\text { BPA: } 2.25(1.10-4.61) \mu \mathrm{g} / \mathrm{L} \\
\text { BPF: } 0.46(0.32-0.72) \mu \mathrm{g} / \mathrm{L} \\
\text { ClxBPA: } 0.16(0.15-0.19) \mu \mathrm{g} / \mathrm{L} \\
\text { BPA Cases: } 1.75(1.11-3.56) \mu \mathrm{g} / \mathrm{L} \\
\text { BPA Controls: } 2.71(1.08-5.91) \mu \mathrm{g} / \mathrm{L}\end{array}$ & {$[1,3,10,11,39-41]$} & [147] \\
\hline Case-control & Turkey & $\begin{array}{l}\text { Children with HT. } \\
\text { Children without HT. } \\
\text { Spot urine samples } \\
\text { collected. }\end{array}$ & $\begin{array}{l}29 \text { cases }(25 \\
\text { females and } 4 \\
\text { males) } \\
29 \text { controls }\end{array}$ & $8-16$ & $\begin{array}{l}\text { No significant difference in urinary } \\
\text { BPA levels between the two } \\
\text { groups. Significant negative } \\
\text { correlation between BPA and FT4 } \\
\text { levels in HT group. No correlation } \\
\text { between urinary BPA } \\
\text { concentration and TPOAb levels. }\end{array}$ & $\begin{array}{l}\text { LOD: } 0.5 \mathrm{ng} / \mathrm{mL} \\
\text { Mean }( \pm \text { standard error of the } \\
\text { mean) } \\
\text { Cases: } 7.31 \pm 1.46 \mu \mathrm{gg} / \mathrm{g} \mathrm{cr} \\
\text { Controls: } 7.72 \pm 1.74 \mu \mathrm{g} / \mathrm{g} \mathrm{cr}\end{array}$ & - & [155] \\
\hline
\end{tabular}


Table 4. Cont.

\begin{tabular}{|c|c|c|c|c|c|c|c|c|}
\hline Study Design & Country & Study Sample & $\begin{array}{l}\text { Sample Size } \\
\text { (N) }\end{array}$ & Age & Principal Results & BPA Concentration & Confounders & Reference \\
\hline Case-control & China & $\begin{array}{l}\text { Women with TNs. } \\
\text { Women without nodules. } \\
\text { First morning urine } \\
\text { collected. }\end{array}$ & $\begin{array}{l}\text { 1416: } \\
705 \text { cases } \\
711 \text { controls }\end{array}$ & $\geq 18$ & $\begin{array}{l}\text { Urinary BPA was significantly } \\
\text { higher in cases than in controls. } \\
\text { Increased prevalence of TNs with } \\
\text { increasing urinary BPA quartiles. } \\
\text { Significant association between } \\
\text { urinary BPA and TNs in all age } \\
\text { groups and in the thyroid } \\
\text { autoantibody positive group. }\end{array}$ & $\begin{array}{l}\text { LOD: } 0.1 \mu \mathrm{g} / \mathrm{L} \\
\text { Median: } \\
\text { Total: } 3.08(1.60-5.81) \mu \mathrm{g} / \mathrm{g} \mathrm{cr} \\
\text { Cases: } 3.27(1.77-6.53) \mu \mathrm{g} / \mathrm{g} \mathrm{cr} \\
\text { Controls: } 2.92(1.44-5.27) \mu \mathrm{g} / \mathrm{g} \mathrm{cr}\end{array}$ & {$[1,3,8,10,11,29-31,44-46]$} & [159] \\
\hline $\begin{array}{l}\text { Multicentre, } \\
\text { cross-sectional }\end{array}$ & Italy & $\begin{array}{l}\text { Patients with TNs. } \\
\text { Patients with DTC. } \\
\text { Blood collected from each } \\
\text { patient. }\end{array}$ & $\begin{array}{l}27 \text { with TNs } \\
28 \text { with DTC }\end{array}$ & $\geq 18$ & $\begin{array}{l}\text { Significant correlation between } \\
\text { urinary BPAF concentration and } \\
\text { risk of DTC in patients with TNs. } \\
\text { BPS and BPB concentrations higher } \\
\text { in patients with TNs, as compared } \\
\text { with DTCs. TSH levels higher in } \\
\text { patients with DTCs and in subjects } \\
\text { exposed to BPE and BPA. }\end{array}$ & $\begin{array}{l}\text { Subjects with TNs (median } \pm \text { SD) } \\
\text { BPAF: } 12.47 \pm 0 \mathrm{ng} \\
\text { BPS: } 59.29 \pm 50.29 \mathrm{ng} \\
\text { BPB: } 29.92 \pm 35.60 \mathrm{ng} \\
\text { Subjects with DTC }(\text { median } \pm \text { SD) } \\
\text { BPAF: } 9.44 \pm 5.41 \mathrm{ng} \\
\text { BPS: } 34.79 \pm 41.86 \mathrm{ng} \\
\text { BPB: } 14.36 \pm 15.31 \mathrm{ng}\end{array}$ & {$[50]$} & [161] \\
\hline Cross-sectional & USA & $\begin{array}{l}\text { Men who are partners of } \\
\text { subfertile couples. Single } \\
\text { spot urine }(\mathrm{N}=167) \text {, } \\
\text { second }(\mathrm{N}=75) \text {, and third } \\
(\mathrm{N}=4) \text { urine samples } \\
\text { collected. }\end{array}$ & 167 & $18-55$ & $\begin{array}{l}\text { Inverse relationship of BPA with } \\
\text { TSH levels. } \\
\text { No effects on T3 and T4 levels. }\end{array}$ & $\begin{array}{l}\text { LOD: } 0.4 \mu \mathrm{\mu g} / \mathrm{L} \\
\text { GM and median: } 1.3 \mu \mathrm{g} / \mathrm{L}\end{array}$ & {$[1-6]$} & [150] \\
\hline Cross-sectional & USA & $\begin{array}{l}\text { Adult and adolescents from } \\
\text { the NHANES 2007-2008. } \\
\text { Single spot urine collected. }\end{array}$ & $\begin{array}{l}1346 \text { adults } \\
329 \text { adolescents }\end{array}$ & $\begin{array}{c}\geq 20 \\
12-19\end{array}$ & $\begin{array}{l}\text { In adults, inverse relationship of } \\
\text { BPA with TT4 levels. Inverse } \\
\text { trends between BPA quintiles and } \\
\text { both TT4 and TSH. }\end{array}$ & $\begin{array}{l}\text { GM: } 2.03 \mu \mathrm{g} / \mathrm{g} \text { cr } \\
\text { GM: } 1.88 \mu \mathrm{g} / \mathrm{g} \text { cr }\end{array}$ & {$[1-3,7-10]$} & [145] \\
\hline Cross-sectional & USA & $\begin{array}{l}\text { Adults and adolescents } \\
\text { from the NHANES } \\
\text { 2007-2008. Urine sample } \\
\text { collected. }\end{array}$ & $\begin{array}{l}710 \text { females; } 850 \\
\text { males }\end{array}$ & $12-85$ & $\begin{array}{l}\text { Negative association between } \\
\text { urinary multiple EDCs including } \\
\text { BPA and TT4 levels in males but } \\
\text { not in females. Positive but not } \\
\text { statically significant association of } \\
\text { EDCs with T3 levels in females. }\end{array}$ & $\begin{array}{l}\text { LOD (BPA): } 0.13 \mu \mathrm{g} / \mathrm{L} \\
\text { Males: } \\
\text { GM: } 2.19(95 \% \text { CI 1.94-2.47) } \mu \mathrm{g} / \mathrm{L} \\
\text { Females: } \\
\text { GM: } 2.00 \text { (95\% CI 1.80-2.23) } \mu \mathrm{g} / \mathrm{L}\end{array}$ & {$[1,2,4,9-11,26]$} & [142] \\
\hline Cross-sectional & China & $\begin{array}{l}\text { Workers in two } \\
\text { semiautomatic epoxy resin } \\
\text { factories. Spot urine } \\
\text { collected at the end of the } \\
\text { shift on Friday. }\end{array}$ & $\begin{array}{l}28 \text { ( } 21 \text { males and } \\
7 \text { females) }\end{array}$ & $22-62$ & $\begin{array}{l}\text { The workers with the highest BPA } \\
\text { concentrations (feeding position) } \\
\text { had higher FT3, TT3, TT4 levels, } \\
\text { and lower TSH levels. Urinary } \\
\text { BPA significantly associated with } \\
\text { higher FT3 levels (when office } \\
\text { workers were excluded). Weak } \\
\text { positive association between BPA } \\
\text { and serum FT4. }\end{array}$ & $\begin{array}{l}\text { Total workers: } \\
\text { GM } \pm \text { SD: } 31.96 \pm 4.42 \mu \mathrm{g} / \mathrm{g} \mathrm{cr} \\
\text { Feeding operators: } \\
\text { GM } \pm \text { SD: } 192.45 \pm 2.78 \mu \mathrm{g} / \mathrm{g} \mathrm{cr} \\
\text { Crushing and packing: } \\
\text { GM } \pm \text { SD: } 17.08 \pm 2.33 \mu \mathrm{g} / \mathrm{g} \mathrm{cr} \\
\text { Office workers: } \\
\text { GM } \pm \text { SD: } 11.60 \pm 1.70 \mu \mathrm{g} / \mathrm{g} \mathrm{cr}\end{array}$ & [11] & [141] \\
\hline
\end{tabular}


Table 4. Cont.

\begin{tabular}{|c|c|c|c|c|c|c|c|c|}
\hline Study Design & Country & Study Sample & $\begin{array}{l}\text { Sample Size } \\
\text { (N) }\end{array}$ & Age & Principal Results & BPA Concentration & Confounders & Reference \\
\hline Cross-sectional & China & $\begin{array}{l}\text { Population-based study. } \\
\text { Spot morning urine } \\
\text { collected. }\end{array}$ & $\begin{array}{l}\text { 3394: } \\
1354 \text { males } \\
2040 \text { females }\end{array}$ & $\geq 40$ & $\begin{array}{l}\text { Significant positive association of } \\
\text { urinary BPA with serum FT3 and } \\
\text { inverse association with TSH } \\
\text { levels both in men and in women. } \\
\text { Positive association between high } \\
\text { thyroid function and high urinary } \\
\text { BPA levels. }\end{array}$ & $\begin{array}{l}\text { LOD: } 0.3 \mu \mathrm{g} / \mathrm{L} \\
\text { Median: } 0.81 \mu \mathrm{g} / \mathrm{L} \\
\text { IQR: } 0.47-1.43 \mu \mathrm{g} / \mathrm{L} \\
\text { Overt and subclinical } \\
\text { hypothyroidism subjects: } \\
\text { GM: } 0.63 \text { (95\% CI } 0.52-0.77) \mu \mathrm{g} / \mathrm{L} \\
\text { Euthyroid subjects: } \\
\text { GM: } 0.81 \text { ( } 95 \% \text { CI } 0.78-0.83) \mu \mathrm{g} / \mathrm{L} \\
\text { Overt and subclinical hypothyroidism } \\
\text { subjects: } \\
\text { GM: } 1.05 \text { (95\% CI } 0.84-1.32) \mu \mathrm{g} / \mathrm{L}\end{array}$ & {$[1,3,4,8,11,17,27]$} & [149] \\
\hline Cross-sectional & China & $\begin{array}{l}\text { Students of primary } \\
\text { schools. First morning } \\
\text { urine samples collected. }\end{array}$ & 718 & $9-11$ & $\begin{array}{l}\text { BPA levels similar among boys and } \\
\text { girls but increased with age. } \\
\text { Significant inverse association } \\
\text { between urinary BPA and thyroid } \\
\text { volume. Risk of TNs increased } \\
\text { with age without any association } \\
\text { with sex or urinary iodine level. } \\
\text { BPA inversely associated with risk } \\
\text { of multiple TNs. }\end{array}$ & $\begin{array}{l}\text { Urinary iodine: } \\
\text { Median: } 159 \mu \mathrm{g} / \mathrm{L} \\
\text { Urinary BPA: } \\
\text { Median (IQR): } 2.45(1.09-5.97) \mu \mathrm{g} / \mathrm{g} \\
\text { cr }\end{array}$ & {$[1,3,7,11,42,43]$} & [158] \\
\hline Cross-sectional & China & $\begin{array}{l}\text { Patients with NG. } \\
\text { Patients with PTC. } \\
\text { Healthy controls. } \\
\text { Spot blood and urine } \\
\text { samples collected in the } \\
\text { morning. }\end{array}$ & $\begin{array}{l}53 \\
60 \\
65\end{array}$ & $\geq 18$ & $\begin{array}{l}\text { Urinary BPA and urinary iodine } \\
\text { levels in NG and PTC groups were } \\
\text { significantly higher than those in } \\
\text { controls. } \\
\text { Urinary BPA levels in the females } \\
\text { of NG group and both the male } \\
\text { and female PTC groups were } \\
\text { higher than those in the control } \\
\text { group of the same sex. Urinary } \\
\text { BPA concentration was } \\
\text { significantly lower in the female } \\
\text { PTC group than in the female NG } \\
\text { group. } \\
\text { Urinary iodine in the PTC or NG } \\
\text { groups was higher than that of } \\
\text { controls of the same sex. } \\
\text { Significant correlation between } \\
\text { urinary BPA and iodine } \\
\text { concentrations in all groups. }\end{array}$ & $\begin{array}{l}\text { LOQ for BPA in urine: } 0.1 \mu \mathrm{g} / \mathrm{L} \\
\text { LOQ for BPA in serum: } 0.2 \mu \mathrm{g} / \mathrm{L} \\
\text { LOD for iodine in urine: } 3 \mu \mathrm{g} / \mathrm{L} \\
\text { Serum BPA } \\
\text { GM: } 7.42(4.03-13.82) \mu \mathrm{g} / \mathrm{L} \\
\text { Urinary BPA: } \\
\text { GM: } 2.82(0.016-59.78) \mu \mathrm{g} / \mathrm{g} \mathrm{cr} \\
\text { Urinary iodine: } \\
\text { GM: } 335.05 \text { (71.25-2995.74) } \mu \mathrm{g} / \mathrm{g} \mathrm{cr} \\
\text { BPA-Control group } \\
\text { GM: } 1.06 \text { (0.015-27.88) } \mu \mathrm{g} / \mathrm{g} \mathrm{cr} \\
\text { BPA-NG group } \\
\text { GM: } 5.22 \text { (0.022-50.78) } \mu \mathrm{g} / \mathrm{g} \mathrm{cr} \\
\text { BPA-PTC group } \\
\text { GM: } 4.68(0.032-29.30) \mu \mathrm{g} / \mathrm{g} \mathrm{cr}\end{array}$ & [11] & [160] \\
\hline
\end{tabular}


Table 4. Cont.

\begin{tabular}{|c|c|c|c|c|c|c|c|c|}
\hline Study Design & Country & Study Sample & $\begin{array}{l}\text { Sample Size } \\
\text { (N) }\end{array}$ & Age & Principal Results & BPA Concentration & Confounders & Reference \\
\hline Cross-sectional & Thailand & $\begin{array}{l}\text { Subjects from the National } \\
\text { survey NHES 2009. Serum } \\
\text { sample collected. }\end{array}$ & 2340 & $\geq 15$ & $\begin{array}{l}\text { Significantly inverse association of } \\
\text { serum BPA with FT4 levels in } \\
\text { males but not in females after } \\
\text { exclusion subjects of thyroid } \\
\text { autoantibodies. No association } \\
\text { with serum TSH in both sexes. }\end{array}$ & $\begin{array}{l}\text { LOD: } 0.3 \mu \mathrm{g} / \mathrm{L} \\
\text { Median: } 0.33(0-66.91) \mu \mathrm{g} / \mathrm{L}\end{array}$ & {$[1,3,7]$} & [144] \\
\hline Cross-sectional & Thailand & $\begin{array}{l}\text { Subjects from the National } \\
\text { survey NHES 2009. Serum } \\
\text { sample collected. }\end{array}$ & 2361 & $\geq 15$ & $\begin{array}{l}\text { Significant association of } \\
\text { increasing BPA quartiles with } \\
\text { positivity for TgAb and TPOAb } \\
\text { both in men and women but not } \\
\text { for TRab. Age, sex, and BMI were } \\
\text { independent predictors of TgAb } \\
\text { and TPOAb positivity. }\end{array}$ & $\begin{array}{l}\text { LOD: } 0.3 \mu \mathrm{g} / \mathrm{L} \\
\text { Median: } 0.32(0-66.9) \mu \mathrm{g} / \mathrm{L}\end{array}$ & - & [156] \\
\hline
\end{tabular}

[1]: age; [2]: race and ethnicity; [3]: BMI; [4]: smoking; [5]: timing of collection of blood/urine samples by season; [6]: timing of collection of blood/urine samples by time of day; [7]: sex; [8]: education level; [9]: serum cotinine; [10]: urinary iodine; [11]: urinary creatinine; [12]: family income; [13]: country of birth; [14]: number of years spent in the United States; [15]: [8] : [16] : parity; [16]: time of heel stick; [22]: prenatal vitamin use; [23]: $\log _{10}$-PCB 153; [24]. delivery by Cesarean section; [25]: gestational week at delivery; [26]: menopausal status; [27]: occupation; [28]: total cholesterol; [29]: triglycerides; [30]: HDL-cholesterol; [31]: LDL-cholesterol; [32]: thyroglobulin antibody; [33]: thyroid peroxidase antibodies; [34]: weight loss; [35]: maternal age; [36]: health insurance provider, [37]: urinary specific gravity; [38]: days of mass screening test; [39]; thyroid hormones; [40]: study site; [41]: disease status; [42]: BSA; [43]: iodized salt consumption; [44]: total cholesterol; [45]: TgAb; [46]: TPOAb; [47]: obesity and other related diseases; [48]: medication; [49]: medical history; [50]: other EDCs. 


\section{Discussion}

The thyroid is highly susceptible to environmental pollutants, which may act as either genotoxic or non-genotoxic carcinogens [147]. BPA is a widespread chemical detected in urine specimens of the majority of adult populations. BPA analogues and derivatives are ubiquitous contaminants, measured in environmental and biological matrices, exhibiting a thyroid disrupting potential comparable and even stronger than BPA. The mechanisms of BPs action on THs are complex and need to be still elucidated.

Overall, the in vitro studies demonstrate that BPs may bind to TRs, acting mainly as TR antagonists, but also as agonists or without exerting any effect on TH signaling. Similarly, different patterns of $\operatorname{Tr} \beta$ expression following BPs exposure were observed in in vivo models. THs and their receptors regulate many important processes such as proliferation, differentiation, and apoptosis, and since TR $\beta$ is the major isoform in the thyroid, it can be hypothesized that disruption of its expression, leading to abnormalities in T3-induced transcriptional activity, could be involved in tumorigenesis [72,162].

In vivo experiments, supported by in vitro evidence, highlighted the ability of BPA and its substituting chemicals to affect thyroid follicular cell gene expression, particularly transcriptional levels of those genes encoding for factors involved in THs synthesis (TPO, NIS, Tg, PAX8). Up-regulation of $\mathrm{Tg}$ and Slc5a5 transcript levels may promote thyroid development to compensate for the depressed T4 concentration, as also reported for polybrominated diphenyl ethers [163]. Transcriptional levels of deiodinases were more elevated in exposed zebrafish, in accordance with a study reporting that hypothyroidism caused by EDCs is associated with higher activity and expression of Dio2 [164]. On the other hand, a recent study reported a reduction of liver DIO1 activity in BPA-treated adult rats [102], which is a finding worth of note as decreased expression of DIO1 was observed in nearly all PTCs and is likely an early event in malignant TC [165].

In rodents and in two different types of cell lines, BPA up-regulated Pax8 transcripts, suggesting a role of BPA in increasing Pax8 expression independent from the cellular context [89]. PAX8 is a cell-lineage-specific transcription factor that has been mainly characterized in the thyroid gland for its role in thyrocyte differentiation, and it has been revealed as a potential diagnostic marker for several cancer sites including TC [166].

TSH should represent an effective index of activation of the HPT axis to evaluate central effects of xenobiotics on thyroid function through measurement of TSH secretion or expression as a compensatory mechanism for maintaining TH homeostasis. Moreover, TSH levels are an independent predictor of thyroid nodule malignancy regardless of age, sex or family history [6]. Increased expression of TSH and TSH $\beta$ observed in vivo was also reported after exposure to pesticides and halogenated chemicals in fish $[163,167]$ suggesting that elevated production of TSH could represent one of the mechanisms of action of BPs, as already hypothesized for other EDCs (9). In pituitary cells, BPA and $\mathrm{E}_{2}$ could further induce release of TSH desensitizing the response to thyrotropin releasing hormone from hypothalamus [118]. In contrast, humans and pregnant ewes exhibited hypothyroxinemia after BPA exposure without significant modifications of TSH, whilst other epidemiological studies reported a decreased TSH production, probably consequent of a direct action of BPA on pituitary gland through estrogen receptor signaling or of a feedback mechanism triggered by BPA-mediated perturbations on circulating T3 and T4 [139].

The frequency of chronic autoimmune Hashimoto's thyroiditis, the most common cause of primary hypothyroidism in western countries, has increased in the last two decades, and a variety of factors such as tobacco smoking, iodine and selenium intake, and exposure to EDCs, may contribute to the elevated incidence by interacting with susceptibility genes (6). Autoimmune thyroiditis may coexist with TC [168], and a recent meta-analysis demonstrated that this condition predisposes patients to the development of the papillary histotype [169]. Thyroid autoantibodies were reported to be positively associated with the level of urinary BPA, therefore subjects with thyroid autoantibodies positivity, as characterized by immune dysfunction and a lower ability to eliminate damaged cells, are probably more vulnerable to the effects of BPs on TNs [159]. 
It cannot be excluded that exposure of thyrocytes to BPA involves hydrogen peroxide generation due to an elevated activity of a calcium-dependent NAPDH oxidase (DUOX) [106]. TPO is a key enzyme in the synthesis of THs, catalyzing, through the cofactor $\mathrm{H}_{2} \mathrm{O}_{2}$, the iodination of tyrosyl residues in $\mathrm{Tg}$ [106]. Thus, the increased oxidative stress in the thyroid gland, which is related to a reduction of TPO activity, corroborates the negative correlation between TPO and DUOX2 in thyroid nodular lesions [170]. Furthermore, oxidant/antioxidant balance was recently reported to be impaired in children affected by autoimmune thyroiditis, though it is unclear whether oxidative stress is the real cause of the disease or the likely consequence of exposure to EDCs, including BPA [155].

Finally, BPA is potentially linked to excess iodine in the pathogenesis of the nodular goiter and TC in animals [105] and humans [160]. High urinary iodine is a risk factor for the development of benign TNs and PTC [171], being associated with reduced expression of NIS, an early abnormality in the pathway of thyroid cell transformation, and increased occurrence of BRAF mutations [172], which are both hallmarks of differentiated TC [173].

\section{Conclusions}

This review aims at evaluating the extensive body of experimental and human studies that in the last two decades have attempted to explore the effects of BPA, its substitutes, and its halogenated derivatives on the thyroid at different levels. Despite the variety of approaches applied and the heterogeneous and sometimes even conflicting results from the examined studies, a series of interesting indications supports the hypothesis of a role of BPs in interfering with the normal thyroid function. Although the toxicity pathways of BPs on the thyroid need to be further elucidated, BPA analogues and halogenated derivatives do not emerge as safer alternatives to BPA in term of TH disruption. There is evidence that BPs alters THs circulating levels, inhibiting TH-negative feedback, act as selective TR antagonists, and interfere with expression of genes involved in thyroid stimulation, TH synthesis, $\mathrm{TH}$ activity, and TH transport and metabolism. Several reported findings, mainly from experimental studies, are, however, rather inconsistent, while the association of BPs exposure with thyroid cancer is so far almost unexplored. The lack of uniformity in experimental methodology, as well as substantial differences in populations investigated in epidemiological studies, do not allow definitive conclusions to be drawn. Standardized in vivo, in vitro, and in silico studies are recommended to evaluate the physiopathology of the damage associated with exposure to environmentally relevant levels of BPs, identify other potential molecular targets, and clarify the structure-activity relationship of BPs. At the same time, large population-based human studies with prospective designs and repeated measures of urine BPs concentrations and thyroid volume over time, as well as an accurate control of confounders, should be performed for the assessment of the temporal relationship between markers of exposure and long-term effects.

Author Contributions: Conceptualization, F.G. and F.B.; methodology, F.G., E.B., and A.C.; data curation, F.G.; writing-original draft preparation, F.G.; writing-review and editing, F.G., E.B., A.C., G.I., F.B.; visualization, F.G., E.B., A.C., G.I., and F.B.; supervision, A.C., G.I., and F.B.; project administration, F.B.; funding acquisition, F.B. All authors have read and agree to the published version of the manuscript.

Funding: This research was funded by the Italian Ministry of Education, University and Research, MIUR-Deliberation CIPE n. 105/2015, 23 December 2015, grant number B62F15001070005.

Conflicts of Interest: The authors declare no conflict of interest. 


\section{Abbreviations}

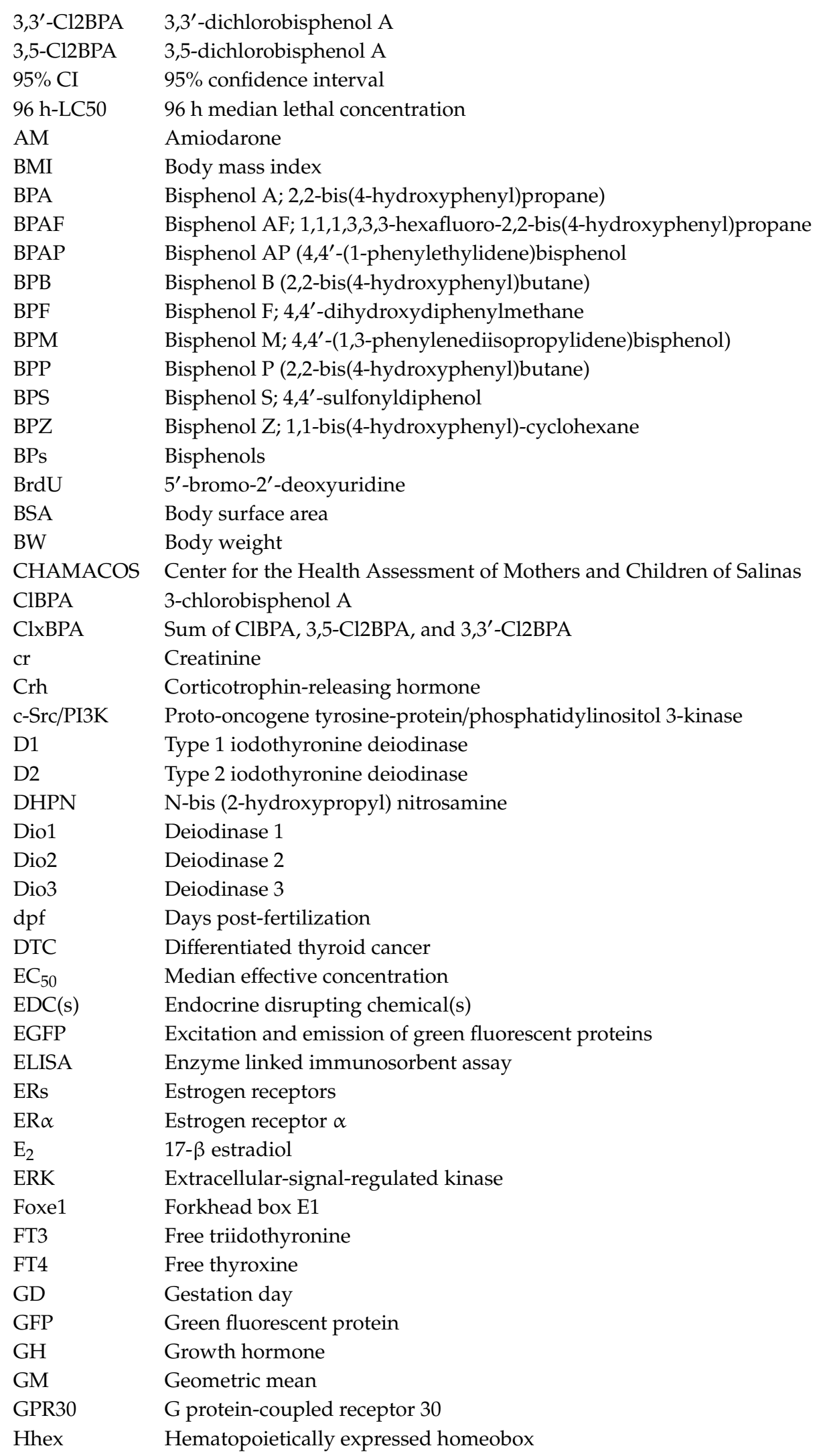




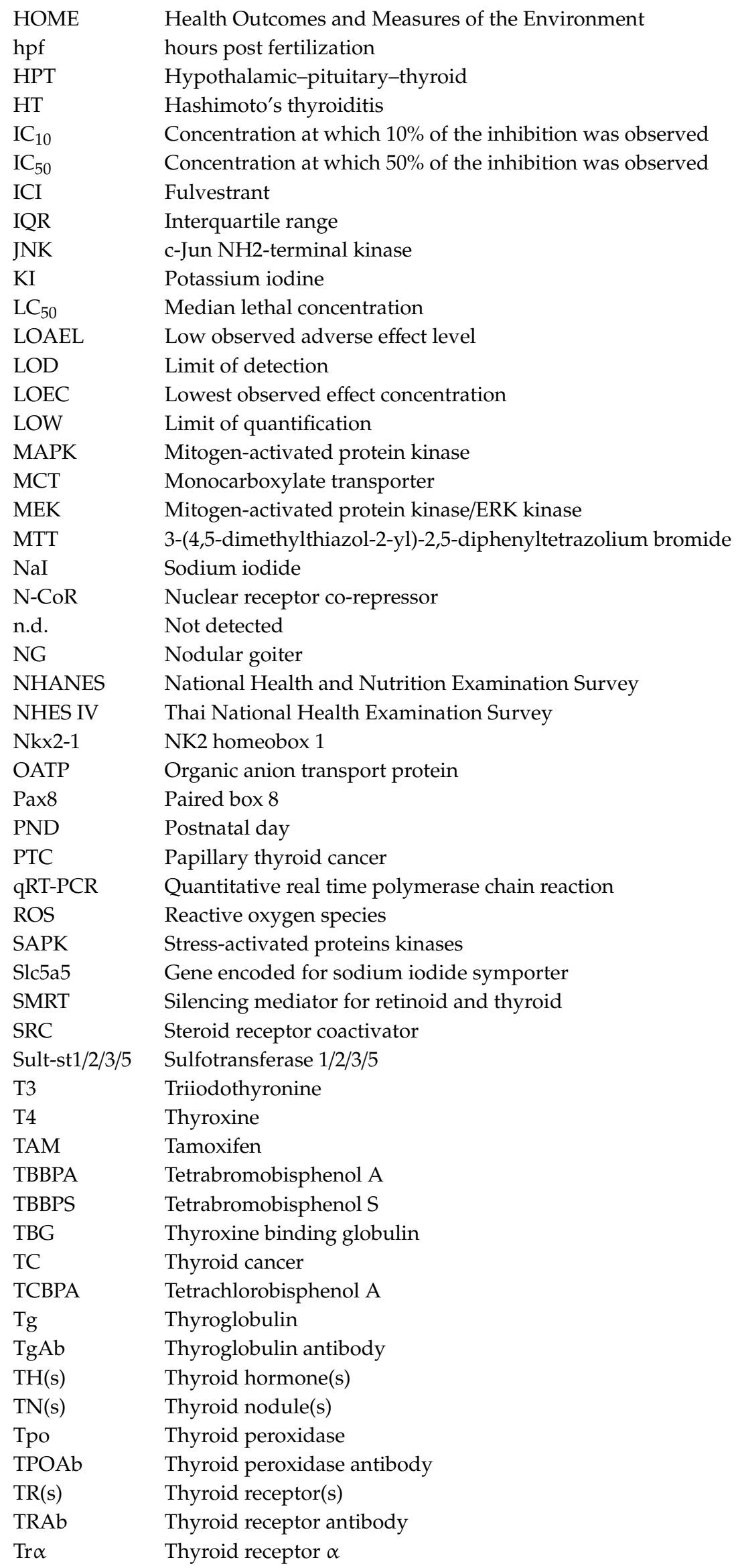




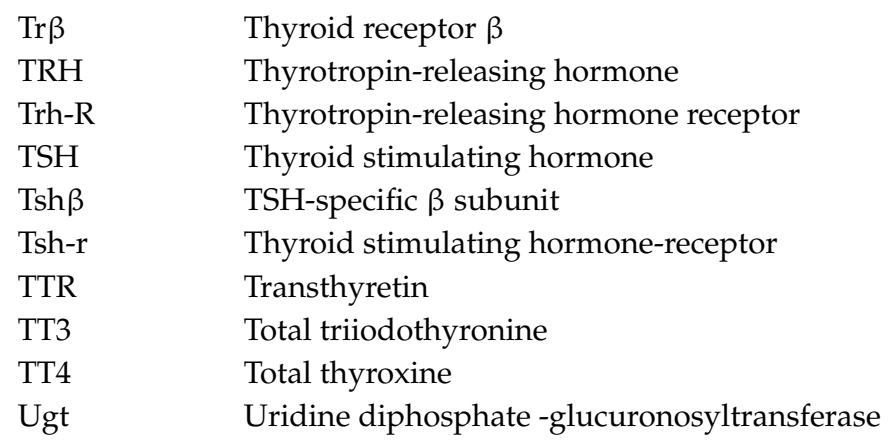

\section{References}

1. Calsolaro, V.; Pasqualetti, G.; Niccolai, F.; Caraccio, N.; Monzani, F. Thyroid Disrupting Chemicals. Int. J. Mol. Sci. 2017, 18, 2583. [CrossRef] [PubMed]

2. Moriyama, K.; Tagami, T.; Akamizu, T.; Usui, T.; Saijo, M.; Kanamoto, N.; Hataya, Y.; Shimatsu, A.; Kuzuya, H.; Nakao, K. Thyroid hormone action is disrupted by bisphenol A as an antagonist. J. Clin. Endocrinol. Metab. 2002, 87, 5185-5190. [CrossRef] [PubMed]

3. Lim, H.; Devesa, S.S.; Sosa, J.A.; Check, D.; Kitahara, C.M. Trends in Thyroid Cancer Incidence and Mortality in the United States, 1974-2013. JAMA 2017, 317, 1338. [CrossRef] [PubMed]

4. Nettore, I.C.; Colao, A.; Macchia, P.E. Nutritional and Environmental Factors in Thyroid Carcinogenesis. Int. J. Environ. Res. Public Health 2018, 15, 1735. [CrossRef] [PubMed]

5. Liu, F.C.; Lin, H.T.; Lin, S.F.; Kuo, C.F.; Chung, T.T.; Yu, H.P. Nationwide cohort study on the epidemiology and survival outcomes of thyroid cancer. Oncotarget 2017, 8, 78429-78451. [CrossRef]

6. Pellegriti, G.; Frasca, F.; Regalbuto, C.; Squatrito, S.; Vigneri, R. Worldwide increasing incidence of thyroid cancer: Update on epidemiology and risk factors. J. Cancer Epidemiol. 2013, 2013, 965212. [CrossRef]

7. Zoeller, R.T.; Brown, T.R.; Doan, L.L.; Gore, A.C.; Skakkebaek, N.E.; Soto, A.M.; Woodruff, T.J.; Vom Saal, F.S. Endocrine-disrupting chemicals and public health protection: A statement of principles from The Endocrine Society. Endocrinology 2012, 153, 4097-4110. [CrossRef]

8. Vandenberg, L.N.; Colborn, T.; Hayes, T.B.; Heindel, J.J.; Jacobs, D.R.; Lee, D.H.; Shioda, T.; Soto, A.M.; vom Saal, F.S.; Welshons, W.V.; et al. Hormones and endocrine-disrupting chemicals: Low-dose effects and nonmonotonic dose responses. Endocr. Rev. 2012, 33, 378-455. [CrossRef]

9. Gorini, F.; Iervasi, G.; Coi, A.; Pitto, L.; Bianchi, F. The Role of Polybrominated Diphenyl Ethers in Thyroid Carcinogenesis: Is It a Weak Hypothesis or a Hidden Reality? From Facts to New Perspectives. Int. J. Environ. Res. Public Health 2018, 15, 1834. [CrossRef]

10. Kitamura, S.; Kato, T.; Iida, M.; Jinno, N.; Suzuki, T.; Ohta, S.; Fujimoto, N.; Hanada, H.; Kashiwagi, K.; Kashiwagi, A. Anti-thyroid hormonal activity of tetrabromobisphenol A, a flame retardant, and related compounds: Affinity to the mammalian thyroid hormone receptor, and effect on tadpole metamorphosis. Life Sci. 2015, 76, 1589-1601. [CrossRef]

11. Welshons, W.V.; Nagel, S.C.; vom Saal, F.S. Large effects from small exposures. III. Endocrine mechanisms mediating effects of bisphenol A at levels of human exposure. Endocrinology 2006, 147, S56-S69. [CrossRef] [PubMed]

12. Rubin, B.S. Bisphenol A: An endocrine disruptor with widespread exposure and multiple effects. J. Steroid Biochem. Mol. Biol. 2011, 127, 27-34. [CrossRef]

13. Vandenberg, L.N.; Maffini, M.V.; Sonnenschein, C.; Rubin, B.S.; Soto, A.M. Bisphenol A and the great divide: A review of controversies in the field of endocrine disruption. Endocr. Rev. 2009, 30, 75-95. [CrossRef]

14. Kim, Y.S.; Hwang, K.A.; Hyun, S.H.; Nam, K.H.; Lee, C.K.; Choi, K.C. Bisphenol A and nonylphenol have the potential to stimulate the migration of ovarian cancer cells by inducing epithelial-mesenchymal transition via an estrogen receptor dependent pathway. Chem. Res. Toxicol. 2015, 28, 662-671. [CrossRef] [PubMed]

15. Yang, M.; Ryu, J.H.; Jeon, R.; Kang, D.; Yoo, K.Y. Effects of bisphenol A on breast cancer and its risk factors. Arch. Toxicol. 2009, 83, 281-285. [CrossRef] [PubMed]

16. Mínguez-Alarcón, L.; Hauser, R.; Gaskins, A.J. Effects of bisphenol A on male and couple reproductive health: A review. Fertil. Steril. 2016, 106, 864-870. [CrossRef] [PubMed] 
17. Mustieles, V.; Pérez-Lobato, R.; Olea, N.; Fernández, M.F. Bisphenol A: Human exposure and neurobehavior. Neurotoxicology 2015, 49, 174-184. [CrossRef]

18. Han, C.; Hong, Y.C. Bisphenol A, Hypertension, and Cardiovascular Diseases: Epidemiological, Laboratory, and Clinical Trial Evidence. Curr. Hypertens. Rep. 2016, 18, 11. [CrossRef]

19. Bertoli, S.; Leone, A.; Battezzati, A. Human Bisphenol A Exposure and the "Diabesity Phenotype". Dose Response 2015, 13, 155932581559917. [CrossRef]

20. Carwile, J.L.; Michels, K.B. Urinary bisphenol A and obesity: NHANES 2003-2006. Environ. Res. 2011, 111, 825-830. [CrossRef]

21. Xu, L.C.; Sun, H.; Chen, J.F.; Bian, Q.; Qian, J.; Song, L.; Wang, X.R. Evaluation of androgen receptor transcriptional activities of bisphenol A, octylphenol and nonylphenol in vitro. Toxicology 2005, 216, 197-203. [CrossRef] [PubMed]

22. Richter, C.A.; Birnbaum, L.S.; Farabollini, F.; Newbold, R.R.; Rubin, B.S.; Talsness, C.E.; Vandenbergh, J.G.; Walser-Kuntz, D.R.; Vom Saal, F.S. In vivo effects of bisphenol A in laboratory rodent studies. Reprod. Toxicol. 2007, 24, 199-224. [CrossRef] [PubMed]

23. Li, D.K.; Zhou, Z.; Miao, M.; He, Y.; Wang, J.; Ferber, J.; Herrinton, L.J.; Gao, E.; Yuan, W. Urine bisphenol-A (BPA) level in relation to semen quality. Fertil. Steril. 2011, 95, 625-630. [CrossRef]

24. Calafat, A.M.; Ye, X.; Wong, L.Y.; Reidy, J.A.; Needham, L.L. Exposure of the U.S. Population to Bisphenol A and 4- tertiary -Octylphenol: 2003-2004. Environ. Health Perspect. 2008, 116, 39-44. [CrossRef] [PubMed]

25. Michałowicz, J. Bisphenol A - sources, toxicity and biotransformation. Environ. Toxicol. Pharmacol. 2014, 37, 738-758. [CrossRef] [PubMed]

26. Flint, S.; Markle, T.; Thompson, S.; Wallace, E. Bisphenol A exposure, effects, and policy: A wildlife perspective. J. Environ. Manag. 2012, 104, 19-34. [CrossRef] [PubMed]

27. Colin, A.; Bach, C.; Rosin, C.; Munoz, J.F.; Dauchy, X. Is drinking water a major route of human exposure to alkylphenol and bisphenol contaminants in France? Arch. Environ. Contam. Toxicol. 2014, 66, 86-99. [CrossRef]

28. Canesi, L.; Fabbri, E. Environmental Effects of BPA: Focus on Aquatic Species. Dose Response 2015, 13, 1559325815598304. [CrossRef]

29. Corrales, J.; Kristofco, L.A.; Steele, W.B.; Yates, B.S.; Breed, C.S.; Williams, E.S.; Brooks, B.W. Global Assessment of Bisphenol A in the Environment: Review and Analysis of Its Occurrence and Bioaccumulation. Dose Response 2015, 13, 155932581559830. [CrossRef]

30. Vogel, S.A. The politics of plastics: The making and unmaking of bisphenol a "safety". Am. J. Public Health 2009, 99, S559-S566. [CrossRef]

31. EFSA, European Food Safety Authority. Scientific Opinion on the risks to public health related to the presence of bisphenol A (BPA) in foodstuffs. EFSA Panel on Food Contact Materials E Flavourings and Processing Aids (CEF). EFSA J. 2015, 13, 3978. [CrossRef]

32. Commission Directive 2011/8/EU of 28 January 2011 amending Directive 2002/72/EC as regards the restriction of use of Bisphenol A in plastic infant feeding bottles (Text with EEA relevance 4). Available online: https://eur-lex.europa.eu/LexUriServ/LexUriServ.do?uri=OJ:L:2011:026:0011:0014:EN:PDF (accessed on 14 February 2020).

33. Food and Drug Administration (FDA). Food Additive Regulations Amended to No Longer Provide for the Use of BPA-Based Materials in Baby Bottles, Sippy Cups, and Infant Formula Packaging. In 2012, 77 Fed. Reg. 41,899.. Available online: https://www.federalregister.gov/documents/2012/07/17/2012-17366/indirect-foodadditives-polymers (accessed on 14 February 2020).

34. Vandenberg, L.N.; Hauser, R.; Marcus, M.; Olea, N.; Welshons, W.V. Human exposure to bisphenol A (BPA). Reprod. Toxicol. 2007, 24, 139-177. [CrossRef] [PubMed]

35. CDC (Centers for Disease Control and Prevention). Fourth National Report on Human Exposure to Environmental Chemicals; CDC: Atlanta, GA, USA, 2013; pp. 1-770.

36. Zhang, T.; Sun, H.; Kannan, K. Blood and urinary bisphenol A concentrations in children, adults, and pregnant women from china: Partitioning between blood and urine and maternal and fetal cord blood. Environ. Sci. Technol. 2013, 47, 4686-4694. [CrossRef] [PubMed]

37. Lee, S.; Kim, C.; Shin, H.; Kho, Y.; Choi, K. 2019 Comparison of thyroid hormone disruption potentials by bisphenols A, S, F, and Z in embryo-larval zebrafish. Chemosphere 2013, 221, 115-123. [CrossRef] [PubMed] 
38. Huang, G.; Tian, X.; Fang, X.; Ji, F. Waterborne exposure to bisphenol F causes thyroid endocrine disruption in zebrafish larvae. Chemosphere 2016, 147, 188-194. [CrossRef] [PubMed]

39. Rochester, J.R.; Bolden, A.L. Bisphenol S and F: A Systematic Review and Comparison of the Hormonal Activity of Bisphenol A Substitutes. Environ. Health Perspect. 2015, 123, 643-650. [CrossRef]

40. Cacho, J.I.; Campillo, N.; Viñas, P.; Hernández-Córdoba, M. Stir bar sorptive extraction coupled to gas chromatography-mass spectrometry for the determination of bisphenols in canned beverages and filling liquids of canned vegetables. J. Chromatogr. A 2012, 1247, 146-153. [CrossRef]

41. Liao, C.; Liu, F.; Moon, H.B.; Yamashita, N.; Yun, S.; Kannan, K. Bisphenol analogues in sediments from industrialized areas in the United States, Japan, and Korea: Spatial and temporal distributions. Environ. Sci. Technol. 2012, 46, 11558-11565. [CrossRef]

42. Zhou, X.; Kramer, J.; Calafat, A.M.; Ye, X. Automated on-line column-switching high performance liquid chromatography isotope dilution tandem mass spectrometry method for the quantification of bisphenol A, bisphenol F, bisphenol S, and 11 other phenols in urine. J. Chromatogr. B Analyt. Technol. Biomed. Life Sci. 2014, 944, 152-156. [CrossRef]

43. Office of Chemical Safety \& Pollution Prevention, EPA. Doc. No.740-R1-4004, TSCA Work Plan Chemical Problem Formulation and Initial Assessment: Tetrabromobisphenol A and Related Chemicals Cluster Flame Retardants 10, 2015. Available online: https:/www.epa.gov/sites/production/files/2015-09/documents/tbbpa_ problem_formulation_august_2015.pdf (accessed on 14 February 2020).

44. Yin, N.; Liang, S.; Liang, S.; Yang, R.; Hu, B.; Qin, Z.; Liu, A.; Faiola, F. TBBPA and Its Alternatives Disturb the Early Stages of Neural Development by Interfering with the NOTCH and WNT Pathways. Environ. Sci. Technol. 2018, 52, 5459-5468. [CrossRef]

45. Malkoske, T.; Tang, Y.; Xu, W.; Yu, S.; Wang, H. A review of the environmental distribution, fate, and control of tetrabromobisphenol A released from sources. Sci. Total Environ. 2016, 569-570, 1608-1617. [CrossRef] [PubMed]

46. Wu, Y.; Li, Y.; Kang, D.; Wang, J.; Zhang, Y.; Du, D.; Pan, B.; Lin, Z.; Huang, C.; Dong, Q. Tetrabromobisphenol A and heavy metal exposure via dust ingestion in an e-waste recycling region in Southeast China. Sci. Total Environ. 2016, 541, 356-364. [CrossRef] [PubMed]

47. Yamazaki, E.; Yamashita, N.; Taniyasu, S.; Lam, J.; Lam, P.K.S.; Moon, H.B.; Jeong, Y.; Kannan, P.; Achyuthan, H.; Munuswamy, N.; et al. Bisphenol A and other bisphenol analogues including BPS and BPF in surface water samples from Japan, China, Korea and India. Ecotoxicol. Environ. Saf. 2015, 122, 565-572. [CrossRef] [PubMed]

48. Liao, C.; Liu, F.; Guo, Y.; Moon, H.B.; Nakata, H.; Wu, Q.; Kannan, K. Occurrence of eight bisphenol analogues in indoor dust from the United States and several Asian countries: Implications for human exposure. Environ. Sci. Technol. 2012, 46, 9138-9145. [CrossRef] [PubMed]

49. Fu, P.; Kawamura, K. Ubiquity of bisphenol A in the atmosphere. Environ. Pollut. 2010, 158, 3138-3143. [CrossRef]

50. Yamamoto, T.; Yasuhara, A.; Shiraishi, H.; Nakasugi, O. Bisphenol A in hazardous waste landfill leachates. Chemosphere 2001, 42, 415-418. [CrossRef]

51. Geens, T.; Neels, H.; Covaci, A. Distribution of bisphenol-A, triclosan and n-nonylphenol in human adipose tissue, liver and brain. Chemosphere 2012, 87, 796-802. [CrossRef]

52. Sun, Y.; Irie, M.; Kishikawa, N.; Wada, M.; Kuroda, N.; Nakashima, K. Determination of bisphenol A in human breast milk by HPLC with column-switching and fluorescence detection. Biomed. Chromatogr. 2004, 18, 501-507. [CrossRef]

53. World Health Organization \& Food and Agriculture Organization of the United Nations (2011). In Proceedings of the Joint FAO/WHO Expert Meeting to Review Toxicological and Health Aspects of Bisphenol A: Final Report, Including Report of Stakeholder Meeting on Bisphenol A, Ottawa, ON, Canada, 1-5 November 2010. Available online: https://apps.who.int/iris/bitstream/handle/10665/44624/97892141564274_eng.pdf? sequence $=1 \&$ isAllowed $=y$ (accessed on 14 February 2020).

54. Liao, C.; Liu, F.; Alomirah, H.; Loi, V.D.; Mohd, M.A.; Moon, H.B.; Nakata, H.; Kannan, K. Bisphenol S in urine from the United States and seven Asian countries: Occurrence and human exposures. Environ. Sci. Technol. 2012, 46, 6860-6866. [CrossRef]

55. Liu, K.; Li, J.; Yan, S.; Zhang, W.; Li, Y.; Han, D. A review of status of tetrabromobisphenol A (TBBPA) in China. Chemosphere 2016, 148, 8-20. [CrossRef] 
56. Yang, S.; Wang, S.; Liu, H.; Yan, Z. Tetrabromobisphenol A: Tissue distribution in fish, and seasonal variation in water and sediment of Lake Chaohu, China. Environ. Sci. Pollut. Res. Int. 2012, 19, 4090-4096. [CrossRef] [PubMed]

57. Zhu, Z.C.; Chen, S.J.; Zheng, J.; Tian, M.; Feng, A.H.; Luo, X.J.; Mai, B.X. Occurrence of brominated flame retardants (BFRs), organochlorine pesticides (OCPs), and polychlorinated biphenyls (PCBs) in agricultural soils in a BFR-manufacturing region of North China. Sci. Total Environ. 2014, 481, 47-54. [CrossRef] [PubMed]

58. Cariou, R.; Antignac, J.P.; Zalko, D.; Berrebi, A.; Cravedi, J.P.; Maume, D.; Marchand, P.; Monteau, F.; Riu, A.; Andre, F.; et al. Exposure assessment of French women and their newborns to tetrabromobisphenol-A: Occurrence measurements in maternal adipose tissue, serum, breast milk and cord serum. Chemosphere 2008, 73, 1036-1041. [CrossRef] [PubMed]

59. EFSA Panel on Contaminants in the Food Chain (CONTAM). Scientific Opinion on Tetrabromobisphenol A (TBBPA) and its derivatives in food: TBBPA and its derivatives in food. EFSA J. 2011, 9, 2477. Available online: https://efsa.onlinelibrary.wiley.com/doi/pdf/10.2903/j.efsa.2011.2477 (accessed on 14 February 2020). [CrossRef]

60. Harvey, C.B.; Bassett, J.H.D.; Maruvada, P.; Yen, P.M.; Williams, G.R. The rat thyroid hormone receptor (TR) $\Delta \beta 3$ displays cell-, TR isoform-, and thyroid hormone response element-specific actions. Endocrinology 2007, 148, 1764-1773. [CrossRef]

61. Kublaoui, B.; Levine, M.A. Receptor transduction pathways mediating hormone action. In Pediatric Endocrinology, 4th ed.; Elsevier Inc.: Amsterdam, The Netherlands, 2014; pp. 34-89.

62. Fattori, J.; Campos, J.L.; Doratioto, T.R.; Assis, L.M.; Vitorino, M.T.; Polikarpov, I.; Xavier-Neto, J.; Figueira, A.C. RXR agonist modulates TR: Corepressor dissociation upon 9-cis retinoic acid treatment. Mol. Endocrinol. 2015, 29, 258-273. [CrossRef]

63. Aagaard, M.M.; Siersbæk, R.; Mandrup, S. Molecular basis for gene-specific transactivation by nuclear receptors. Biochim. Biophys. Acta 2011, 1812, 824-835. [CrossRef]

64. Guyot, R.; Chatonnet, F.; Gillet, B.; Hughes, S.; Flamant, F. Toxicogenomic analysis of the ability of brominated flame retardants TBBPA and BDE-209 to disrupt thyroid hormone signaling in neural cells. Toxicology 2014, 325, 125-132. [CrossRef]

65. Jugan, M.L.; Lévy-Bimbot, M.; Pomérance, M.; Tamisier-Karolak, S.; Blondeau, J.P.; Lévi, Y. A new bioluminescent cellular assay to measure the transcriptional effects of chemicals that modulate the alpha-1 thyroid hormone receptor. Toxicol. In Vitro 2007, 21, 1197-1205. [CrossRef]

66. Iwamuro, S.; Yamada, M.; Kato, M.; Kikuyama, S. Effects of bisphenol A on thyroid hormone-dependent up-regulation of thyroid hormone receptor $\alpha$ and $\beta$ and down-regulation of retinoid X receptor $\gamma$ in Xenopus tail culture. Life Sci. 2006, 79, 2165-2171. [CrossRef]

67. Seiwa, C.; Nakahara, J.; Komiyama, T.; Katsu, Y.; Iguchi, T.; Asou, H. Bisphenol A exerts thyroid-hormone-like effects on mouse oligodendrocyte precursor cells. Neuroendocrinology 2004, 80, 21-30. [CrossRef] [PubMed]

68. Lu, L.; Zhan, T.; Ma, M.; Xu, C.; Wang, J.; Zhang, C.; Liu, W.; Zhuang, S. Thyroid Disruption by Bisphenol S Analogues via Thyroid Hormone Receptor $\beta$ : In Vitro, in Vivo, and Molecular Dynamics Simulation Study. Environ. Sci. Technol. 2018, 52, 6617-6625. [CrossRef] [PubMed]

69. Terasaki, M.; Kosaka, K.; Kunikane, S.; Makino, M.; Shiraishi, F. Assessment of thyroid hormone activity of halogentaed bisphenol A using a yeast two-hybrid assay. Chemosphere 2011, 84, 1527-1530. [CrossRef] [PubMed]

70. Kudo, Y.; Yamauchi, K.; Fukazawa, H.; Terao, Y. In vitro and in vivo analysis of the thyroid system-disrupting activities of brominated phenolic and phenol compounds in Xenopus laevis. Toxicol. Sci. 2006, 92, 87-95. [CrossRef]

71. Kitamura, S.; Jinno, N.; Ohta, S.; Kuroki, H.; Fujimoto, N. Thyroid hormonal activity of the flame retardants tetrabromobisphenol A and tetrachlorobisphenol A. Biochem. Biophys. Res. Commun. 2002, 293, 554-559. [CrossRef]

72. Hofmann, P.J.; Schomburg, L.; Köhrle, J. Interference of Endocrine Disrupters with Thyroid Hormone Receptor-Dependent Transactivation. Toxicol. Sci. 2009, 110, 125-137. [CrossRef]

73. Sun, H.; Shen, O.X.; Wang, X.R.; Zhou, L.; Zhen, S.; Chen, X. Anti-thyroid hormone activity of bisphenol A, tetrabromobisphenol A and tetrachlorobisphenol A in an improved reporter gene assay. Toxicol. In Vitro 2009, 23, 950-954. [CrossRef] 
74. Otsuka, S.; Ishihara, A.; Yamauchi, K. Ioxynil and tetrabromobisphenol a suppress thyroid-hormone-induced activation of transcriptional elongation mediated by histone modifications and RNA polymerase II phosphorylation. Toxicol. Sci. 2014, 138, 290-299. [CrossRef]

75. Yang, J.; Chan, K.M. Evaluation of the toxic effects of brominated compounds (BDE-47, 99, 209, TBBPA) and bisphenol A (BPA) using a zebrafish liver cell line, ZFL. Aquat. Toxicol. 2015, 159, 138-147. [CrossRef]

76. Freitas, J.; Cano, P.; Craig-Veit, C.; Goodson, M.L.; David Furlow, J.; Murk, A.J. Detection of thyroid hormone receptor disruptors by a novel stable in vitro reporter gene assay. Toxicol. In Vitro 2011, 250, 257-266. [CrossRef]

77. Sheng, Z.G.; Tang, Y.; Liu, Y.X.; Yuan, Y.; Zhao, B.Q.; Chao, X.J.; Zhu, B.Z. Low concentrations of bisphenol a suppress thyroid hormone receptor transcription through a nongenomic mechanism. Toxicol. Appl. Pharmacol. 2012, 259, 133-142. [CrossRef] [PubMed]

78. Bhargava, M.; Lei, J.; Ingbar, D.H. Nongenomic actions of L-thyroxine and 3,5,3'-triiodo-L-thyronine. Focus on "L-Thyroxine vs. 3,5,3'-triiodo-L-thyronine and cell proliferation: Activation of mitogen-activated protein kinase and phosphatidylinositol 3-kinase". Am. J. Physiol. Cell Physiol. 2009, 296, C977-C979. [CrossRef] [PubMed]

79. Sheng, Z.; Wang, C.; Ren, F.; Liu, Y.; Zhu, B. Molecular mechanism of endocrine-disruptive effects induced by Bisphenol A: The role of transmembrane G-protein estrogen receptor 1 and integrin $\alpha \mathrm{v} \beta 3$. J. Environ. Sci. (China) 2019, 75, 1-13. [CrossRef] [PubMed]

80. Zhang, Y.F.; Ren, X.M.; Li, Y.Y.; Yao, X.F.; Li, C.H.; Qin, Z.F.; Guo, L.H. Bisphenol A alternatives bisphenol $\mathrm{S}$ and bisphenol $\mathrm{F}$ interfere with thyroid hormone signaling pathway in vitro and in vivo. Environ. Pollut. 2018, 237, 1072-1079. [CrossRef] [PubMed]

81. Ghisari, M.; Bonefeld-Jorgensen, E.C. Impact of environmental chemicals on the thyroid hormone function in pituitary rat GH3 cells. Mol. Cell. Endocrinol. 2005, 244, 31-41. [CrossRef] [PubMed]

82. Schriks, M.; Vrabie, C.M.; Gutleb, A.C.; Faassen, E.J.; Rietjens, I.M.C.M.; Murk, A.J. T-screen to quantify functional potentiating, antagonistic and thyroid hormone-like activities of poly halogenated aromatic hydrocarbons (PHAHs). Toxicol. In Vitro 2006, 20, 490-498. [CrossRef]

83. Kitamura, S. Comparative study of the endocrine-disrupting activity of bisphenol a and 19 related compounds. Toxicol. Sci. 2005, 84, 249-259. [CrossRef]

84. Hamers, T.; Kamstra, J.H.; Sonneveld, E.; Murk, A.J.; Kester, M.H.A.; Andersson, P.L.; Legler, J.; Brouwer, A. In vitro profiling of the endocrine-disrupting potency of brominated flame retardants. Toxicol. Sci. 2006, 92, 157-173. [CrossRef]

85. Lee, J.; Kim, S.; Choi, K.; Ji, K. Effects of bisphenol analogs on thyroid endocrine system and possible interaction with $17 \beta$-estradiol using GH3 cells. Toxicol. In Vitro 2018, 53, 107-113. [CrossRef]

86. Zhang, Y.H.; Wei, F.; Zhang, J.; Hao, L.; Jiang, J.; Dang, L.; Mei, D.; Fan, S.; Yu, Y.; Jiang, L. Bisphenol A and estrogen induce proliferation of human thyroid tumor cells via an estrogen-receptor-dependent pathway. Arch. Biochem. Biophys. 2017, 633, 29-39. [CrossRef]

87. Strack, S.; Detzel, T.; Wahl, M.; Kuch, B.; Krug, H.F. Cytotoxicity of TBBPA and effects on proliferation, cell cycle and MAPK pathways in mammalian cells. Chemosphere 2007, 67, S405-S411. [CrossRef] [PubMed]

88. English, J.; Pearson, G.; Wilsbacher, J.; Swantek, J.; Karandikar, M.; Xu, S.; Cobb, M.H. New insights into the control of MAP kinase pathways. Exp. Cell Res. 1999, 253, 255-270. [CrossRef]

89. Gentilcore, D.; Porreca, I.; Rizzo, F.; Ganbaatar, E.; Carchia, E.; Mallardo, M.; De Felice, M.; Ambrosino, C. Bisphenol A interferes with thyroid specific gene expression. Toxicology 2013, 304, 21-31. [CrossRef]

90. Cao, J.; Guo, L.-H.; Wan, B.; Wei, Y. In vitro fluorescence displacement investigation of thyroxine transport disruption by bisphenol A. J. Environ. Sci. (China) 2011, 23, 315-321. [CrossRef]

91. Ishihara, A.; Sawatsubashi, S.; Yamauchi, K. Endocrine disrupting chemicals: Interference of thyroid hormone binding to transthyretins and to thyroid hormone receptors. Mol. Cell. Endocrinol. 2003, 199, 105-117. [CrossRef]

92. Meerts, I.A.T.M. Potent competitive interactions of some brominated flame retardants and related compounds with human transthyretin in vitro. Toxicol. Sci. 2000, 56, 95-104. [CrossRef]

93. Marchesini, G.R.; Meimaridou, A.; Haasnoot, W.; Meulenberg, E.; Albertus, F.; Mizuguchi, M.; Takeuchi, M.; Irth, H.; Murk, A.J. Biosensor discovery of thyroxine transport disrupting chemicals. Toxicol. Appl. Pharmacol. 2008, 232, 150-160. [CrossRef] 
94. Dong, H.; Wade, M.G. Application of a nonradioactive assay for high throughput screening for inhibition of thyroid hormone uptake via the transmembrane transporter MCT8. Toxicol. In Vitro 2017, 40, $234-242$. [CrossRef]

95. Friesema, E.C.; Kuiper, G.G.; Jansen, J.; Visser, T.J.; Kester, M.H. Thyroid hormone transport by the human monocarboxylate transporter 8 and its rate-limiting role in intracellular metabolism. Mol. Endocrinol. 2006, 20, 2761-2772. [CrossRef]

96. Strømme, P.; Groeneweg, S.; Lima de Souza, E.C.; Zevenbergen, C.; Torgersbråten, A.; Holmgren, A.; Gurcan, E.; Meima, M.E.; Peeters, R.; Visser, W.E.; et al. Mutated Thyroid Hormone Transporter OATP1C1 Associates with Severe Brain Hypometabolism and Juvenile Neurodegeneration. Thyroid 2018, 28, 1406-1415. [CrossRef]

97. Trajkovic, M.; Visser, T.J.; Mittag, J.; Horn, S.; Lukas, J.; Darras, V.M.; Raivich, G.; Bauer, K.; Heuer, H. Abnormal thyroid hormone metabolism in mice lacking the monocarboxylate transporter 8. J. Clin. Investig. 2007, 117, 627-635. [CrossRef] [PubMed]

98. Johannes, J.; Jayarama-Naidu, R.; Meyer, F.; Wirth, E.K.; Schweizer, U.; Schomburg, L.; Köhrle, J.; Renko, K. Silychristin, a Flavonolignan Derived From the Milk Thistle, Is a Potent Inhibitor of the Thyroid Hormone Transporter MCT8. Endocrinology 2016, 157, 1694-1701. [CrossRef] [PubMed]

99. Lee, S.; Kim, C.; Youn, H.; Choi, K. Thyroid hormone disrupting potentials of bisphenol A and its analogues - in vitro comparison study employing rat pituitary (GH3) and thyroid follicular (FRTL-5) cells. Toxicol. In Vitro 2017, 40, 297-304. [CrossRef] [PubMed]

100. Wu, Y.; Beland, F.A.; Fang, J.L. Effect of triclosan, triclocarban, 2,2' 4 4, $4^{\prime}$-tetrabromodiphenyl ether, and bisphenol $\mathrm{A}$ on the iodide uptake, thyroid peroxidase activity, and expression of genes involved in thyroid hormone synthesis. Toxicol. In Vitro 2016, 32, 310-319. [CrossRef]

101. Porreca, I.; Ulloa Severino, L.; D’Angelo, F.; Cuomo, D.; Ceccarelli, M.; Altucci, L.; Amendola, E.; Nebbioso, A.; Mallardo, M.; De Felice, M.; et al. "Stockpile" of Slight Transcriptomic Changes Determines the Indirect Genotoxicity of Low-Dose BPA in Thyroid Cells. PLoS ONE 2016, 11, e0151618. [CrossRef]

102. da Silva, M.M.; Gonçalves, C.F.L.; Miranda-Alves, L.; Fortunato, R.S.; Carvalho, D.P.; Ferreira, A.C.F. Inhibition of Type 1 Iodothyronine Deiodinase by Bisphenol A. Horm. Metab. Res. 2019, 51, 671-677. [CrossRef]

103. Chan, S.; Kachilele, S.; Hobbs, E.; Bulmer, J.N.; Boelaert, K.; McCabe, C.J.; Driver, P.M.; Bradwell, A.R.; Kester, M.; Visser, T.J.; et al. Placental iodothyronine deiodinase expression in normal and growth-restricted human pregnancies. J. Clin. Endocrinol. Metab. 2003, 88, 4488-4495. [CrossRef]

104. Zoeller, R.T.; Bansal, R.; Parris, C. Bisphenol-A, an environmental contaminant that acts as a thyroid hormone receptor antagonist in vitro, increases serum thyroxine, and alters RC3/neurogranin expression in the developing rat brain. Endocrinology 2005, 146, 607-612. [CrossRef]

105. Zhang, J.; Zhang, X.; Li, Y.; Zhou, Z.; Wu, C.; Liu, Z.; Hao, L.; Fan, S.; Jiang, F.; Xie, Y.; et al. Low dose of Bisphenol A enhance the susceptibility of thyroid carcinoma stimulated by DHPN and iodine ecxcess in F344 rats. Oncotarget 2017, 8, 69874-69887.

106. Silva, M.M.D.; Xavier, L.L.F.; Gonçalves, C.F.L.; Santos-Silva, A.P.; Paiva-Melo, F.D.; Freitas, M.L.D.; Fortunato, R.S.; Alves, L.M.; Ferreira, A.C.F. Bisphenol A increases hydrogen peroxide generation by thyrocytes both in vivo and in vitro. Endocr. Connect. 2018, 7, 1198-1207. [CrossRef]

107. Saegusa, Y.; Fujimoto, H.; Woo, G.H.; Inoue, K.; Takahashi, M.; Mitsumori, K.; Hirose, M.; Nishikawa, A.; Shibutani, M. Developmental toxicity of brominated flame retardants, tetrabromobisphenol A and 1,2,5,6,9,10-hexabromocyclododecane, in rat offspring after maternal exposure from mid-gestation through lactation. Reprod. Toxicol. 2009, 2, 456-467. [CrossRef] [PubMed]

108. Kobayashi, K.; Miyagawa, M.; Wang, R.S.; Suda, M.; Sekiguchi, S.; Honma, T. Effects of in utero and lactational exposure to bisphenol A on thyroid status in F1 rat offspring. Ind. Health 2005, 43, 685-690. [CrossRef] [PubMed]

109. Bansal, R.; Zoeller, R.T. CLARITY-BPA: Bisphenol A or Propylthiouracil on Thyroid Function and Effects in the Developing Male and Female Rat Brain. Endocrinology 2019, 160, 1771-1785. [CrossRef] [PubMed]

110. Osimitz, T.G.; Droege, W.; Hayes, A.W. Subchronic toxicology of tetrabromobisphenol A in rats. Hum. Exp. Toxicol. 2016, 35, 1214-1226. [CrossRef] [PubMed] 
111. Xu, X.; Fan, S.; Guo, Y.; Tan, R.; Zhang, J.; Zhang, W.; Pan, B.X.; Kato, N. The effects of perinatal bisphenol A exposure on thyroid hormone homeostasis and glucose metabolism in the prefrontal cortex and hippocampus of rats. Brain Behav. 2019, 9, e01225. [CrossRef]

112. Xu, X.; Liu, Y.; Sadamatsu, M.; Tsutsumi, S.; Akaike, M.; Ushijima, H.; Kato, N. Perinatal bisphenol A affects the behavior and SRC-1 expression of male pups but does not influence on the thyroid hormone receptors and its responsive gene. Neurosci. Res. 2007, 58, 149-155. [CrossRef]

113. Jiang, W.; Cao, L.; Wang, F.; Ge, H.; Wu, P.C.; Li, X.W.; Chen, G.H. Accelerated reduction of serum thyroxine and hippocampal histone acetylation links to exacerbation of spatial memory impairment in aged CD-1 mice pubertally exposed to bisphenol A. Age (Dordr) 2016, 38, 405-418. [CrossRef]

114. Van der Ven, L.T.M.; Van de Kuil, T.; Verhoef, A.; Verwer, C.M.; Lilienthal, H.; Leonards, P.E.G.; Schauer, U.M.D.; Cantón, R.F.; Litens, S.; De Jong, F.H.; et al. Endocrine effects of tetrabromobisphenol-A (TBBPA) in Wistar rats as tested in a one-generation reproduction study and a subacute toxicity study. Toxicology 2008, 245, 76-89. [CrossRef]

115. Silva, B.S.; Bertasso, I.M.; Pietrobon, C.B.; Lopes, B.P.; Santos, T.R.; Peixoto-Silva, N.; Carvalho, J.C.; Claudio-Neto, S.; Manhães, A.C.; Cabral, S.S.; et al. Effects of maternal bisphenol A on behavior, sex steroid and thyroid hormones levels in the adult rat offspring. Life Sci. 2019, 218, 253-264. [CrossRef]

116. Ahmed, R.G.; Walaa, G.H.; Asmaa, F.S. Suppressive effects of neonatal bisphenol A on the neuroendocrine system. Toxicol. Ind. Health 2018, 34, 397-407. [CrossRef]

117. Fernandez, M.O.; Bourguignon, N.S.; Arocena, P.; Rosa, M.; Libertun, C.; Lux-Lantos, V. Neonatal exposure to bisphenol A alters the hypothalamic-pituitary-thyroid axis in female rats. Toxicol. Lett. 2018, 285, 81-86. [CrossRef] [PubMed]

118. Delclos, K.B.; Camacho, L.; Lewis, S.M.; Vanlandingham, M.M.; Latendresse, J.R.; Olson, G.R.; Davis, K.J.; Patton, R.E.; da Costa, G.G.; Woodling, K.A.; et al. Toxicity Evaluation of Bisphenol A Administered by Gavage to Sprague Dawley Rats From Gestation Day 6 Through Postnatal Day 90. Toxicol. Sci. 2014, 139, 174-197. [CrossRef] [PubMed]

119. Matos, L.P.L.; Penha, R.C.C.; Cardoso-Weide, L.C.; Freitas, M.L.; Silva, D.L.S.G.; Ferreira, A.C.F. Regulation of thyroid sodium-iodide symporter in different stages of goiter: Possible involvement of reactive oxygen species. Clin. Exp. Pharmacol. Physiol. 2018, 45, 326-334. [CrossRef] [PubMed]

120. Fortunato, R.S.; Lima de Souza, E.C.; Ameziane-el Hassani, R.; Boufraqech, M.; Weyemi, U.; Talbot, M.; Lagente-Chevallier, O.; de Carvalho, D.P.; Bidart, J.M.; Schlumberger, M.; et al. Functional consequences of dual oxidase-thyroperoxidase interaction at the plasma membrane. J. Clin. Endocrinol. Metab. 2010, 95, 5403-5411. [CrossRef] [PubMed]

121. Yafune, A.; Taniai, E.; Morita, R.; Akane, H.; Kimura, M.; Mitsumori, K.; Shibutani, M. Immunohistochemical cellular distribution of proteins related to $\mathrm{M}$ phase regulation in early proliferative lesions induced by tumor promotion in rat two-stage carcinogenesis models. Exp. Toxicol. Pathol. 2014, 66, 1-11. [CrossRef] [PubMed]

122. Viguié, C.; Collet, S.H.; Gayrard, V.; Picard-Hagen, N.; Puel, S.; Roques, B.B.; Toutain, P.L.; Lacroix, M.Z. Maternal and fetal exposure to bisphenol $\mathrm{A}$ is associated with alterations of thyroid function in pregnant ewes and their newborn lambs. Endocrinology 2013, 154, 521-528. [CrossRef]

123. Guignard, D.; Gayrard, V.; Lacroix, M.Z.; Puel, S.; Picard-Hagen, N.; Viguié, C. Evidence for bisphenol A-induced disruption of maternal thyroid homeostasis in the pregnant ewe at low level representative of human exposure. Chemosphere 2017, 182, 458-467. [CrossRef]

124. Fisher, D.A.; Polk, D.H.; Wu, S. Fetal thyroid metabolism: A pluralistic system. Thyroid 1994, 4, 367-371. [CrossRef]

125. Marelli, F.; Persani, L. How zebrafish research has helped in understanding thyroid diseases. F1000Res. 2017, 6, 2137. [CrossRef]

126. Terrien, X.; Fini, J.B.; Demeneix, B.A.; Schramm, K.W.; Prunet, P. Generation of fluorescent zebrafish to study endocrine disruption and potential crosstalk between thyroid hormone and corticosteroids. Aquat. Toxicol. 2011, 105, 13-20. [CrossRef]

127. Raldúa, D.; Thienpont, B.; Babin, P.J. Zebrafish eleutheroembryos as an alternative system for screening chemicals disrupting the mammalian thyroid gland morphogenesis and function. Reprod. Toxicol. 2012, 33, 188-197. [CrossRef] [PubMed]

128. Zhu, B.; Zhao, G.; Yang, L.; Zhou, B. Tetrabromobisphenol A caused neurodevelopmental toxicity via disrupting thyroid hormones in zebrafish larvae. Chemosphere 2018, 197, 353-361. [CrossRef] [PubMed] 
129. Zhang, D.; Zhou, E.; Yang, Z. Waterborne exposure to BPS causes thyroid endocrine disruption in zebrafish larvae. PLoS ONE 2017, 12, e0176927. [CrossRef] [PubMed]

130. Tang, T.; Yang, Y.; Chen, Y.; Tang, W.; Wang, F.; Diao, X. Thyroid Disruption in Zebrafish Larvae by Short-Term Exposure to Bisphenol AF. Int. J. Environ. Res. Public Health 2015, 12, 13069-13084. [CrossRef] [PubMed]

131. Naderi, M.; Wong, M.Y.L.; Gholami, F. Developmental exposure of zebrafish (Danio rerio) to bisphenol-S impairs subsequent reproduction potential and hormonal balance in adults. Aquat. Toxicol. 2014, 148, 195-203. [CrossRef] [PubMed]

132. Baumann, L.; Ros, A.; Rehberger, K.; Neuhauss, S.C.F.; Segner, H. Thyroid disruption in zebrafish (Danio rerio) larvae: Different molecular response patterns lead to impaired eye development and visual functions. Aquat. Toxicol. 2016, 172, 44-55. [CrossRef]

133. Chan, W.K.; Chan, K.M. Disruption of the hypothalamic-pituitary-thyroid axis in zebrafish embryo-larvae following waterborne exposure to BDE-47, TBBPA and BPA. Aquat. Toxicol. 2012, 108, 106-111. [CrossRef]

134. Kwon, B.; Kho, Y.; Kim, P.G.; Ji, K. Thyroid endocrine disruption in male zebrafish following exposure to binary mixture of bisphenol AF and sulfamethoxazole. Environ. Toxicol. Pharmacol. 2016, 48, 168-174. [CrossRef]

135. Berto-Júnior, C.; Santos-Silva, A.P.; Ferreira, A.C.F.; Graceli, J.B.; de Carvalho, D.P.; Soares, P.; Romeiro, N.C.; Miranda-Alves, L. Unraveling molecular targets of bisphenol A and S in the thyroid gland. Environ. Sci. Pollut. Res. Int. 2018, 25, 26916-26926. [CrossRef]

136. Liang, Y.Q.; Huang, G.Y.; Ying, G.G.; Liu, S.S.; Jiang, Y.X.; Liu, S. Progesterone and norgestrel alter transcriptional expression of genes along the hypothalamic-pituitary-thyroid axis in zebrafish embryos-larvae. Comp. Biochem. Physiol. C Toxicol. Pharmacol. 2015, 167, 101-107. [CrossRef]

137. Bianco, A.C.; Salvatore, D.; Gereben, B.Z.; Berry, M.J.; Larsen, P.R. Biochemistry, cellular and molecular biology, and physiological roles of the iodothyronine selenodeiodinases. Endocr. Rev. 2002, 23, 38-89. [CrossRef] [PubMed]

138. Lévy-Bimbot, M.; Major, G.; Courilleau, D.; Blondeau, J.P.; Lévi, Y. Tetrabromobisphenol-A disrupts thyroid hormone receptor alpha function in vitro: Use of fluorescence polarization to assay corepressor and coactivator peptide binding. Chemosphere 2012, 87, 782-788. [CrossRef] [PubMed]

139. Aung, M.T.; Johns, L.E.; Ferguson, K.K.; Mukherjee, B.; McElrath, T.F.; Meeker, J.D. Thyroid hormone parameters during pregnancy in relation to urinary bisphenol A concentrations: A repeated measures study. Environ. Int. 2017, 104, 33-40. [CrossRef] [PubMed]

140. Kim, U.J.; Oh, J.E. Tetrabromobisphenol A and hexabromocyclododecane flame retardants in infant-mother paired serum samples, and their relationships with thyroid hormones and environmental factors. Environ. Pollut. 2014, 184, 193-200. [CrossRef]

141. Wang, F.; Hua, J.; Chen, M.; Xia, Y.; Zhang, Q.; Zhao, R.; Zhou, W.; Zhang, Z.; Wang, B. High urinary bisphenol A concentrations in workers and possible laboratory abnormalities. Occup. Environ. Med. 2012, 69, 679-684. [CrossRef]

142. Przybyla, J.; Geldhof, G.J.; Smit, E.; Kile, M.L. A cross sectional study of urinary phthalates, phenols and perchlorate on thyroid hormones in US adults using structural equation models (NHANES 2007-2008). Environ. Res. 2018, 163, 26-35. [CrossRef]

143. Chevrier, J.; Gunier, R.B.; Bradman, A.; Holland, N.T.; Calafat, A.M.; Eskenazi, B.; Harley, K.G. Maternal urinary bisphenol A during pregnancy and maternal and neonatal thyroid function in the CHAMACOS study. Environ. Health Perspect. 2013, 121, 138-144. [CrossRef]

144. Sriphrapradang, C.; Chailurkit, L.; Aekplakorn, W.; Ongphiphadhanakul, B. Association between bisphenol A and abnormal free thyroxine level in men. Endocrine 2013, 44, 441-447. [CrossRef]

145. Meeker, J.D.; Ferguson, K.K. Relationship between urinary phthalate and bisphenol A concentrations and serum thyroid measures in U.S. adults and adolescents from the National Health and Nutrition Examination Survey (NHANES) 2007-2008. Environ. Health Perspect. 2011, 119, 1396-1402. [CrossRef]

146. Minatoya, M.; Sasaki, S.; Araki, A.; Miyashita, C.; Itoh, S.; Yamamoto, J.; Matsumura, T.; Mitsui, T.; Moriya, K.; Cho, K.; et al. Cord Blood Bisphenol A Levels and Reproductive and Thyroid Hormone Levels of Neonates. Epidemiology 2017, 28, S3-S9. [CrossRef]

147. Andrianou, X.D.; Gängler, S.; Piciu, A.; Charisiadis, P.; Zira, C.; Aristidou, K.; Piciu, D.; Hauser, R.; Makris, K.C. Human Exposures to Bisphenol A, Bisphenol F and Chlorinated Bisphenol A Derivatives and Thyroid Function. PLoS ONE 2016, 11, e0155237. [CrossRef] [PubMed] 
148. Romano, M.E.; Webster, G.M.; Vuong, A.M.; Thomas Zoeller, R.; Chen, A.; Hoofnagle, A.N.; Calafat, A.M.; Karagas, M.R.; Yolton, K.; Lanphear, B.P.; et al. Gestational urinary bisphenol A and maternal and newborn thyroid hormone concentrations: The HOME study. Environ. Res. 2015, 138, 453-460. [CrossRef] [PubMed]

149. Wang, T.; Lu, J.; Xu, M.; Xu, Y.; Li, M.; Liu, Y.; Tian, X.; Chen, Y.; Dai, M.; Wang, W.; et al. Urinary bisphenol A concentration and thyroid function in Chinese adults. Epidemiology 2013, 24, 295-302. [CrossRef] [PubMed]

150. Meeker, J.D.; Calafat, A.M.; Hauser, R. Urinary Bisphenol A Concentrations in relation to serum thyroid and reproductive hormone levels in men from an infertility clinic. Environ. Sci. Technol. 2010, 44, 1458-1463. [CrossRef] [PubMed]

151. Sugiura-Ogasawara, M.; Ozaki, Y.; Sonta, S.; Makino, T.; Suzumori, K. Exposure to bisphenol A is associated with recurrent miscarriage. Hum. Reprod. 2005, 20, 2325-2329. [CrossRef] [PubMed]

152. Geens, T.; Dirtu, A.C.; Dirinck, E.; Malarvannan, G.; Van Gaal, L.; Jorens, P.G.; Covaci, A. Daily intake of bisphenol $\mathrm{A}$ and triclosan and their association with anthropometric data, thyroid hormones and weight loss in overweight and obese individuals. Environ. Int. 2015, 76, 98-105. [CrossRef]

153. Takeuchi, T.; Tsutsumi, O.; Nakamura, N.; Ikezuki, Y.; Takai, Y.; Yano, T.; Taketani, Y. Gender difference in serum bisphenol A levels may be caused by liver UDP-glucuronosyltransferase activity in rats. Biochem. Biophys. Res. Commun. 2004, 325, 549-554. [CrossRef]

154. Takeuchi, T.; Tsutsumi, O. Serum bisphenol A concentrations showed gender differences, possibly linked to androgen levels. Biochem. Biophys. Res. Commun. 2002, 291, 76-78. [CrossRef]

155. Sur, U.; Erkekoglu, P.; Bulus, A.D.; Andiran, N.; Kocer-Gumusel, B. Oxidative stress markers, trace elements and endocrine disrupting chemicals in children with Hashimoto's thyroiditis. Toxicol. Mech. Methods 2019, 29, 1-30. [CrossRef]

156. Chailurkit, L.; Aekplakorn, W.; Ongphiphadhanakul, B. The Association of Serum Bisphenol A with Thyroid Autoimmunity. Int. J. Environ. Res. Public Health 2016, 13, 1153. [CrossRef]

157. American Thyroid Association (ATA) Guidelines Taskforce on Thyroid Nodules and Differentiated Thyroid Cancer; Cooper, D.S.; Doherty, G.M.; Haugen, B.R.; Kloos, R.T.; Lee, S.L.; Mandel, S.J.; Mazzaferri, E.L.; McIver, B.; Pacini, F.; et al. Revised American Thyroid Association management guidelines for patients with thyroid nodules and differentiated thyroid cancer. Thyroid 2009, 19, 1167-1214. [CrossRef] [PubMed]

158. Wang, N.; Zhou, Y.; Fu, C.; Wang, H.; Huang, P.; Wang, B.; Su, M.; Jiang, F.; Fang, H.; Zhao, Q.; et al. Influence of Bisphenol A on Thyroid Volume and Structure Independent of Iodine in School Children. PLoS ONE 2015, 10, e0141248. [CrossRef] [PubMed]

159. Li, L.; Ying, Y.; Zhang, C.; Wang, W.; Li, Y.; Feng, Y.; Liang, J.; Song, H.; Wang, Y. Bisphenol A exposure and risk of thyroid nodules in Chinese women: A case-control study. Environ. Int. 2019, 126, 321-328. [CrossRef] [PubMed]

160. Zhou, Z.; Zhang, J.; Jiang, F.; Xie, Y.; Zhang, X.; Jiang, L. Higher urinary bisphenol A concentration and excessive iodine intake are associated with nodular goiter and papillary thyroid carcinoma. Biosci. Rep. 2017, 37, BSR20170678. [CrossRef]

161. Marotta, V.; Russo, G.; Gambardella, C.; Grasso, M.; La Sala, D.; Chiofalo, M.G.; D'Anna, R.; Puzziello, A.; Docimo, G.; Masone, S.; et al. Human exposure to bisphenol AF and diethylhexylphthalate increases susceptibility to develop differentiated thyroid cancer in patients with thyroid nodules. Chemosphere 2019, 218, 885-894. [CrossRef]

162. Puzianowska-Kuznicka, M.; Nauman, A.; Madej, A.; Tanski, Z.; Cheng, S.; Nauman, J. Expression of thyroid hormone receptors is disturbed in human renal clear cell carcinoma. Cancer Lett. 2000, 155, 145-152. [CrossRef]

163. Chen, Q.; Yu, L.; Yang, L.; Zhou, B. Bioconcentration and metabolism of decabromodiphenyl ether (BDE-209) result in thyroid endocrine disruption in zebrafish larvae. Aquat. Toxicol. 2012, 110-111, 141-148. [CrossRef]

164. Jia, P.P.; Ma, Y.B.; Lu, C.J.; Mirza, Z.; Zhang, W.; Jia, Y.F.; Li, W.G.; Pei, D.S. The Effects of Disturbance on Hypothalamus-Pituitary-Thyroid (HPT) Axis in Zebrafish Larvae after Exposure to DEHP. PLoS ONE 2016, 11, e0155762. [CrossRef]

165. Arnaldi, L.A.; Borra, R.C.; Maciel, R.M.; Cerutti, J.M. Gene expression profiles reveal that DCN, DIO1, and DIO2 are underexpressed in benign and malignant thyroid tumors. Thyroid 2005, 15, 210-221. [CrossRef]

166. Li, C.G.; Nyman, J.E.; Braithwaite, A.W.; Eccles, M.R. PAX8 promotes tumor cell growth by transcriptionally regulating E2F1 and stabilizing RB protein. Oncogene 2011, 30, 4824-4834. [CrossRef] 
167. Zhang, X.; Tian, H.; Wang, W.; Ru, S. Exposure to monocrotophos pesticide causes disruption of the hypothalamic-pituitary-thyroid axis in adult male goldfish (Carassius auratus). Gen. Comp. Endocrinol. 2013, 193, 158-166. [CrossRef]

168. Latina, A.; Gullo, D.; Trimarchi, F.; Benvenga, S. Hashimoto's thyroiditis: Similar and dissimilar characteristics in neighboring areas. Possible implications for the epidemiology of thyroid cancer. PLoS ONE 2013, 8, e55450. [CrossRef] [PubMed]

169. Lai, X.; Xia, Y.; Zhang, B.; Li, J.; Jiang, Y. A meta-analysis of Hashimoto's thyroiditis and papillary thyroid carcinoma risk. Oncotarget 2017, 8, 62414-62424. [CrossRef] [PubMed]

170. Ginabreda, M.G.P.; Cardoso, L.C.; Nobrega, F.M.; Ferreira, A.C.F.; Gonçalves, M.D.C.; Vaisman, M.; Carvalho, D.P. Negative correlation between thyroperoxidase and dual oxidase $\mathrm{H} 2 \mathrm{O} 2$-generating activities in thyroid nodular lesions. Eur. J. Endocrinol. 2008, 158, 223-227. [CrossRef] [PubMed]

171. Wang, F.; Wang, Y.; Wang, L.; Wang, X.; Sun, C.; Xing, M.; Zhao, W. Strong association of high urinary iodine with thyroid nodule and papillary thyroid cancer. Tumour Biol. 2014, 35, 11375-11379. [CrossRef]

172. Guan, H.; Ji, M.; Bao, R.; Yu, H.; Wang, Y.; Hou, P.; Zhang, Y.; Shan, Z.; Teng, W.; Xing, M. Association of High Iodine Intake with the T1799A BRAF Mutation in Papillary Thyroid Cancer. J. Clin. Endocrinol. Metab. 2009, 94, 1612-1617. [CrossRef]

173. Filetti, S.; Bidart, J.; Arturi, F.; Caillou, B.; Russo, D.; Schlumberger, M. Sodium/iodide symporter: A key transport system in thyroid cancer cell metabolism. Eur. J. Endocrin. 1999, 141, 443-457. [CrossRef]

(C) 2020 by the authors. Licensee MDPI, Basel, Switzerland. This article is an open access article distributed under the terms and conditions of the Creative Commons Attribution (CC BY) license (http://creativecommons.org/licenses/by/4.0/). 